Illinois State University

ISU ReD: Research and eData

Theses and Dissertations

10-19-2021

\title{
Deepening Partisan-Identity Polarization in the US: A Content Analysis of Major Party Platforms, 1980-2016
}

Nicholas Alan Mullins

Illinois State University, nickalanmullins@gmail.com

Follow this and additional works at: https://ir.library.illinoisstate.edu/etd

\section{Recommended Citation}

Mullins, Nicholas Alan, "Deepening Partisan-Identity Polarization in the US: A Content Analysis of Major Party Platforms, 1980-2016" (2021). Theses and Dissertations. 1498.

https://ir.library.illinoisstate.edu/etd/1498

This Thesis is brought to you for free and open access by ISU ReD: Research and eData. It has been accepted for inclusion in Theses and Dissertations by an authorized administrator of ISU ReD: Research and eData. For more information, please contact ISUReD@ilstu.edu. 


\section{DEEPENING PARTISAN-IDENTITY POLARIZATION IN THE US: A CONTENT}

ANALYSIS OF MAJOR PARTY PLATFORMS, 1980-2016

\section{NICHOLAS ALAN MULLINS}

\section{Pages}

This thesis examines Democratic and Republican party platforms over the 1980-2016 period in a content analysis to test claims of partisanship increasing on identity lines in American politics. As a key issue facing democracies in recent years, polarization has coincided with challenges for democratic governance. Cases of 'pernicious' polarization that extend partisan rifts into social life, and especially those that feature an 'existential' or 'formative rift' dynamic as in the US case, may be prone to intractable partisan conflict and politics amenable to democratic erosion. The tensions may also create space for democracy enhancements. The findings of the content analysis offer support for increasing partisan-identity polarization in American politics in recent decades. Republican party platforms seem to increasingly reproduce a historical majoritarian appeal on religious-cultural or ethnic identity lines, in contrast to Democratic party platforms that likewise increasingly contest the meaning of 'American' in more identitarian albeit inclusive in a multicultural sense of community and belonging. KEYWORDS: deconsolidation, democracy, democratic erosion, identity, nation, partisanship, polarization 


\section{DEEPENING PARTISAN-IDENTITY POLARIZATION IN THE US: A CONTENT}

ANALYSIS OF MAJOR PARTY PLATFORMS, 1980-2016

NICHOLAS ALAN MULLINS

A Thesis Submitted in Partial Fulfillment of the Requirements for the Degree of

MASTER OF SCIENCE

Department of Politics and Government

ILLINOIS STATE UNIVERSITY 
(C) 2021 Nicholas Alan Mullins 


\section{DEEPENING PARTISAN-IDENTITY POLARIZATION IN THE US: A CONTENT}

ANALYSIS OF MAJOR PARTY PLATFORMS, 1980-2016

NICHOLAS ALAN MULLINS

COMMITTEE MEMBERS:

Lane Crothers, Chair

Ali Riaz

Yusuf Sarfati 


\section{ACKNOWLEDGMENTS}

I am eternally grateful to my wife for her support and sacrifice of my time spent writing this thesis. It is also an enormous debt of gratitude I owe to my chair for working with me. The project would not have been a success without Dr. Crothers' patience and constructive criticisms, not to mention his time and efforts that have made me a better writer and thinker throughout the process. Without the support of my committee members, Dr. Sarfati and Dr. Riaz, I could not have completed this work. Their feedback likewise made the paper stronger. It was Dr. Riaz's seminar on Democracy in Crisis that helped to inspire the research topic. Lastly, I appreciate Laura Severs for her time commitment as research assistant in the content analysis, no small task to say the least.

N.A.M. 


\section{CONTENTS}

Page

ACKNOWLEDGMENTS

$\begin{array}{ll}\text { CONTENTS } & \text { ii }\end{array}$

TABLES

FIGURES

CHAPTER I: INTRODUCTION 1

$\begin{array}{ll}\text { Theoretical Approach } & 1\end{array}$

$\begin{array}{ll}\text { Thesis Outline } & 6\end{array}$

CHAPTER II: THE ISSUE OF PARTISAN-IDENTITY POLARIZATION 7

$\begin{array}{ll}\text { From Partisanship to Pernicious Polarization } & 7\end{array}$

Partisanship and Its Influence $\quad 9$

$\begin{array}{ll}\text { Partisan Dynamics } & 16\end{array}$

Possible Positive or Negative Implications of Partisanship $\quad 20$

Democratic Function Against Extreme Partisanship 34

Systems of Democracy in the Third Reverse Wave 35

Factors in Deconsolidation: Severe Polarization Into Partisan-Identity Blocs 43

$\begin{array}{ll}\text { Partisanship and Deconsolidation Trends } & 58\end{array}$

$\begin{array}{ll}\text { Methods } & 60\end{array}$

Content Analysis of Democratic and Republican Party Platforms, 1980-2016 61

Identifying Shifts in Party Messaging on Universal and Identitarian Bases 61

Managing and Reporting Intercoder Reliability 63 
CHAPTER III: ANALYSIS

Results in Numbers: Less Neutral, More Identity $\quad 67$

Democratic Party Platforms (1980, 1992, 2004, 2016) 72

Republican Party Platforms (1980, 1992, 2004, 2016) 95

Deepening Partisan-Identity Polarization in Democratic and Republican Party Platforms 127

CHAPTER IV: CONCLUSION 131

$\begin{array}{ll}\text { REFERENCES } & 141\end{array}$

$\begin{array}{ll}\text { APPENDIX A: CODING RUBRIC } & 151\end{array}$

APPENDIX B: INTERCODER RELIABILITY 156

APPENDIX C: DEMOCRATIC PARTY, CODER 1 AND 2 COMPARISOn 157

APPENDIX D: REPUBLICAN PARTY, CODER 1 AND 2 COMPARISON 158 


\section{TABLES}

Table

Page

1. Universal Civic Identity Phrasing and Language in Democratic Party Platforms

2. Hybrid 'Universal-Identitarian' Phrasing and Language in Democratic Party Platforms

3. Identitarian Identity Phrasing and Language in Democratic Party Platforms

4. Universal Civic Identity Phrasing and Language in Republican Party Platforms

5. Hybrid 'Universal-Identitarian' Phrasing and Language in Republican Party Platforms

106

6. Identitarian Identity Phrasing and Language in Republican Party Platforms 


\section{FIGURES}

Figure

1. Democratic Party Platforms 1980-2016, Average, Coders 1 and 2, Grouped Bar 66

2. Republican Party Platforms 1980-2016, Average, Coders 1 and 2, Grouped Bar 66

3. Democratic Party Platforms 1980-2016, Average, Coders 1 and 2, Line 68

4. Republican Party Platforms 1980-2016, Average, Coders 1 and 2, Line 70 


\section{CHAPTER I: INTRODUCTION}

This thesis examines political party platforms from 1980-2016 as an empirical test of claims that partisanship on identity lines has been increasing in American politics. As will be seen, the issue is important for several reasons. For one, challenges in democratic governance are evident throughout the world, including even in established democracies like the United States. A recent period of historic growth in the total number of democracies has stalled in the early $21^{\text {st }}$ century and may be continuing a pattern of decline. This trend coincides with growth in mixed regime types combining democratic and autocratic tendencies in governance. Moreover, liberal democracies faced with increasing public disaffection and discontent have experienced growth in populist politics from politicians answering to incentives of popular resentments. Accordingly, polarization is a key issue facing democracies around the world today.

The thesis explores the issue through its analysis of US political party platforms. It uses a content analysis to assess shifts in political party messaging in platform space devoted to universal, narrowed, or hybrid universal-identitarian appeals over time. Its analysis contributes to an empirical grounding of any such partisan dynamics by showing a growing rift between the major parties. It thereby affirms claims of increasing party polarization in two broadly contrasting partisan appeals to identity in American electoral politics. The findings inform a concluding discussion of partisanship and potential trends ahead for liberal democracy in the US.

\section{Theoretical Approach}

Foremost, extreme partisan politics as understood in the concept of 'pernicious polarization' is instructive for this thesis (e.g., LeBas 2018; McCoy and Somer 2019; McCoy, Rahman, and Somer 2018). It is particularly useful in the analysis of American party platforms to evaluate shifts in partisanship on identity lines from 1980-2016. Pernicious cases of partisanship 
reflect a deep divide and alignment of politicized identities and interests to the extent that mutually exclusive political groups of 'us' and 'them' spills from politics into everyday social relations (McCoy and Somer 2019). Such polarization rises to 'pernicious' intensity as parties align around two poles of a cross-cutting social boundary (LeBas 2018). This approach underscores the role of group identity as a "proxy or marker" for divisions "linking citizens to a particular leader or partisan identity" (McCoy and Somer 2019, 236). I further adopt the notion that sometimes, as in the US case, a 'formative rift' may underlie and thereby prolong and intensify cases of pernicious polarization (McCoy and Somer 2019). These cases involve longstanding historical debates over components of national identity and culture, citizenship rights, identity and belonging in the polity, or else politicized differences between subgroups that make polarized conflicts more difficult to resolve (Layman, Carsey, and Horowitz 2006; McCoy and Somer 2019; McCoy, Rahman, and Somer 2018). Grievances around race and culture may have a large part in the dynamics of severe party polarization in the US (Abramowitz and McCoy 2018; Kaufman and Haggard 2019; Levitsky and Ziblatt 2018).

More broadly, partisanship guides political identification, affiliation, or attachment (Abramowitz and Saunders 2008; Abramowitz and McCoy 2018; Barber and Pope 2019; Bartels 2000; Fiorina and Adams 2008; Goren 2005; Graham and Svolik 2020; Hetherington 2001; Layman, Carsey, and Horowitz 2006; Mason 2014; LeBas 2018; McCoy and Somer 2019; Vegetti 2018). American partisanship is not historically new but has generally been increasing over the last few decades despite earlier indicators of possible decline during the mid-20th century (Abramowitz and Saunders 2008; Bartels 2000; Hetherington 2001; Layman, Carsey, and Horowitz 2006). The two major parties in American politics are becoming more polarized in recent history, sorting into partisan-ideological alignment between blocs, and showing signs of a 
rift in polarized political identities of either liberal Democrats or conservative Republicans. Even as this modern polarization has increased on all levels in American politics, together with mass party identification including party leaners at elections, the divide may not be so far apart on policy issues (Fiorina and Adams 2008; Mason 2014). Political preferences for partisans may, indeed, be less tied to policy and more rooted in social and psychological forms of political identity (Barber and Pope 2019; Mason 2014). As a typical manifestation in democratic competition, partisanship may at times be advantageous or concerning for regimes. It is frequently a positive influence on political participation and steering voter decisions. However, at intensity, the dynamics may embolden political extremism (Lupu 2014). Negative effects can prove dysfunctional at best and deleterious at worst for democratic governance (Levitsky and Ziblatt 2018).

The increasing polarization in American politics is happening from elite levels down to activists and mass identifiers. Elites disproportionately influence partisan dynamics though it is an interactive relationship vis-à-vis party activists' and mass demands (Abramowitz and Saunders 2008; Layman, Carsey, and Horowitz 2006). As elite cues frequently precede and weigh on mass political behavior (Goren 2005), the analysis of party platforms in this thesis evaluates for 'pernicious' dynamics of polarization from a top-down perspective. The influence of party elites is crucial in constructing or intensifying cleavages in exclusive appeals to mobilize electoral support (McCoy, Rahman, and Somer 2018). Given the importance of partisanship as a motivator of mass political views and participation, this thesis advances empirical work on severe partisanship by testing claims around dynamics of party polarization in American democracy over the last few decades. It is an effort to pinpoint the nature and intensity of changes in competing value systems or narratives of belonging in American party politics 
underlying polarization. The results of such an approach may offer validation for theories around US party polarization and otherwise clues for political outlooks ahead.

Features of partisanship under sharply polarized conditions could signal deeper problems contributing to democratic deconsolidation. Spectacle events, like the January 6, 2021, proTrump and intensely partisan mass gatherings against the legitimacy of election outcomes devolving into historic violent uprisings on the US capitol, are certainly less frequent; even more rare are full democratic breakdowns like the Myanmar military coup on February 1, 2021, ending a brief transition course of democratization. Gradual regime shifts away from liberal democratic ideals are less obvious, though more frequent and measurable. Now formerly the "world's oldest, continuous democracy," the POLITY scale of democracy recently dropped the US from full democracy status to anocracy, that is, the regime now falls between the spectrum of traits in autocratic and democratic governance (Center for Systemic Peace 2020). They point to actions during the Trump administration, such as rejections of congressional oversight, purging nonloyalists from the administration, forceful response to protests, vilifying the opposition, and casting doubts into American elections while attempting to circumvent legitimate electoral outcomes (Center for Systemic Peace 2020). The US registered its lowest performance indicator in the 2020 Freedom in the World annual report on equal treatment under law, policies, and practices. The report cites a few examples, from Trump's efforts to dismantle Obama administration policies enacted in the same authority to protect sexual and gender minorities, to hasty reversals under the executive on immigration with "blatantly discriminatory" bans on travel from select Muslim-majority countries on claims of national security (Freedom House 2020). Still another study judging the nature of American democracy against a large dataset from 
1981-2002 suggests less majority rule in response to interests of citizens than a reflection of elite or organized interests:

When a majority of citizens disagrees with economic elites or with organized interests, they generally lose. Moreover, because of the strong status quo bias built into the U.S. political system, even when fairly large majorities of Americans favor policy change, they generally do not get it (Gilens and Page 2014, 571).

With several factors likely at work in contemporary problems for democratic governance, the underlying trends in political dynamics that could give rise to undemocratic trends and spectacle figures or events are important to emphasize. This thesis therefore underscores the dynamics of severe partisan polarization on identity lines to build on the understanding of where things could go from here for liberal democratic systems. For example, indicators of democratic health, intense polarization and deep social mistrust are broadly affecting regimes in contemporary deconsolidation trends (V-Dem Institute 2020). So long as 'mutual toleration' runs short, rivals may stop viewing or tolerating one another as legitimate democratic opponents, unworthy of the same respect and perhaps even unacceptable as family or friends (Levitsky and Ziblatt 2018; VDemo Institute 2020). Polarizing dynamics may still contribute to political mobilization for democratic reforms (Layman, Geoffrey, and Carsey 2006; Levitsky and Ziblatt 2018; McCoy, Rahman, and Somer, 2018; McCoy and Somer 2019). They may be "generative" for democracy through development of checks and balances from the tensions of polarization and/or stronger political structures like party organizations that drive participation (LeBas 2018). Yet, deepening polarization may be potentially unstable for democratic function. Two blocs who severely distrust one another, from political elites to their loyal supporters, can "become less likely to adhere to democratic rules in the struggle for power" (V-Dem Institute 2020, 22; see also, e.g., Graham 2020; LeBas 2018; McCoy and Somer 2019). Of most direct consequence, accordingly, scholars see a present risk of severe partisanship or 'pernicious' polarization in the unraveling of 
democratic regimes at the agency of elected officials (Bermeo 2016; Cheeseman and Klaas 2018; Ercan and Gagnon 2014; Foa and Mounk 2017; Levitsky and Ziblatt 2018; McCoy and Somer 2019; Mietzner 2018; Waldner and Lust 2018).

\section{Thesis Outline}

This Chapter One introduces the thesis. It provides a synthesis of the literature and an overview of the thesis chapters. In Chapter Two, I address why the issue of partisan-identity polarization matters and how I approach it. I include brief examples that bridge the two subfields of American Politics and Comparative Politics. I then present a thorough methodology using content analysis of major party platforms to evaluate elite appeals in American politics for dynamics of pernicious polarization that may have consequential influence on democratic regime trajectory, for better or worse. This unique contribution extends rare studies of partisan-identity polarization to a longer period and thereby supports theoretical development around suggestive cases in severe polarization with similarities in partisan-identity rifts and contestation over national belonging. Accordingly, the Chapter Two discussion sets up the content analysis of Democratic and Republican party platforms, which I unpack in Chapter Three. Finally, I explore the implications of this research in the concluding Chapter Four. The findings give some direction for American politics as well as future projects involving pernicious dynamics and partisan-identity polarization in liberal democracies. 


\section{CHAPTER II: THE ISSUE OF PARTISAN-IDENTITY POLARIZATION \\ From Partisanship to Pernicious Polarization}

The importance of this thesis is carving into a less explored empirical space within the scholarly debate on growing divisions, partisanship and polarization in American politics. The US case of increasing party polarization of masses preceded by elites over the last several decades is well-established in the literature, but the dynamics and implications of partisanship I address in this study remain fertile grounds for research. Partisanship, or party identification and thereby loyalty to a political bloc, is a key motivator of political participation, mass voting behavior, and political activism. Thus, changes in intensity of party attachment and polarization on cross-cutting party lines may potentially influence changes in political outlooks and ideals reflected in American politics, plus general political or economic stability for the US. In large part, the literature establishes that elites play a key role in driving party polarization and its implications through cues or political appeals intended to mobilize popular support to secure power. Moreover, recent decades increasingly reflect extended partisan-ideological divisions coupled with political identity alignment between the Democrats and Republicans, the two major parties in American politics. In short, the US case of severe partisanship seems mired in racial and cultural identity divisions, as argued by Steven Levitsky and Daniel Ziblatt (2018). It may further reflect a political identity rift dynamic of 'pernicious' polarization, according to Jennifer McCoy and Murat Somer (2019). Preexisting cleavages on the basis of group and citizens' belonging, with deep historical roots in the American polity, may exacerbate the effects and duration of party polarization (LeBas 2018). Although there are potential democracy-enhancing reservations for partisanship, it remains possible for severe cases of party polarization to have debilitative effects on democratic norms, such as eroding mutual tolerance and restraint, in 
addition to instability for the regime that could lead to democratic backsliding or breakdown. By exploring partisanship in a rigorous analysis of major party messaging from 1980-2016, this thesis lays bare any elite partisan appeals or party divergence in messaging along identity lines that may contribute to 'pernicious' polarization on the basis of belonging and toleration in American society and politics.

The overarching themes in the literature on partisanship address its influence on democratic politics. Especially for extreme cases, the literature tends to highlight issues of partisanship with respect to political polarization and deep divisions within a society. Three themes emerge in the literature, somewhat chronologically. For one, a large body of earlier work debates the decline of partisanship in the United States since roughly the 1950s, followed by party resurgence. Scholars were trying to determine whether or not the impact of party identification on political behavior had weakened. To the contrary, scholarship at the turn of the $21^{\text {st }}$ century came to near-consensus that the 'partisan decline' thesis of older conventions was wrong (see, e.g., Abramowitz and Saunders 2008; Bartels 2000; Hetherington 2001; Layman, Carsey, and Horowitz 2006). American partisanship rebounded, if not crystalized, from earlier signs of decline in effect on elites and voting behavior starting around the late $20^{\text {th }}$ century through today. Second, the dynamics and implications of partisanship thus increasingly became a major influence and focus within the literature (see, e.g., Barber and Pope 2019; Brown, Touchton, and Whitford 2011; Druckman, Peterson, and Slothuus 2013; Layman, Carsey, and Horowitz 2006; LeBas 2018; Lupu 2014; Mason 2014). Third, most recently, the debate on partisanship has turned to what increasing party polarization may mean for democratic governance in the United States as well as other liberal democracies (see, e.g., Abramowitz and McCoy 2018; Graham and Svolik 2020; McCoy and Somer 2019; McCoy, Rahman, and Somer 
2018; Tworzecki 2018; Vegetti 2018). The main themes I address in this review on the issue of partisanship, including partisan influence, dynamics, and its positive and negative implications, inform the empirical analysis of Republican and Democratic party platforms to follow.

\section{Partisanship and Its Influence}

Partisanship in the American political system has long been a focal point in social science as well as media narratives given its influence in democratic politics. It is commonplace in many analyses of American elections (e.g., so-called "red" and "blue" states in the American electoral system to describe Republican party and Democratic party strongholds). This frequency comes as a key dynamic of partisanship is its influence on political behavior and outcomes in electoral politics. But what is partisanship, and what does it mean to be a partisan? Partisanship essentially describes the political behavior or devotions of partisans. Conversely, acting as a partisan reflects individual partisanship. The literature often discusses these concepts in modest terms when the scope of partisanship is less intense or concerning, while more severe cases tend to have emphasis on polarizing heights of far-reaching partisan behavior.

First, put simply, a partisan is an individual who identifies (see, e.g., Abramowitz and Saunders 2008; Abramowitz and McCoy 2018; Barber and Pope 2019; Bartels 2000; Fiorina and Adams 2008; Goren 2005; Mason 2014; McCoy and Somer 2019; LeBas 2018; Vegetti 2018), affiliates (see, e.g., Graham and Svolik 2020), or attaches oneself to a political party (see, e.g., Barber and Pope 2019; Bartels 2000; Goren 2005; Hetherington 2001; Layman, Carsey, and Horowitz 2006; LeBas 2018; Lupu 2014; Mason 2014; McCoy and Somer 2019). Such party identification, affiliation, or attachment is both social and psychological (Barber and Pope 2019; Mason 2014). Its varying levels in strength or intensity in terms of party influence and individual loyalty is a recurrent characteristic in the literature. For example, Bartels (2000) adopted a 
measurement of partisanship to assess voting in American elections on a seven-point scale from strong to weak party attachment, capturing Democratic and Republican leaners as a middle way while excluding minor party voters and nonvoters. On the latter point, partisanship is distinct from political independence insofar as nonpartisans are without "attachment to one side or the other" in terms of political identification and predictable voting behavior (Hetherington 2001, 627). Partisans include the party elites, the parties' mass coalitions, and activist bases (Layman, Carsey, and Horowitz 2006). As for the masses, partisan identifiers are more likely subjects of party influence in their attitudes on political issues, whereas independents are not as likely to change issue attitudes on elite cues (Druckman, Peterson, and Slothuus 2013; Layman, Carsey, and Horowitz 2006). Moreover, partisan identifiers may have "a sense of emotional attachment ... rooted in the social images of the parties" (Goren 2005, 881). The relationship for partisans is personal, one of loyalty, and inclined to produce close feelings vis-à-vis party-associated social groups (Goren 2005). In government, partisanship is often visible in elite party members' voting records on party lines, perhaps even a sense of devotion to the effect of unwillingness to compromise with political rivals (Layman, Carsey, and Horowitz 2006). Indeed, strong party attachments may embolden political extremism (Lupu 2014). As a social identity with "powerful effects," partisanship often entails biases corresponding to its identification with the party (Mason 2014, 128; see also, e.g., Barber and Pope 2019; Druckman, Peterson, and Slothuus 2013). A partisan, in other words, behaves "more like a sports fan than like a banker choosing an investment" (Mason 2014, 129). Partisans also "feel emotionally connected to the welfare of the party; they prefer to spend time with other members of the party; and when the party is threatened, they become angry and work to help conquer the threat even if they disagree with some of the issue positions taken by the party" (Mason 2014, 129; see also, e.g., LeBas 2018). 
Partisanship is the "most prominent political identity" because it is the parties that directly compete for political power (Mason 2014, 130). It manifests as a consequence of democratic competition between leaders and organizations in ways that express public policy so masses can participate in the political decision-making process (Druckman, Peterson, and Slothuus 2013).

Lastly, as later discussed in detail but an important conceptual distinction to note, political polarization characterizes severe partisanship with a deeper political and cultural divide, including elites, activists, and masses (Abramowitz and Saunders 2008). When partisan rifts extend from political to everyday social relations, the ensuing polarization may be an uncompromising and "totalizing system" of 'us versus them' political identities (McCoy and Somer 2019; see also Vegetti 2018). Under polarized extremes, partisan competition may resemble political 'tribes,' rather than more modest democratic party distinctions (Kaufman and Haggard 2019). Norms of mutual tolerance and 'forbearance' between political opponents, in other words, may be absent or run dry (Levitsky and Ziblatt 2018).

Partisan influence is often a matter of extent and direction, whether resurgent or waning and either elite- or mass-driven. Despite some signs of mid-to-late $20^{\text {th }}$ century decline, it is clear that party identification for American elites and the electorate persists. An earlier assessment of voting in American national elections from 1952-1996 explored the extent of partisan influence on voting behavior using a simple probit analysis to capture changes in its electoral distribution and relevance. Larry Bartels (2000) showed that partisan influence on voting behavior increased nationally over each of the presidential elections in review, although with lower intensity for congressional elections on the same trajectory. By 1996, partisanship was higher than any election spanning the previous 50 years (Bartels 2000). Voters were also consistently more partisan than nonvoters (Bartels 2000), hinting at some advantage of partisanship for democratic 
regimes by enhancing voter turnout. In a similar assessment, the relationship between masses and elites engaged in partisanship further explains partisan influence using individual-level data from American National Election Studies (ANES) and an ideological scoring system between members of Congress over the period of 1949-1997. Like Bartels (2000), the findings contradict earlier conventions of the 'partisan decline' thesis after some waning from the late 1940s through the 1960s (Hetherington 2001). Instead, a rise in elite party polarization began in the 1970s, as mass partisanship trended closely behind (Hetherington 2001). A subsequent study using ANES data likewise found that ideological polarization for both masses and elites has sharply increased since the 1970s (Abramowitz and Saunders 2008). The growing partisan divisions are vast between outlooks of Democrats versus Republicans, both elites and voters, and the split spans the American public rather than only a small segment of activists (Abramowitz and Saunders 2008). Even so, divisions are sharpest across partisan voters, who are also most interested, informed, and active in politics (Abramowitz and Saunders 2008). An extensive survey of the theoretical and empirical literature on party polarization and partisan change, in which researchers compare the recent period to earlier political eras, affirms these changes in American partisan politics (Layman, Casey, and Horowitz 2006). For the two major political parties in the US, they find increasing polarization in all major policy realms (Layman, Casey, and Horowitz 2006). A subsequent survey of literature on the concept of polarization and evidence of the phenomena concludes elite polarization in the US is substantially empirically grounded (Fiorina and Adams 2008). The same survey finds less support for increased polarization on policy positions among masses in recent decades but concludes that mass partisan identification has indeed increased (Fiorina and Adams 2008). Subsequent survey analysis continues to lend strong 
support for increasing partisanship among the masses, while generally supporting the finding that political preferences are less tied to policy issues (Mason 2014).

But what drives partisanship? Is it influenced by mass demands, or is the supply of elite cues to blame? Although the literature tends to support both possibilities, the latter carries more weight. Still others point to party activists for wielding particular influence, while some theorize that crises stimulate both political and social polarization (see, e.g., della Porta 2017; McCoy, Rahman, and Somer 2018). Based on ANES data, ascent of highly partisan, ideological leaders and members of Congress may explain increased partisanship in voting behavior (Bartels 2000; Goren 2006; Hetherington 2001). Such findings suggest partisan influence is directional, from elites to masses. The political elites may, in other words, "activate latent partisan biases in the minds of citizens, which in turn subtly affect their core political values," based on models of attitude stability and constraints on various political issues (Goren 2005, 894). In fact, recent statements made by the then President Donald Trump allowed for tests of elite cues against survey respondents. An experiment found that party loyalists are more likely to accept Trump's cues regardless of liberal or conservative leaning in messages (Barber and Pope 2019). This pattern held for even self-described conservative voters, and this supports an elites-to-masses causal lens for partisan influence (Barber and Pope 2019). Other research applying cross-national and longitudinal survey data linked party polarization as a causal factor in increased partisanship among the American masses. As citizens perceive parties more polarized, voters are more likely to act as partisans (Lupu 2014). From the extensive survey of literature on partisanship already mentioned, the broad picture of supply/demand in partisanship is that elites versus mass party polarization is very much like a chicken-and-egg scenario about what first emerges in politics (Layman, Casey, and Horowitz 2006). The paper ultimately concludes a middle way that the 
relationship is interactive, though more likely an elite-driven phenomenon since elites have preceded mass polarization (Layman, Casey, and Horowitz 2006). The authors nevertheless argue that party activists may fuel polarization given slanted participation in presidential nominating processes after reforms allowed for more open selection of candidates. Party activists are more ideologically extreme than the masses, and least likely to compromise; they are “opinion leaders of their communities, shaping the electorate's perception of the parties' policy positions" (Layman, Casey, and Horowitz 2006, 97). However, subsequent analysis of ANES data tested such claims, finding vast partisan divisions between the outlooks of Democrats and Republican voters in so-called red and blue states, and religious and secular voters across a large segment of the American public - in other words, not only a small minority of activists (Abramowitz and Saunders 2008). Additional survey experiments provide further evidence that party polarization is influencing decision-making among the masses, even boosting confidence in political views untethered to substantive information by stimulating "partisan motivated reasoning" (Druckman, Peterson, and Slothuus 2013, 57).

More recently, the question of a directional relationship in partisanship between elites and masses has turned to comparative country cases. In a single-country case study of Hungary, drawing from a broad range of sources, it is mainly the elites fueling divisions between two poles with little middle ground. Elite political rhetoric has been antagonistic and along mostly party lines (Vegetti 2018). Likewise, a comparative study of Hungary, US, Turkey, and Venezuela finds that the role of elites is critical because they construct and intensify existing cleavages or resentments through political messaging (McCoy, Rahman, and Somer 2018). The divisive strategy advances political causes by mobilizing masses in 'us versus them' terms (McCoy, Rahman, and Somer 2018). In addition, a case study of Poland underscores the importance of 
elite cues on the question of democratic backsliding caused by polarization. The lack of any strong underlying cleavages in the Polish case offers support to the argument that the extreme party polarization was largely top-down from elite cues and political messaging, as opposed to bottom-up from mass demands (Tworzecki 2018).

Other perspectives from the literature suggest more to the relationship of partisanship and outlook than an interactive and influential relationship between elites and masses. As an alternate perspective, from an analysis of ANES data, an important theoretical distinction is partisanship as a social and psychological identity (Mason 2014). Rooted in this frame are characteristics of partisan influence such as in-group bias and reactions to party threats with strong emotions. In other words, partisans have greater likelihood to participate in politics and act especially on the party's behalf when identification is strong (Mason 2014). Moreover, earlier analysis of ANES data lends support to this view of partisanship on identity lines to the extent that it is highly stable and influential in shaping American citizens' values (Goren 2005). This aspect of partisan influence resonates to Michael Barber and Jeremy Pope's (2019) work on links in partisanship and liberal versus conservative ideology in an experimental survey of respondents against Trump's political statements. For example, group loyalty to the party leader's cues trumped ideology to shape the opinions of respondents (Barber and Pope 2019). In brief, partisanship is a matter of identification, affiliation, attachment, or loyalty to a political party. The literature supports an interactive relationship in partisan influence between elites and masses, though topdown cues and messaging from elites seems to carry the most weight versus mass demands in driving partisanship and extreme cases of polarization. As a further matter, partisanship as a political identity is a crucial motivator in political outlook and behavior of masses. Elites can use partisan influence for purposes of mobilization around their political cause. 


\section{Partisan Dynamics}

As partisanship increasingly influences American elites and voters, the various dynamics of the recent period are more salient in the literature. How are things polarized, and what are the implications? To be sure, party polarization has existed in fact "on some set of issues for most of [American] political history" (e.g., in the 1790s between Federalists and JeffersonianRepublicans over tariffs, a national bank, federal versus state and citizen power; in the 1830s and 1840s between Whigs and Democrats comparable to the 1790s; between Democrats and Republicans over slavery in the 1850s, agrarian and currency in the 1890 s, social welfare programs around the New Deal in the 1930s, and over civil rights in the 1960s) (Layman, Carsey, and Horowitz 2006, 85). Yet this history contrasts in ways with recent polarization, as "party conflict has extended [emphasis added] from older issues to newer issues," instead of displacing interparty conflicts with new ones (Layman, Carsey, and Horowitz 2006, 87). In other words, the idea of 'conflict extension' describes recent polarization similar to what Lilliana Mason (2014) expounds as partisan-ideological sorting of the American electorate. According to Mason's (2014) later survey analysis, this trend has continued as mass partisan and political identity alignment strengthens. Thus, the parties and their supporters are becoming more polarized over the last few decades. Republicans are trending more conservative, and Democrats are trending more liberal (Layman, Carsey, and Horowitz 2006).

Since the 1970s, divisions between the two major parties in American politics are extending from former economic and social welfare agendas into issues around culture, religion versus secularism, and moral issues like abortion and gay rights (Layman, Carsey, and Horowitz 2006). Scholars have offered that Southern realignment after collapse of electoral support for the old Democratic party in the region may have sharply distinguished the two parties (see, e.g., 
Bartels 2000). Others similarly found party realignment attributable to changes in civil rights and racial equality, as white southerners fled the Democratic party, and African American voters mostly coalesced behind it (Layman, Carsey, and Horowitz 2006). Until such political identity alignment and partisan-ideological sorting over the last few decades, issues around race and culture were more likely to inflame conflicts within parties (Layman, Carsey, and Horowitz 2006). Now, scholars contend they are tinder for fiery political conflicts between parties in a polarized dynamic (Abramowitz and McCoy 2018; Layman, Carsey, and Horowitz 2006; see also, e.g., Levitsky and Ziblatt 2018). For example, a study using ANES survey data after the 2016 presidential election found that Trump's campaign messaging around racial and ethnic resentment aided his victory with support of white working-class voters, albeit deterring support from college-educated white voters and most non-white voters (Abramowitz and McCoy 2018). In a similar study albeit contrasting results, Christian nationalism was statistically significant and highly predictive of voting for Trump in the 2016 presidential election (Whitehead, Perry, and Baker 2018). For controls, the same study found no significant association between voting for Trump and views on economic satisfaction, illegal immigrants, sexism, and racial prejudice. Each study alludes to the salience of cultural, racial, and moral issues in contemporary American politics.

Moreover, comparative research into democratic dysfunction and decline found parallels of extreme polarization for the US and cases of Venezuela, Turkey, and Hungary. Each of the cases shares similarities to "increasing polarization in American society around economic, racial, and ethnic grievances" (Kaufman and Haggard 2019). The voters attracted to populist appeals in all four countries share economic grievances that hinge on the impacts of globalization like wage stagnation, increasing inequality, and specific crises like the Great Recession (Kaufman and 
Haggard 2019). For American politics particularly, characteristics of party realignment and polarization are "intimately tied to identity politics" in ways that resemble polarization in at least two out of the three other cases (Kaufman and Haggard 2019). For example, the authors point to US cleavages on cultural-identity lines between the two major parties over the Civil Rights Movement of the 1960s as well as issues like affirmative action, welfare, and immigration policy, which all have "deep racial, ethnic, and cultural overtones" rooted in American history (Kaufman and Haggard 2019). In parallel to the polarizing leadership of Donald Trump in the US, Recep Tayyip Erdoğan in Turkey and Viktor Orbán in Hungary each mobilized mass racial and ethnic resentments with their top-down messaging and through the demonization of minorities (Kaufman and Haggard 2019). By contrast in Venezuela, Chavez rose to power on populist political appeals from the left by demonizing the 'neoliberal' elites, not unlike Trump's 'drain the swamp' rhetoric during his 2016 presidential campaign (Kaufman and Haggard 2019). Increasingly, it seems scholars studying the US case in partisanship are either assuming or arriving at ideological, racial, and cultural divisions at the root of its extremes in recent decades (see, e.g., Abramowitz and McCoy 2018; Levitsky and Ziblatt 2018). Indeed, the US case of polarization may extend "beyond policy differences into an existential conflict over race and culture" (Levitsky and Ziblatt 2018, 9).

The literature has started to flesh out a rift dynamic of polarization for the US as well as elsewhere around the world. In a theory-building study involving four case studies in subSaharan Africa, Adrienne LeBas (2018) stresses party polarization as "realignment around a single social boundary" splitting into two poles capable of strengthening intraparty or group solidarity (LeBas 2018). This theoretical exercise leans heavily on the concept of 'pernicious polarization' scholars are developing in regards to severe cases of political polarization. This 
kind of polarization is not necessarily between ideological distance of political parties and candidates. Rather, these severe cases of polarization feature politicized identities and interests aligning to create a mutually exclusive divide between groups, extending partisanship throughout daily life and into social relations (McCoy and Somer 2019). Pernicious polarization can take on different forms, which scholars have described in lucid terms:

The dividing line between the camps may be simply support of, or opposition to, a personalistic political leader, such as pro- and anti-Trump in the United States, chavistas and anti-chavistas (for and against former president Hugo Chávez) in Venezuela, or proand anti-Erdoğan people in Turkey. But that dividing line may also reflect competing value systems (such as religious vs. secular), different visions of democracy (such as representative vs. participatory), or different definitions of citizenship and what rights should be afforded to immigrants. Group identity, which may act as a proxy or marker for the other aggregated divisions, is the key, linking citizens to a particular leader or partisan identity [emphasis added] (McCoy and Somer 2019, 236).

In other words, Layman, Carsey, and Horowitz (2006) earlier reflected on whether longstanding differences between subgroups in the US population were becoming more relevant, and possibly damaging to political and cultural consensus. The 'pernicious polarization' as McCoy and Somer (2019) have described above, or the 'extreme partisan polarization' as told by Levitsky and Ziblatt (2018), each resonate with that earlier discussion. Extreme partisanship can develop into mutual distrust aligning on two political poles in 'us' and 'them' terms (McCoy and Somer 2019; McCoy, Rahman, and Somer 2018). It is a political rift dynamic to the extent that political rivals may no longer accept the other as legitimate (Levitsky and Ziblatt 2018). Some cases may be riper for development of such 'pernicious' rifts in polities where there are "unresolved historical debates over what constitutes the core component of national identity or the basis of citizenship rights" (McCoy and Somer 2019, 264). These cases involving a 'formative rift' may be "more enduring and pernicious...precisely because they involve state identity and belonging," thereby making for intergroup disputes that are more difficult to resolve (McCoy and Somer 2019, 264). The authors ascribe this rift characterization of severe polarization extended to identity and 
belonging in the state as likely for contemporary cases in Bangladesh, Zimbabwe, Turkey, South Africa, and the US (McCoy and Somer 2019). A comparable study recognized cleavages on binaries of "globalist/cosmopolitan versus nationalist; religious versus secular; urban versus rural; traditional versus modern cultural values; and participatory versus representative democratic models" (McCoy, Rahman, and Somer 2018, 20). The contemporary polarizing rhetoric as an electoral strategy is also increasingly populist in contrasting "the people versus elites," and accusing the latter of "frustrating" the interests of a collective identity of the people (McCoy, Rahman, and Somer 2018, 20). I have so far explored the influence and dynamics of partisanship in the literature, which increasingly refers to its important implications. I now turn to the latter.

\section{Possible Positive or Negative Implications of Partisanship}

Certain aspects of partisanship may be beneficial or concerning. While more recent literature may emphasize the latter, there are a few common and positive reservations about partisanship. In any event, implications typically correspond to influence on democratic governance. Some earlier hints gave ways for looking ahead, often in summary discussions on growing partisan influence among elites or masses in American politics. For example, Hetherington (2001) suggested a resurgence of partisanship might prove as beneficial if, following earlier theories of democracy and parliamentary systems, voters perceive parties to represent distinct ideologies that allow for simple rationale in the selection of candidates for election. By contrast, Abramowitz and Saunders (2008) suggested the possibility for political divisiveness due to increasing ideological polarization between Democrats and Republicans in the American political context. These seemingly incompatible ideas are clues to the range of potential implications for the issue, as assessments in the literature are now more developed. 
To start, the beneficial aspects of partisanship are generally democracy-enhancing. It may be fruitful for democratic governance, as supported largely in quantitative analyses of American elections and survey data. For the masses, as hinted above, party polarization may improve representation in the political process by clarifying differences between political parties for voters to choose from candidates prudently as partisans (Druckman, Peterson, and Slothuus 2013; Layman, Carsey, and Horowitz 2006; Lupu 2014). Partisan candidates may more likely reflect the views of their constituents and vice versa. As majorities in government, partisans might also behave more coherently and unified to pursue policy agendas on which they have campaigned (Layman, Carsey, and Horowitz 2006). A flipside is that mass partisanship makes for more ideological behavior to the effect of less frequent ticket splitting among voters (Layman, Carsey, and Horowitz 2006). Characteristic of such party-line voting behavior is a greater likelihood for masses to turn out at elections as partisans (Bartels 2000; Lupu 2014). In contrast, nonvoters are less likely to identify with either party (Bartels 2000). A stronger partisan identity may also generate more political activism (Mason 2014). Since partisans have in-group bias, strong party identity boosts the chances for political participation while acting on behalf of the party (Mason 2014). Similarly, as partisans, voter choices may be more ideologically coherent. A possible upside is that low-information voters in these conditions may follow the lead of high-information voters based on partisan cues, thus making for more informed electoral decisions (Druckman, Peterson, and Slothuus 2013). For developing democracies, party polarization and mass partisanship may enhance electoral stability (Lupu 2014). The institutionalization of party systems that comes with polarization may allow for more stable elections and consolidation of new democracies by driving voter turnout and influencing mass party loyalty (Lupu 2014). 
Potential advantages of partisan politics and polarization are likewise evident in crossnational survey data and comparative case studies. In fact, democracies around the world remain lively in terms of political participation. Widescale voter turnout and party membership are each trending upward, despite indicators of disillusionment with traditional parties and formal political institutions as supported by data collected in the World Values Survey, Eurobarometer, Latinobarómetro, and Afrobarometer (The Economist Intelligence Unit 2019). Voter engagement and political activism are up in countries around the world (The Economist Intelligence Unit 2019). As for the US in particular, indeed a longstanding democracy, the increasing political polarization has coincided with historic levels of voter turnout and activism. The 2008, 2016, and 2020 presidential elections were highpoints for turnout over the last century of American politics, and most recently just shy of the previous highpoint among the voting age population that turned out in 1960. Moreover, the day after Trump's inauguration in January 2017, after sending shockwaves around the world with his surprise electoral defeat of Hillary Clinton in 2016 presidential elections, a sort of "counterinauguration" organized hundreds of thousands to the Women's March on Washington (Hartocollis and Alcindor 2017). A historic turnout, the opposition demonstrators in the US as well as in parallel around the world united in opposition to Trump, around issues like reproduction, immigration, and civil rights. By contrast, roughly eight years earlier, the 2008 election of Barack Obama as the first biracial president sparked "a counter-mobilization of White, conservative, and evangelical voters in the Tea Party," a movement against government spending in distributive programs (McCoy, Rahman, and Somer 2018, 30). Each of these distinct and mostly partisan (see, e.g., Bayagich 2017, in case of the former, and Abramowitz 2011, in case of the latter) mass mobilizations in American politics resonates to the turnout and participatory dynamics of increased polarization. In fact, the 
increased civic engagement in recent years around issues like women's rights, immigration, and mass shootings improved democracy indicators for the US on freedom of assembly (Freedom House 2019a).

Polarized politics may also have beneficial institution-building effects (LeBas 2018) or impact that could lead to democratic reforms (McCoy, Rahman, and Somer 2018). Of new democracies, two case studies in sub-Saharan Africa show possible democracy-enhancing aspects of party as well as general political polarization. From these developing democracies, LeBas (2018) identifies that checks and balances emerge from tensions and conflicts of polarization that can potentially reinforce the political accountability of those in power. In addition, sustained polarization may produce incentives for political elites to improve structures in the political system and mobilize their bases to turn out at elections, i.e., strengthening party organizations and democratic participation (LeBas 2018). For example, polarization in Burkina Faso drew lines between the government and anti-government blocs, absent any 'formative rift' around identity and belonging as earlier described of potentially augmenting dynamics of severe partisanship. Peak polarization opened the door for democracy in 2014, when hundreds of thousands of protesters took to the streets against President Blaise Compaoré after he tried to remove constitutional term limits to secure power. This opposition led to his exile in an effective check on political power (LeBas 2018). A similar incident occurred in 2015 elections when protesters organized against a Compaoré loyalist guard's coup attempt. The political polarization was democracy-enhancing to the effect that it twice mobilized a strong opposition that held political power to account. In Ghana, party polarization served to strengthen and institutionalize the country's two-party system (LeBas 2018). President Jerry Rawlings was first to win elections at Ghana's founding in 1992. However, he had earlier seized power twice in military coups. 
When he won elections in 1992, an opposition party coalesced and grew enough strength to win $48 \%$ of the presidential vote by 2000 . The opposition then split the parliamentary vote with the ruling party. Elections since have all been highly competitive between the two major parties, thrice turning over power (Le Bas 2018). These accounts compare well to cross-national panel data supporting ideological polarization as predictive of corruption perceptions (Brown, Touchton, and Whitford 2011). The dynamics of political polarization may control corruption through legislative and executive oversights and forced political compromise (Brown, Touch, and Whitford 2011).

Negative implications of partisanship, on the other hand, may stem from the fact that "issues at the heart of partisan change are those on which people are least likely to change their minds" (Layman, Carsey, and Horowitz 2006, 92). The concerning aspects of partisanship tend to be debilitative effects on democratic regimes. Media narratives and some political leaders in the $21^{\text {st }}$ century have certainly portrayed increasing party polarization in the US as harmful in terms of American democracy. For example, the Washington Post earlier worried over gridlock in Congress as well as citizens' alienation from government (Layman, Carsey, and Horowitz 2006). The 2004 GOP chairman viewed party polarization as deleterious for political balance and foreboded stalemate in policymaking (Layman, Carsey, and Horowitz 2006). Studies tend to support these depictions of contemporary American politics. Lupu (2014) points to various research linking American party polarization to legislative gridlock, elite incivility, income inequality, and disengagement from politics, plus democratic breakdown, corruption, and economic decline in other countries. Political cleavages between major factions may produce policy volatility and harm economies, such as the case of ex-communists and anti-communists in the post-communist world with divergent views on economic structure (Frye 2002). 
With increasing alignment of partisan-ideological identities, Mason (2014) suggests the possibility for major political changes. Political thought, behavior, and emotions may become untethered from policy preferences, steering away from democratic ideals. Settling a score or redressing grievances on partisan bases could drive politics (Mason 2014). Party polarization increasingly drawn on identity bases may produce more activism, but it might also encourage biases and anger, just as survey data suggests voters remain relatively close on policy issues (Mason 2014). In other words, motivated reasoning from stronger partisan identities may influence less informed, more dogmatic political opinions to the extent of "extreme inflexibility and intolerance," irrespective of the strength of arguments (Druckman, Peterson, and Slothuus 2013, 75). A recent study involves two experimental methods, including a natural experiment in Montana's 2017 special election for US House of Representatives. The results bode poorly for US democracy under increasing party polarization by exposing that only a subset of Americans prioritize democratic principles in electoral decision-making (Graham and Svolik 2020). Americans may be willing to tradeoff democratic ideals for considerations of partisan loyalty, political ideology, and policy preferences (Graham and Svolik 2020). In the US, Levitsky and Ziblatt (2018) have similarly labelled a key challenge of extreme partisan polarization as erosion of the unwritten democratic norm of "mutual toleration" in rejection of political opponents as legitimate rivals. These accounts underpin possible 'pernicious' dynamics of partisanship and political polarization at extremes and its important implications for democratic governance.

Notably, polarization may be more concerning where there exists a 'formative rift' dynamic of partisanship in mutually exclusive narratives of citizenship and group belonging (LeBas 2018; McCoy and Somer 2019). The trouble in political bargaining under such dynamics exacerbates the difficulties to resolve conflicts, particularly involving exclusionary notions of 
citizenship (LeBas 2018). Each building on similar ideas, LeBas (2018) and McCoy and Somer (2019) arrive at slightly different viewpoints for how historical identity cleavages might affect the implications of severe partisan polarization. The former distinctly argues that preexistence of identity-oriented rifts involving exclusion or inequality of rights for citizens makes it more likely for political polarization to result in large-scale violence and democratic breakdown (LeBas 2018). As a further matter, presence of a substantial power imbalance between poles may raise chances that polarization is short-lived, concluding with the preservation of those in power if not permanent exclusion of opposition or marginalized groups (LeBas 2018). If neither a preexisting identity cleavage nor power imbalance are present in polarized conditions, LeBas (2018) posits that such dynamics may have the reverse effect of institution-building, accommodation, and compromise for new democracies in reform (e.g., Burkina Faso and Ghana as discussed).

McCoy and Somer (2019) differ from LeBas (2018) in the way they find the 'formative rift' dynamic of polarization as not necessarily to blame, even if the preexistence of such identity cleavages may influence longer term costs of severe political divisions. They argue that polarization arises as a consequence of political entrepreneurs making polarizing political appeals in pursuit of their political objectives (McCoy and Somer 2019). Specifically, they identify that concerning implications of polarization stem from the use of divisive, demonizing, and exploitative appeals to existing popular grievances as a basis for political mobilization. In turn, 'pernicious polarization' arises when elite political opponents either reciprocate using similar strategies or fail to neutralize polarizing messages (McCoy and Somer 2019). Like LeBas (2018), they contend that negative implications of polarized blocs worsen in a power imbalance, which increases the possibility for democratic erosion (McCoy and Somer 2019). Moreover, polarizing parties' use of harsh rhetoric may delegitimize opponents in addition to the political 
system, even if real policy differences between parties are minimal (McCoy and Somer 2019). The polarizing rhetoric may amplify prevalence of disinformation and high levels of confidence among the masses in unsubstantiated opinions (McCoy and Somer 2019). In matters of political outlook, McCoy and Somer (2019) imagine that gradual democratic erosion is a more likely consequence of political polarization than violence or democratic breakdown. Because intense party attachments can be uncompromising and encourage political extremism rather than deliberation, polarized settings that influence strong partisan identities have potential to weaken democratic institutions (Lupu 2014). Elite cues may thus drive partisanship and its consequences.

Several case studies shed additional light on severely polarized politics. It is often in these extremes where partisanship may be most concerning from the standpoint of democratic ideals in governance as well as general political stability. Foremost for this study is the case of US democracy, which the 2019 Freedom House report on democracies around the world found straining in ways starting before Donald Trump's 2016 election to the presidency. Indeed, growing political polarization, including partisan media increasingly displacing fact-based reporting, plus eminence of special interests in American politics in contrast to low economic mobility are all factors "afflicting the health of American democracy well before [Trump's inauguration]" (Freedom House 2019a,17). Surveillance programs that began under George W. Bush continuing into the Obama administration and crackdown on press leaks for the latter are two prime examples of a longer trend (Freedom House 2019a). However, under President Trump essential democratic institutions such as "separation of powers, a free press, an independent judiciary, the impartial delivery of justice, safeguards against corruption, and most disturbingly, the legitimacy of elections" are under duress (Freedom House 2019a, 17). Though the US remains in the 'Free' category on aggregate for the 100-point scale Freedom in the World report, 
measurable decline in political rights and civil liberties is clear from about 2010, beginning before Trump (Freedom House 2019a). The score for equal treatment before law particularly worsened under Trump's leadership, given the administration's improper restrictions on rights of asylum seekers, discrimination in refugee resettlement policies, and harsh immigration enforcements like separation of immigrant children from families (Freedom House 2019a). Longer term, general democratic dysfunction and electoral manipulation, such as partisan gerrymandering, are among other concerns for American democracy (Freedom House 2019a). Further democracy indicators on societal-level polarization and respect in public deliberations, too, show notable declines for the US in recent years (V-Dem Institute 2019). These features may be part of a larger trend. For about a decade, polarization indicators show growing intensity in 33 countries around the world, in conjunction with a rising trend of political parties in at least 30 countries deploying hate speech targeting specific groups (V-Dem Institute 2019). For the US, Trump may have worsened preexisting polarization through his "attempts to undermine the legitimacy of elections [most notably in claims of rigging and refusal to accept results of his loss as legitimate in the 2020 elections], repeated calls that all media are the enemy of the people, and vilification of political opponents" (V-Dem Institute 2019, 20).

The impact on democratic institutions under intense polarization and leaders like Trump greatly depends on whether elite party members defend democracy or act as loyal partisans. If loyalists publicly defend controversial behavior or otherwise continue to show passive support for the executive through congressional inaction and votes on party lines, there is potential for institutional erosion (Levitsky and Ziblatt 2018). Another key factor is public support, which, if high, could blunt critics and make judges loath to rule against the government, as political rivals worry about staking an unpopular position (Levitsky and Ziblatt 2018). Lastly, a major security 
crisis may embolden a political entrepreneur like Trump by relaxing institutional constraints (Levitsky and Ziblatt 2018). Yet, even with the COVID-19 pandemic, certainly a historic crisis, there was no such power grab under Trump and loyalist Republicans (in contrast, see, e.g., Gebrekidan 2020). Trump's norm breaking may nevertheless contribute to gradual democratic erosion (Levitsky and Ziblatt 2018), a case in point echoing theories on the negative implications under severe dynamics of partisanship. The fact that the Republican party mostly tolerated Trump's deviance spills into the Republican electorate and influences mass attitudes determining what is politically acceptable (Levitsky and Ziblatt 2018). Partisan loyalties from elites to the masses may have enabled political leadership under Trump to push against the boundaries of American democratic norms.

Polarization in the US "feeds off a formative rift" around questions of citizenship and enjoyment of rights dating back to American origins (e.g., African slavery, Native Americans, women, race, religion, birthright and naturalized citizenship) (McCoy and Somer 2019, 240). Rival narratives of belonging in American politics once led to the Civil War as well as continued legal and informal discrimination up through the 1964 Civil Rights Act, then "repolarization" near the end of the $20^{\text {th }}$ century and aggravating under Obama and Trump administrations (McCoy and Somer 2019, 239). Besides frequently anti-establishment, Trump's rhetoric and actions on the campaign trail and as president have certainly been polarizing. His political appeals have drawn lines between 'us,' in terms of a romanticized past of American industry tied to upward mobility and traditional cultural predominance, and 'them,' as immigrants, minorities, and elites together thwarting American greatness (McCoy and Somer 2019). From Obama's second-term election through the end of Trump's first and only term as a political outsider, research has found racial resentment, ethno-nationalism, and prejudice play a large role in voting 
behavior of white Americans (McCoy and Somer 2019). Moreover, the Trump administration made frequent policy directives by executive order to dismantle Obama administration policies enacted under the same authority meant to protect sexual and gender minorities against discrimination (Freedom House 2019a). The Trump administration similarly responded to the Obama tenure using executive authority to act on immigration policy, sometimes in ways plainly discriminatory, in blunt partisan reversal from his predecessor (Freedom House 2019a).

Another longstanding democracy may be experiencing similar dynamics over Brexit stemming from 2016 referendum results against European Union (EU) membership (Hobolt, Leeper, and Tilley 2020; McCoy and Somer 2019). Though political polarization in the United Kingdom (UK) does not appear to fall on party lines, the case is informative. Instead, group identification and mass polarization may be emerging on the basis of opinion among voters who identify with either side of the consequential vote for the UK to remain or leave the EU (Hobolt, Leeper, and Tilley 2020). Survey analysis with over a million respondents, using mostly YouGov data, supports the notion of political identities arising out of the Brexit vote (Hobolt, Leeper, and Tilley 2020). The results suggest more people in Britain are claiming an identity of Leaver or Remainer on the Brexit question than identifying as either Conservative or Labour members (Hobolt, Leeper, and Tilley 2020). As a novel phenomenon, attachment to Brexit identity in a polarized dynamic may indicate a similar 'formative rift' (McCoy and Somer 2019), or notions of belonging in the 'nation' or British community along an "underlying fault line between social liberals with weak national identities... and social conservatives with stronger national identities" in Britain (Hobolt, Leeper, and Tilley 2020, 9). Age and education have been main predictors for either side of this UK rift, with younger and more educated voters likely to identify as Brexit Leavers compared with older and less educated Britons likely to identify as Remainers (Hobolt, 
Leeper, and Tilley 2020). Similar to party attachment and polarization in the US, the salience of Brexit 'leave' versus 'remain' identity tends to cross-cut into social life. For example, Remainers and Leavers are each more likely to show bias in preference for their in-groups in choice of public leaders, even for non-partisan matters, as well as social settings like marriage and talking politics (Hobolt, Leeper, and Tilley 2020). Severe polarization may not be a strictly partisan phenomenon, though the US and UK cases are similar in that they point to underlying rival narratives of belonging for matters formulating political as well as social identities. In case of Brexit, issue attachment has, for now, beaten partisan identities in a tense political polarization that "has still not been fully subsumed into normal lines of party competition" (Hobolt, Leeper, and Tilley 2020,15$)$. In contrast for the US, party attachment and group narratives of citizenship and belonging tend to go hand in hand.

Nevertheless, comparative survey data from 20 western democracies on 'affective' polarization, or mass-level hostility across party lines, suggests things in the US may not be so intense after all. In comparative perspective, surveys on positive or negative feelings of respondents towards political parties in their country finds the US as relatively middle ground in terms of hostility against rivals among the masses (Gidron, Adams, and Horne 2019). The country registering highest for affective polarization in the study was Switzerland. Interestingly, their most influential political party, the Swiss People's party, is similar to right-wing American politics under Trump's party leadership insofar as opposition to mass immigration and support for other populist right issues. The multiparty parliamentary system in Switzerland compared with the American two-party system may contribute to the differing reports of affective polarization as negative sentiments towards radical right-wing parties in the former averages more intense than other political opponents (Gidron, Adams, and Horne 2019). Fearing loss of 
national or local identity and thus sense of control in an era of globalization-including ascent of transnational political and economic institutions, mass mobility and migrations, multicultural proliferation, and newly transnational 'communities' developing over the internet — may be influencing the salience of modern cultural nationalisms linked with traditional ethnic and religious identities (Juergensmeyer 2018; see also the 'cultural backlash' thesis and evidence from 31 European countries linking cultural values to rising support for populist parties in Western societies, e.g., Inglehart and Norris, 2016; Kaufman and Haggard 2019).

As for newer and developing democracies, Côte d'Ivoire (Ivory Coast) and Kenya are two cases involving 'pernicious' polarization, where negative implications include the prospect for hardened group divisions, absolutist politics, and violent scapegoating (LeBas 2018). Each of these cases feature political appeals to group belonging or citizenship as key narratives driving polarized politics. In Côte d'Ivoire, elites were largely responsible for shaping country divisions along religious and regional lines in appeals to their constituencies for popular mobilization purposes. Consequently, an 'us versus them' narrative against non-indigeneity led to regime breakdown and violence, with civil war erupting 12 years after transition to multiparty rule in 1990 (LeBas 2018). A political ideology around belonging influenced doubts about loyalty to the nation for citizens with non-native parents as well as Muslims (LeBas 2018). With new forms of identity around which to mobilize, the 2000 and 2010 elections each produced violent clashes and spread of civil war as "party competition centered entirely on the issue of Ivorian national identity" (LeBas 2018, 68). By contrast, although the Kenyan case similarly involved political appeals to indigeneity and belonging to the nation, its group conflict and ethnic salience prevailed before polarization (LeBas 2018). Kenyan political elites began using exclusionary rhetoric around ethnicity and violent displacement for political mobilization starting in the 
1990s. Their electoral strategy has influenced high ethnic segregation, mass voting chiefly along ethnic lines, and widespread distrust between ethnic groups (LeBas 2018).

Still alternate theories on 'pernicious' aspects of polarization look to other case studies for guidance on political implications. For example, in Poland, even absent any preexisting identity cleavages, the Law and Justice Party reflected anti-establishment and populist sentiments as it gained popular support to win elections before rewriting constitutional rules to the party's benefit (Tworzecki 2018). Hence, a second key challenge of severe party polarization against underlying democratic norms according to Levitsky and Ziblatt (2018) is political restraint of elected leaders from using temporary powers to maximize partisan advantage. In other examples, a case study of Hungary, Turkey, and Venezuela in comparison to US polarization finds elites are central in constructing or intensifying existing cleavages in partisan extremes (McCoy, Rahman, and Somer 2018). Often in times of economic or state crisis, the elites in these countries have used divisive messages along mutually exclusive lines of 'us' and 'them' to mobilize sectors of the population perceived as marginalized or disunited from the whole (McCoy, Rahman, and Somer 2018). Under polarizing dynamics in Hungary, Turkey, and Venezuela, new groups in power enacted measures to consolidate political control, including constitutional changes, increasingly majoritarian electoral systems, and less constraints on executive power through appointment of political or party loyalists (McCoy, Rahman, and Somer 2018). In all four cases, there has been backlash to new or previously marginalized groups reaching political power (e.g., US election of Barack Obama and subsequent Tea Party mobilization in opposition). Some strategies of political opposition include polarizing rhetoric, mass protests, or even coup attempts in pursuit of power (McCoy, Rahman, and Somer 2018). In rhetoric, the US case echoes counterparts in Hungary, Turkey, and Venezuela insofar as Trump 
"evoked the same majoritarian contempt" through demonization of racial and ethnic minorities as a key theme of his 2016 presidential campaign (Kaufman and Haggard 2019). Drawing from these comparative cases, three potential trajectories for democracy under severe partisan dynamics include: Gridlock and policy 'careening' from one party in power to another; democratic erosion or collapse under new elites or dominant groups; and democratic erosion or collapse under old elites or dominant groups (McCoy, Rahman, and Somer 2018). For the US, however, support for Trump during his tenure remained relatively weak with robust opposition (Kaufman and Haggard 2019). It nevertheless remains possible for extreme polarization to turn gainful by way of democratic reforms (McCoy, Rahman, and Somer 2018).

\section{Democratic Function Against Extreme Partisanship}

The problems of partisanship may be a factor in democratic deconsolidation. It is an important issue concerning the function of democratic regimes. To that effect, this thesis emphasizes one issue among many possibilities influencing apparent crises among democratic regimes around the world. While democratic systems vary in concept and practice, there are broad trends in the challenges facing democratic governance in conjunction with rising authoritarianism, including even long-established regimes like the United States. Several prominent annual reports on the state of democracy indicate a 'reverse wave' of democratization may be ongoing over the last few decades (see, e.g., The Economist Intelligence Unit 2018; VDem Institute 2019; V-Dem Institute 2020; Freedom House 2019b; Freedom House 2020b). Here, I explore democracy in concept to lay the groundwork for addressing dynamics of severe partisanship that could be pernicious for democratic function of government. I explain the present state of democracy in nation-states throughout the world for context, drawing from literature including annual democracy reports showing a historically recent rise of 'illiberal' 
democracies, hybrid regimes, or electoral authoritarianism. Scholars identify several factors in undemocratic trends, from economic grievances to cultural backlash fueling electoral change. To situate my analysis of Democratic and Republican party platforms as a test of partisan-identity polarization in American politics from 1980-2016, I underscore possible concerns for democratic regimes mired in socio-political divisions hardening on identity lines.

\section{Systems of Democracy in the Third Reverse Wave}

The concept of democracy and context within which it resides as a state system are essential groundwork for any analysis dealing with deconsolidation. More countries than any time in history now hold elections but tend to have defects including poor representation of citizens' interest in governance, low political participation other than casting a ballot, abuse of laws and powers by public officials, shaky legitimacy of elections, low public confidence in government, or poor performance of state institutions (Carothers 2002). These problems in

democratic governance allude to the current period some label a 'third wave' of autocratization (see, e.g., Luhrmann and Lindberg 2019; V-Dem Institute 2020) or, inversely, a 'third reverse wave' of democracy (see, e.g., Huntington 1991).

Free and fair elections are often a bare minimum for democratic systems (see, e.g., Carothers 2002; Collier and Levitsky 1997; Cheeseman and Klaas 2018; Collier and Levitsky 1997; The Economist Intelligence Unit 2018; Freedom House 2020; Huntington 1991; Linz and Stepan 1996; Luhrmann and Lindberg 2019; Schmitter and Karl 1991; V-Dem Institute 2019). Yet as scholars have observed in recent decades, with the rise of so-called pseudo-democracies, hybrid, illiberal, or competitive/electoral authoritarian regimes, holding elections is insufficient alone to distinguish a democracy from autocratic regimes or grey area in between (see, e.g., Bogaards 2009; Cassani 2014; Cheeseman and Klaas 2018; Diamond 2002; Mietzner 2018; 
Levitsky and Way 2010; Luhrmann and Lindberg 2019; Waldner and Lust 2018). As a start, citizens in a democracy hold rulers accountable for their actions and channel interests in competitive, regular, and fair elections (Schmitter and Karl 1991). Fairness of elections means they are equal and open for matters of competition between political parties, without government restrictions or harassment of opposition groups (Huntington 1991). These features are part of notable requisites in Robert Dahl's seven procedural democratic conditions, including (1) elected officials controlling government and policy; (2) frequent, free and fair elections without coercion; (3) virtually universal adult suffrage; (4) virtually universal eligibility among adults to run for elected office; (5) freedom of expression; (6) freedom to seek alternative information; and (7) freedom of association (Schmitter and Karl 1991; see also, e.g., Luhrman and Lindberg 2019). Two supplemental criteria are (i) elected leaders must not be subject to overriding vetoes from unelected officials and (ii) the regime is self-governing without external constraints such as from another political system (Schmitter and Karl 1991). Others specify fully contested elections without fraud, held under universal suffrage and with guaranteed civil liberties like free speech, assembly, and association (Collier and Levitsky 1997). In other words, it requires "free elections, broad protection of civil liberties, and a reasonably level playing field" to distinguish it from an authoritarian regime (Levitsky and Way 2010, 7). As focal points in recent literature relative to 'crisis' in democratic systems of governance, some simply refer to regime types like liberal (Hobson 2018) or representative (Ercan and Gagnon 2014) democracies. Others differentiate functioning democracy from hybrid regimes as satisfying key criteria of freedom, equality, and checks on political power (Bogaards 2009). A fully authoritarian regime characteristically holds no elections whatsoever. Some regimes falling short of functioning democracy might administer 
elections but have severe-to-moderate constraints on political rights and civil liberties or rigging in contested albeit unfair and undemocratic electoral competition (Cheeseman and Klaas 2018).

Democracy functions by societal and political consensus. It operates in principle on the consent of the people and "contingent consent of politicians acting under conditions of bounded uncertainty" in elections (Schmitter and Karl 1991, 10). Key to democracy is that representatives informally agree that those who win greater electoral support or influence over policy will not use their temporary superiority to bar the losers from taking office or exerting influence in the future, and that in exchange for this opportunity to keep competing for power and place, momentary losers will respect the winners' right to make binding decision (Schmitter and Karl 1991, 10).

Political elites, in other words, must "believe, at a minimum, that democracy is the least bad form of government for their societies and themselves" (Huntington 1991, 33-4). This means not sacrificing democratic consensus in society and politics for partisan gain. Citizens are likewise informally bound in a democratic system to accept results of an election, assuming all is fair (Schmitter and Karl 1991). In this sense, democratic practice is rooted in political culture (The Economist 2014). Of the US case lately in particular under the Trump administration, Levitsky and Ziblatt $(2018,147)$ underscore two foundational norms of democracy in American society they say are "unraveling," which I elaborate in factors below. As a matter of functioning democracy, (i) mutual toleration of political rivals and (ii) institutional restraint from using temporary powers to maximize partisan gain are vital norms and reinforcers of democratic governance (Levitsky and Ziblatt 2018). A democracy is hard work that requires "negotiation, compromise, and concessions," where "setbacks [are] inevitable, victories always partial" (Levitsky and Ziblatt 2018, 77). Limits in power may cause frustrations but underlie the political culture and consensus of stable democracies (Levitsky and Ziblatt 2018). A consolidation or full democratic transition is thus satisfactory agreement over political procedures and nature of democracy for free and popularly elected government to determine state policies, without which 
breakdowns are possible (Linz and Stepan 1996). If functioning properly, the system is routine; internal to the social, institutional, and psychological life of its citizens in a shared identity with the state (Linz and Stepan 1996). In short, democracy is not only institutional insofar as central tenets of a political system in protection of political rights, but attitudinal and behavioral among actors within the polity to believe in the system (Linz and Stepan 1996). Weak commitment to its values and practices in leadership can be a "serious impediment" (Huntington 1991, 22).

However, democracy varies in practice and over time (Ercan and Gagnon 2014; Linz and Stepan 1996; Schmitter and Karl 1991). Samuel Huntington (1991) identified three periods of democratization and two reversals from roughly 1820-1990. He highlights in the first period or 'wave' an expansion of suffrage for much of the American male population. The total number of democracies over a stretch of regime transitions first peaked in 1926 (Huntington 1991). After a trend of decline, a second wave of democratization reached its high in 1962 with a total of 36 democracies, followed again with a second trend of decline until around 1975 (Huntington 1991). At the time of writing, he was within an upswing period of democratic transitions or a "third wave of democratization in the history of the modern world" and briefly mused a subsequent reverse trend to come (Huntington 1991, 12). Huntington's (1991) analysis is a minimalist conception of democracy, primarily concerning equal and open electoral competition without restrictions on opposition groups.

Other measures allow a more robust view of the 'third reverse wave' period. For example, the Freedom House Freedom in the World annual report evaluates countries and territories of the world on political rights and civil liberties. They distinguish "electoral democracy" from "liberal democracy" as the former reflects minimum standards while the latter signifies higher scores on a range of criteria-based questions on democratic ideals (Freedom 
House 2021). The indicator also assigns free, partly free, or not free status to regimes, covering a breadth of regime characteristics. It accounts for electoral processes (i.e., free and fair elections); political pluralism and participation (i.e., rights to organize in political parties or other coalitions, free of undue obstacles in political competition or external influence, and full political rights for all groups within the population); function of government (i.e., elected representatives determine policies, safeguards against corruption, and openness and transparency); and political rights (i.e., civil liberties, association and organization, rule of law, and individual rights and personal autonomy). Varieties of Democracy (V-Dem) likewise offers a rich indicator on the yearly state of democracy worldwide. Their approach emphasizes political liberalism foundations in "Enlightenment principles of rights, reason, and tolerance," which have "led the world from societies governed by repression and prejudice to open societies based on merit and freedom" (V-Dem Institute 2020, 4). The Liberal Democracy Index (LDI) operationalizes these values by measuring democracy using more than 3,000 world country-experts' combined judgements. Liberal and electoral components comprise the LDI in 71 total indicators assessing regime traits (V-Dem Institute 2020). Like the Freedom in the World indicator, it differentiates electoral components as a base level of democratic features in free and fair elections, including freedoms of association and expression, clean elections, suffrage, and an elected government. The liberal components of the LDI also extend democratic components to capture checks on political power like guaranteed individual liberties, equality before law, and institutional checks and balances (V-Dem Institute 2020). Together they reveal degree shifts in regime traits on a sliding scale from closed or electoral autocracies to electoral or liberal democracies (V-Dem Institute 2020). Accordingly, Huntington's (1991) earlier musing on a 'third reverse wave' now seems prescient. The V-Dem Institute (2019) annual reporting identified an ongoing 'third wave of 
autocratization' after 2018, as democratic regime traits in the LDI declined in 24 countries. Over the next year, there were "intensifying" trends with deterioration of liberal democratic institutions in 26 nation-state systems (V-Dem Institute 2020, 4). Since 2001, autocratic regimes now surpass democracies over a majority of state systems around the world (V-Dem Institute 2020). Attacks on freedom of expression and media in 31 countries, the decline of clean elections in 16 countries, and repression of civil society including censorship in 37 countries are all trending signs of democratic regime deterioration. In addition, civil society indicators reflect $13 \%$ average decline in academic freedom and $14 \%$ average decline in rights to peaceful assembly and protest over the last 10 years among de-democratizing trends. They recently report 'toxic polarization,' 'pro-autocracy' protests, and political violence as growing threats to democracy, even as a wave of pro-democracy protests in resistance or demands for more democracy throughout the world may at times permit some optimism (V-Dem Institute 2020). Total liberal and electoral democracies in the world tallied at 45 (peak) and 55 state systems in 2010, and fell to 37 and 50, respectively, by the end of 2019, according to indicators (V-Dem Institute 2020). The 2019 Freedom in the World data tracks 14 consecutive year of overall decline since 2005, owing to fraying political rights and civil liberties in 64 countries, as 37 countries showed improvements (Freedom House 2020). Pluralism may be "under assault" by elected leaders who show disregard for democratic institutions and respect for the rights of critics and minorities in pursuit of their political agendas (Freedom House 2020, 1). Even in the US, liberal democracy may have "lost its way" (V-Dem Institute 2020, 4).

Deconsolidation trends may be inflicting established as well as politically influential regimes and major economies of the world (The Economist Intelligence Unit 2014; Freedom House 2019; V-Dem Institute 2020). A key figure in American politics in recent years is Donald 
Trump. His actions as a candidate and president in American politics have undermined democratic norms of electoral integrity, independent judiciary, abuse of powers, equal treatment under law, and rhetorical attacks on media (Freedom House 2020). For example, in what led to a failed impeachment attempt by Congress, Trump unsuccessfully sought aid from Ukrainian president Volodymyr Zelenskyy to investigate his potential political rival to bolster his reelection chances. He further abused his powers to temporarily block military aid allocated by Congress to Ukraine to pressure the then president, and then in orders to "current and former officials to defy all congressional subpoenas for documents and testimony on the matter" (Freedom House 2020b). Still, as discussed in detail in the above section, some argue the trends began decades prior to "serial norm breaker" Trump's electoral rise, particularly in dynamics of intensifying partisan polarization around issues of race and culture (Levitsky and Ziblatt 2018, 146).

Meanwhile in the world's largest democracy of India, Hindu nationalism threatens a secular and inclusive political system, by implementing undemocratic practices such as restrictions on the rights of some segments of the Muslim population and exclusive citizenship registration laws (Freedom House 2020). In Israel, the then Prime Minister Benjamin Netanyahu oversaw bans on foreign activists and enactment of discriminatory policy reserving rights of self-determination strictly to Jewish people (Freedom House 2020). Like elsewhere in Europe, centrist parties in Spain have lost ground in elections to radical right-wing nationalists in recent years (Freedom House 2020). Poland's Law and Justice party in 2016 took measures in power to erode judicial independence, dominate media, and stifle opponents. Over the last decade under Viktor Orban's populist-nationalist leadership, Hungary became the first European Union member state whose status in the Freedom in the World report fell to partly free (Freedom House 2020). 
In particular, Western societies are facing more unpredictable elections, more antiestablishment and populist challenges to the liberal democratic establishment, and potential shakeups in longstanding patterns of electoral competition (Inglehart and Norris 2016; see also, e.g., Foa and Mounk 2017; Mietzner 2018). The 2007-2008 financial crisis and resulting global economic recession may have driven disillusionment to be a feature in current trends (The Economist 2014). In 2011, the Occupy Wall Street movement and nationwide protests against economic inequality made a spectacle of unrest. More recently, from a global pandemic to mass discontent, protests and riots in cities throughout the US after the police killing of a black man in custody, American democracy may be more divided on partisan lines as ever in modern history. President Trump faced a historic second impeachment in early 2021 on charges of "incitement of insurrection" after rejecting the November 2020 election as fraudulent. Notably, Trump's baseless claims of election rigging culminated in a Washington rally speech after which loyal supporters staking one side of a deep partisan divide apparently took his cues in the resulting Capitol Hill riots and masses 'storming of the capitol' on January 6, 2021. The large pro-Trump gathering-turned-riots or 'insurrection' temporarily paused congressional hearings to certify election results (BBC News 2021). This precarious moment for American democracy may exemplify a "potent ideational mix of populism, ethno-nationalism, and authoritarianism [that] has rallied large numbers of supporters in established democracies behind a radical-right agenda" (Bonikowski 2017, S182). In other words, the nativist drift in US and European politics may be "a passive consequence of macro-level socioeconomic development," in which there is "cultural content and structural context of political preferences" (Bonikowski 2017, S183). Trends may be rational responses to local historical and international incentives, but their context is ambiguous in terms of democratic erosion since institutions of democracy backed by popular support often 
legitimate them (Bermeo 2016). In other words, there is a façade of democratic governance even if trends push the boundaries of a democratic regime.

In sum, regimes that mix democratic and authoritarian characteristics are more common in recent years (Bogaards 2009; Cassani 2014; Diamond 2002; Carothers 2002; Levitsky and Way 2010). Defects in freedom, fairness, inclusiveness, and meaningfulness of elections, in other words, distinguish hybrid from democratic regimes (Diamond 2002). Despite more elections, democratic functions are increasingly dubious, e.g., due to gerrymandering, votebuying, repression, election hacking, ballot stuffing, or threading external actors to favor one party or candidate at the expense of others (Cheeseman and Klaas 2018). More often, political elites are influencing a gradual shift away from democratic regimes (Cheeseman and Klaas 2018; Levitsky and Ziblatt 2018). The patterns are usually "incremental rather than sudden" (Bermeo 2016, 14) and lawful unlike past iterations (Bonikowski 2017; Luhrman and Lindberg 2019; VDem Institute 2019; Waldner and Lust 2018). Scholars using V-Dem indicators recently found autocratization trends are now "almost global and more in democracies than anywhere else," in a protracted subversion of democratic attributes while maintaining a façade of electoral choice in modern 'illiberal' regimes (Luhrman and Lindberg 2019, 1104). Since deconsolidation in the 'third reverse wave' is occurring through gradual deterioration of liberal democratic ideals, political dynamics like polarization may be instructive.

\section{Factors in Deconsolidation: Severe Polarization Into Partisan-Identity Blocs}

While recent problems of democratic deconsolidation appear as multicausal according to surveys of literature on the issue (see, e.g., Ercan and Gagnon 2014; Hobson 2018), this thesis zeroes on specific dynamics that may influence trends in the shift away from liberal democratic regime characteristics towards more authoritarian governance. Principally, extreme and 
intensifying polarization in societies might create space for direct challenges to democracy by undermining key norms of a functioning system. If divisions extend to produce feelings of mutual hostility and encourage support for actors willing to bend democratic rules for political advantage, they might especially contribute to problems that deteriorate democratic regime characteristics (LeBas 2018; Levitsky and Ziblatt 2018; McCoy and Somer 2019). As mentioned, elected officials may be fraying two fundamental and reinforcing values of democracy in recent years, in part due to dynamics of severe partisanship. Mutual toleration of political rivals as legitimate opponents, as opposed to existential enemies, and institutional forbearance in restraint from abuse of temporary powers in elected office are two essential "unwritten rules of the game" (Levitsky and Ziblatt 2018, 104). I clarify below how extreme polarization - to the extent in US context that being a Democrat or Republican "has become not just a partisan affiliation but an identity" (Levitsky and Ziblatt 2018, 168) — can potentially fuel democratic deconsolidation, or sometimes lead to democratic reforms. With brief examples, I suggest the potential role of intensifying polarization of group or national identity politics as influential in recent trends. The possible issues suggest why growing partisan divisions along identity lines and belonging in the US could be consequential and therefore important for the longstanding American democracy.

Dynamics of severe polarization are different from conventional understandings of ideological distance between political parties and candidates (McCoy and Somer 2019; Vegetti 2018). These possibly de-democratizing trends instead involve alignment of identity and political interests along a single polarizing divide (LeBas 2018; McCoy and Somer 2019). Divisions grow 'pernicious' to the extent that a "Manichean, moralizing character" dominates political discourse in society, and partisans favor their in-group while unfavorably stereotyping the out-group (McCoy and Somer 2019, 244). The two sides in a socio-political divide may come to view 
matters in tribal terms. Devotion to in-group members may come at the expense of bias and prejudice for others in ways that dehumanize and personalize politics inconsistent to mutual trust (McCoy and Somer 2019). The tendency for alienation from out-groups and concentration with in-groups could entrench divisions to leave little-to-no middle ground (Vegetti 2018).

The cases of 'pernicious' polarization deviate from "healthy pluralism in democratic society" on the basis of prominent features, including the following from 11 comparative studies: (i) mutually hostile, exclusive and antagonistic electoral blocs, along which multiple partisan cleavages collapse into a dominant binary; (ii) "political identity of the two camps becomes a social identity in which members feel they belong to a 'team' and demonstrate strong loyalty to it" in matters of "good" and "evil," and with us or against us mentality (246); (iii) the two identity blocs drive political demands and interests for members in between-group antagonisms that undermine potential common interests; (iv) presence of extensive "[s]tereotyping and prejudice" on account of negligible social interaction between groups; (v) institutional dominance including media "by one bloc or the other through discursive changes as well as changes in ownership, management, and staff, weakening the middle ground in public and political discourses" (247); and, not least, (vi) antagonism in both physical and psychological separations between groups in a broadly polarized society (McCoy and Somer 2019). In brief, when polarization encloses social interactions in sharp lines of "us vs. them identity politics, interactions along all other planes diminish considerably, channels of communication between groups break down, and intragroup solidarity increases at the expense of intergroup cohesion" (McCoy and Somer 2019, 247). At such extremes, dynamics may be "totalizing" (McCoy and Somer 2019, 247). Party and rival distinctions may harden in unintentional but reinforcing ways for problems of democratic function (McCoy, Rahman, and Somer 2018; McCoy and Somer 
2019; Vegetti 2018). Erosion of key norms of mutual toleration and institutional forbearance may thereby turn ordinary democratic rivalry into existential conflict above policy differences (Levitsky and Ziblatt 2018).

In that sense, sharp partisan polarization in the US may reflect intensifying cleavages around conflicting narratives that involve race, culture, and belonging in political representation (Abramowitz and McCoy 2018; Layman, Carsey, and Horowitz 2006; Levitsky and Ziblatt 2018; McCoy and Somer 2019). Indeed, "the basic question of citizenship and who enjoys the rights espoused by the founding fathers... has been debated since the founding of the republic and its differentiated citizenship for African slaves, Native Americans, and women" (McCoy and Somer 2019, 239). These sorts of contending narratives were present leading up to civil war, then a century thereafter in formal and informal modes of discrimination, and again from the late $21^{\text {st }}$ century into bittering polarization under Obama and Trump administrations (McCoy and Somer 2019, 239). Features of extreme polarization between "incompatible worldviews" as such may develop into "perceptions of mutual threat" that incentivize partisan actors to seek absolute ends using temporary powers of elected office (Levitsky and Ziblatt 2018, 116). Still, within potentially democracy-debilitating dynamics of deep polarization, there may be space for democratizing reforms, e.g., the obvious case of slavery abolition after years of polarization leading up to US Civil War. Democratizing possibilities may underlie one of a few patterns of political utility in polarizing elite tactics. Elites in competition may use polarizing strategies for general self-interest to mobilize electoral support, although not necessarily for democratizing ends (McCoy and Somer 2019). By contrast, they might seek transformative ends in one of two other patterns in recent years. The "progressive-inclusionary" strategies that seek to lift marginal populations could potentially influence democratizing reforms, while "exclusionary-reactionary" 
strategies might contradict liberal-democratic norms by appealing to "exclusive impulses of masses who feel they have suffered loss of status and resources" to the status quo (McCoy and Somer 2019, 248). Still, incumbents or opposition could influence regime trajectories either way. Hence, polarizing politics "can sometimes serve useful democratic ends and should not be regarded as a necessarily bad feature of governance" (McCoy and Somer 2019, 257).

Accordingly, political elites tend to act as agents of severe polarization through strategies and discourse tactics that build on existing cleavages and salient discursive grievances in society (McCoy and Somer 2019). Contemporary rifts might include populist ascriptions of elites versus people; religious/secular or church/state; cosmopolitan/nationalist; cultural value bases of traditional/modern, conservative/liberal, or communitarian/universalist; place- or status-based values and interests; economic ideology or class; political ideology, including concept of democracy and sources of legitimacy; or citizenship rights and national identity in 'formative' rifts of the state (McCoy and Somer 2019). As political and media discourse channel popular anxieties (Bonikowski 2017), tactics of political elites may aggravate extant societal cleavages or grievances if they stoke "fears, anxieties, and resentments that then become expressed as hostility, bias, and eventually enmity" on course to 'pernicious' polarization (McCoy and Somer 2019, 240). As a case example in deconsolidation trends (Foa and Mounk 2017), a political rift between Democrats and Republicans in the US cuts deep on social, ethnic, and cultural bases of community (Levitsky and Ziblatt 2018). The 'formative' rift dynamics of severe polarization are thus important to this thesis especially; when preexisting historical rifts around belonging are salient and feature exclusionary narratives of citizenship, there may be greater potential to fuel undemocratic behavior (LeBas 2018; McCoy and Somer 2019; McCoy, Rahman, and Somer 2018). At extremes, appeals within formative polarizing dynamics on grounds of belonging may 
serve as grounds for violence or exclusion (LeBas 2018). Many democracies persist in some way at contesting the 'nation' in political communities, though not always actively except for recent popular nationalist mobilizations (Bonikowski 2017). While differences " $m a y$ be associated with an ascriptive identity, insofar as political narratives built around pluralism or regional autonomy might be attractive to ethnic or religious minorities," split ideological conceptions of the state in "foundational debates can be cross-cutting and generate polarization even if they have little association with pre-existing identity-based cleavages" (LeBas and Munemo 2019, 210; see also, e.g., McCoy and Somer 2019). Foundational debates either way tend to sustain polarizations and partisan loyalties (LeBas and Munemo 2019). Still, some contextual factors might offer a resonant backdrop for similar 'pernicious' polarization to develop (McCoy and Somer 2019), including appeals of various populist, authoritarian, and ethnonationalist politics of resentment gaining recent popular support (Bermeo 2016; Bonikowski 2017; Inglehart and Norris 2016). On the one hand, features in recent decades may be economic such as sharp growth in inequality, stagnant middle-class wages as top incomes rise, loss of traditional manufacturing industries in global trade, and collapse of union memberships (Bonikowski 2017). In other words, these factors may be possible context drivers of 'economic grievance' politics around which elites may emphasize polarizing strategies (McCoy and Somer 2019). On the other hand, and like historic 'formative' rifts an important focus of this thesis, political elites might deploy polarizing discursive tactics with resonant 'cultural grievances' and 'political grievances or crisis of representation' (McCoy and Somer 2019).

Between "progressive-inclusionary" and "exclusionary-reactionary" patterns of polarizing strategies (McCoy and Somer 2019, 248), national cultural rifts in recent years typically feature political appeals between advocates and opponents of progressive changes in 
egalitarianism, cosmopolitanism, and multiculturalism (Bonikowski 2017; Inglehart and Norris 2016). As the latter blocs adhere to "previously stable and valued collective identities, rooted in class position and national belonging," some members could perceive an evolving cultural or ethnic landscape as "antithetical to their way of life" (Bonikowski 2017, S203). In other words, severe polarization around cultural grievances may develop in societies from perceptions of declining social or economic status by members of a once dominant group (Bonikowski 2017; McCoy and Somer 2019). Competing narratives of political community and cultural belonging as well as attitudes towards others might thereby incentivize political tactics evoking nationalist appeals, including potential "exclusionary understandings of the nation... as a confluence of grievances associated with economic, social and cultural change has increased the salience of nationalist beliefs" (Bonikowski 2017, S204). Evidence from 2002-2014 European Social Survey data suggests cultural 'backlash' to modern progressive values may, indeed, carry greater weight for masses in recent electoral developments than economic appeals (Inglehart and Norris 2016). More prominent in Western societies since the 1970s are post-materialist and self-expressive issues of “[s]ocial liberalism” like women's and minority rights, LGBT issues, gender fluidity, open borders, and "tolerance of social, intellectual, and political diversity" (Inglehart and Norris 2016, 8). There is now more social acceptance of "diverse lifestyles, religions, and cultures, multiculturalism, global cooperation, democratic governance, and protections of fundamental freedoms and human rights" (Inglehart and Norris 2016, 29). Against conflicting narratives of belonging, some segments of past majorities in Western politics and culture may feel resentful and "marginalized within their own communities" in reaction to "being told that traditional values are now "politically incorrect"' (Inglehart and Norris 2016, 29). Donald Trump may be a case in point through political appeals favoring "older, religious white traditionalists who find 
themselves left behind by growing support in America for such issues as same-sex marriage, rights for transexuals [sic], gender equality for women in politics, and immigration rights." These views are rooted in the Republican base (Inglehart and Norris 2016, 31).

Lastly, polarizing actors may strategize to use rhetoric around political or representational grievances (McCoy and Comer 2019). These cleavages are like cultural grievance or formative rift dynamics on grounds of inclusion or exclusion. In particular, some populations may experience or actually lack representation in society, like cases of exclusion in apartheid South Africa or pre-civil rights era American South (McCoy and Somer 2019). Other times, some voters may turn away from unrepresentative political parties they feel are either "corrupt (i.e., too little polarization) or unresponsive technocrats divorced from the people" (McCoy and Somer 2019, 240). These cases, like polarization influencing mobilization for an eventual end to apartheid South Africa, suggest how severe partisanship of political grievance cleavages may at times contribute to a political climate amenable to democratic reforms or struggle (McCoy and Somer 2019). Across virtually all cases of severe polarization, hence, the democratic regime trajectories rest largely on political strategies and agency of elites. While "both supply and demand factors are important," it is political leaders who generally bring intensity of pernicious dynamics in polarization to the fore of national interests and mass demands, thereby potentially destabilizing regimes for better or worse (McCoy and Somer 2019, 263). Power struggles in elite political and party competition may thus underlie extreme cases of polarization, in which actors may respond to incentives by capitalizing on popular anxieties in ways that influence further enhancement or erosion of democratic regime traits (McCoy and Somer 2019). However, entrenchment of extreme partisanship may develop into a Manichean binary of exclusive "us" versus "them" terms that could undermine democratic norms of mutual tolerance among political 
opponents turning into cross-cutting, hostile and antagonist socio-political identity camps (LeBas 2018; Levitsky and Ziblatt 2018; McCoy and Somer 2019). Notably, foundational debates including formative rift dynamics over national belonging or state purpose may make for longerlasting and more pernicious outcomes (LeBas 2018; McCoy and Somer 2019). For cases involving backlash to new political inclusion of formerly excluded or marginalized segments of a population, results may still vary such as through “a) gridlock and/or instability, with alternating governments failing to achieve governability; b) removal of the new group from power; or c) increasing authoritarian behavior by the incumbent to stay in power" (McCoy and Rahman 2016, 2). Furthermore, if partisan identities cut through society into social space, polarization may preclude beliefs of national coexistence among citizens, and less social interaction typically means sharper polarization (McCoy and Rahman 2016). In any case, potentially destabilizing or transformative dynamics of polarization are worth our attention.

Several cases might offer insights into possible concerns for democratic or democratizing regimes when political polarization hardens on partisan-identity lines. Specifically, democracydeteriorating possibilities may suggest why pernicious polarization in the otherwise longstanding US democracy could lead to problems for the regime. It may also be that polarization of identity issues like inclusion and representation can influence democratic enhancements or reforms (LeBas 2018; McCoy and Somer 2019; Southall 2019). Severe partisanship and polarization are not sole causal factors in contemporary challenges to democratic governance, without a doubt, but the dynamics may sometimes make ripe for elites or outsiders to act on partisan demands at the expense of ordinary democratic functions in pursuit of power.

Murat Somer (2001) describes polarization in the former Yugoslavia as "the division of a people into mutually exclusive and distrustful ethnic categories" (128). History between ethnic 
groups shows a mix of cooperation as well as conflict, in both inclusive as well as compatible terms pre-polarization before exclusive portrayals in polarized society were dominant. A "snowballing or bandwagon" effect of cross-cutting divisions may have influenced ethnic polarization in Yugoslavia, as relations from one ethnic identity to another split to the extent that "separate feelings of belonging reinforce[d] each other and lead to the growth of negative and hostile images" (Somer 2001, 131). Depictions of problems around political disintegration of Yugoslavia range from "historic animosities" between exclusive notions of 'us' against 'them' (although historical accounts indicate cooperation and peace more than violent periods), to "strategic decisions of the country's elites, who exploited ethnic sensitivities to consolidate their own power" (Somer 2001, 135). Polarizing dynamics may have allowed elites to leverage ethnonational incentives in their efforts to capture or hold power. The case is ultimately an unsuccessful transition to liberal democracy as a result of many factors, among which potential "dynamics of rapid and massive polarization were in play" from elite strategies to a "large and responsive audience" of masses (Somer 2001, 135). As with other cases, the United States differs from Yugoslavia as a longstanding and mature regime, including a fairly robust political culture according to survey evidence (see, e.g., Touchton, Klofstad, and Uscinski 2020; Carey et al 2020), which could help to sustain regime durability. Somer (2001) argues that severe dynamics of polarization were paramount in generating interethnic hatreds in the Balkans, which underscores the importance of the issue if similar dynamics were to develop elsewhere.

On another case in severe partisan divisions, David Moshman (2007) argues that normal identity processes in political matters may sometimes have extreme results, such as genocide. According to Moshman, Hutu and Tutsi distinctions in pre-colonial Rwanda began on bases of ancestry and socioeconomic status, but relations for many years were such that they still 
"intermarried, shared religious beliefs, and were integral parts of a single society—Rwanda"; that is, until colonial Belgium in the early 20th century "reified and exploited the Hutu/Tutsi distinction to control the country by enabling the Tutsi, operating within Belgian parameters, to solidify and enhance their traditional domination of the Hutu" (Moshman 2007, 119). The sharp Hutu-Tutsi distinction persisted through independence, when the Hutu majority rose to power despite Tutsi beliefs that "authority in Rwanda had always rightly been theirs, and should be regained" (Moshman 2007, 119). Media outlets, especially radio, elevated Hutu ideology seeking to recapture power. As "middle ground collapsed, you had to stand on our side or theirs" amid dynamics of a dehumanizing dichotomization of 'us' versus 'them' splitting Rwandan society (Moshman 2007, 119). There were "moralizing" patterns in pernicious polarizing political discourse (McCoy and Somer 2019, 244). Narratives of elimination of Tutsis swept popular discourse as if morally imperative to elevate Hutu power. It remains common among perpetrators of the 1994 genocide to identify their actions as righteous, "given the existential threat posed by the Tutsi to the Hutu and Rwandan nation" (Moshman 2007, 129). The US in contemporary context again differs as a consolidated democratic regime, in contrast to post-colonial, newlyindependent Rwanda under a fledgling democratizing regime. Political violence to the extent of genocide is less likely a concern for the longstanding US regime than subtle democratic erosion (McCoy and Somer 2019). Still, preexisting identity cleavages over group belonging or inequal rights for citizens might raise the odds for dynamics of political polarization to influence events of political violence (LeBas 2018). Years later the Rwandan government continues to work towards construction of a national identity that stitches "back together the social fabric" of national citizenship untethered to ethnicity (Moran and Samso 2019). 
The case of Zimbabwe may be most different in its historical context in comparison to the US. The former is a landlocked post-colonial state without yet a full century of establishment in its independence, and the latter has longstanding general stability despite its pitfalls. These differences could produce different outcomes. For example, two episodes of party-based polarization in 1980-1987 and 2000-2008 each feature elites in a shared-power settlement but with key differences. The later period more closely fits McCoy, Rahman, and Somer's (2018) theory of pernicious polarization. It is "marked by deeper societal penetration and segregation" and may thus be "less amenable to resolution" (LeBas and Munemo, 2019, 212). The earlier episode of partisanship had intense ethnic conflict between two nationalist parties turning violent and contributing to many deaths, although ending abruptly in a pact between elites (LeBas and Munemo 2019). In contrast, the later period persists, with features of "foundational myths about the nation and the state's purpose" (LeBas and Munemo 2019, 210). While a power-sharing settlement stemmed intensity of peak polarization and partisan violence, a penetrating two-party split continues to leave party members "in separate worlds in terms of public opinion and civic space" (LeBas and Munemo 2019, 212). Partisan lines cut across all aspects of social and political life, from friendships to church and a "segregated" civil society, with ongoing breakouts of violence and polarizing language between ruling elites and opposition (LeBas and Munemo 2019 , 212). Curiously, a study of partisan sorting in the US involving 180 million voters recently found comparable geographic segregation across regions and within cities between Democrats and Republicans (Brown and Enos 2021). Durability of the second episode of polarization for Zimbabwe may be attributable to rival parties sharply contesting foundational beliefs, from Zimbabwe's liberation war to conceptions of the state (LeBas and Munemo 2019). Its pernicious 
dynamics endure, such as in military fire on opposition protesters, allegations of election rigging, and both sides using "language of warfare and confrontation" (LeBas and Munemo 2019, 223).

From "tumultuous street violence" to "a deep divide between two opposing political mass movements," Prajak Kongkirati (2019) argues that Thailand fits the profile of cases in pernicious polarization (24). After a new constitution and 1997 economic crisis, a populist party rose to prominence starting in 2001. As party founder, Thaksin Shinawatra led electorally through appeals to grievances of the urban and rural lower class and lower middle class. He gained support in his "strong and decisive leadership" and with policies that were "highly popular and admired by the poor" (Kongkirati 2019, 27). The party "fundamentally transformed the relationship between state and citizen, with a slew of innovative policies targeting rural areas and the poor politically awakening long-ignored parts of the Thai nation" (Selway 2020). However, Thaksin's “domineering power and popularity made him a real threat to the old network of elites," stirring "fear and perturbation among opponents" after electoral victories in 2005 won a supermajority (Kongkirati 2019, 28). The old-elite opposition feared for their status in Thai society, losing a social and economic position to a more inclusive political system (Kongkirati 2019). Protests against the government grew into a movement known as Yellow Shirts, whose supporters allied with the opposition "royal-military-bureaucratic elites" and "comprised mainly of urban middle- and urban-classes as well as big business groups" (Kongkirati 2019, 25). Things grew more intense in 2006 after Thaksin sought to bolster political legitimacy through a snap election, which left his party largely unopposed as opposition mostly boycotted (Kongkirati 2019, 28). With support of the monarchy, military ultimately staged a coup in 2006 to regain traditional authority, prompting the Red Shirts counter-movement and further polarization in the country (Kongkirati 2019; Selway 2020). Many people in the Red Shirt movement, supporters of 
Thaksin, reported lower levels of education, income, and economic security, and were often from rural and poorer regions where migrant workers concentrate (Kongkirati 2019). Yellow and Red Shirt political identities are now signifiers of mutually exclusive interests in Thai society, on anti- and pro-Thaksin lines as well as in regional and rural-urban disparities (Kongkirati 2019). Elites and media increasingly segment between the two camps, leaving little room for differences in "political contestation with fervent emotions of love and hate, as if they were watching sports or reality TV" (Kongkirati 2019, 37). Rivals-turned-enemies experience "different political realities" and live in "two different worlds" (Kongkirati 2019, 37). Like other cases, political leaders may have "activated the existing social cleavages, and ideological framing exacerbated and deepened the polarization to the extent that it spiraled out of the elites' control" (Kongkirati 2019, 37). Politics in Thailand are increasingly moralistic matters of 'good' and 'evil,' or deep lines of 'us' against 'them' between traditional elites and a populist democracy with more egalitarian values. Lack of democratic consensus around "rules of the game" made Thai politics “dysfunctional and unstable," plus now under strong military rule (Kongkirati 2019, 37). The polarization over Thai nationalism continues between those who prefer traditional military and monarchic control, and opposition who "define themselves as part of a broader Asian democratic movement" (Selway 2020).

South Africa under apartheid, with white oppression over the black majority, became a severely polarized society over extreme problems of political inclusion and representation (Southall 2019). The political grievances of black racial oppression fueled a movement under the leadership of the African National Congress in popular revolt that eventually won democratizing concessions between opposing elites. Roger Southall (2019) argues that the dynamics of political polarization over apartheid may have created space for democratic reforms, despite persistent 
socioeconomic inequalities. The process of negotiation over a democratic political settlement in elite transition "was crucial in defusing distrust and allowing mutually exclusive political identities to give way to a broader sense of South Africanism" (Southall 2019, 198). In short, the "political polarization under apartheid [may have] provided the platform for a democratic settlement" (Southall 2019, 203).

In Chile as a final example, dynamics of extreme partisanship may have created space amenable for the US to succeed with sponsoring a coup. It was once Latin America's "oldest and most successful democracy," with "vibrant democratic norms" and compromise as a political culture across an ideological spectrum from Marxists to reactionaries for most of the $20^{\text {th }}$ century (Levitsky and Ziblatt 2018, 113). Cold War politics strained Chile with polarization beginning in the 1960s, with Cuban Revolution inspiration on the left, and the right wing fearful of the left gaining power in response (Levitsky and Ziblatt 2018). When left politician Salvador Allende won the presidency in 1970, right-wing partisan panic cut through any sense of mutual toleration, even if Allende was a committed democrat. While left allies referred to opposition as fascist "enemies of the people," the right wing in turn saw Allende and the left in the opposite frame as a "communist threat" (Levitsky and Ziblatt 2018, 115). Partisan tensions grew through 1973 midterms. Neither side won a legislative majority nor accepted compromise. Allende's attempts at policy by executive decree sparked calls for impeachment. In response, an opposition senator appealed that he was an "illegitimate head of state," and in August 1973 the Chamber of Deputies declared Allende's government unconstitutional before the military seized power (Levitsky and Ziblatt 2018, 117).

As the cases suggest, extreme polarization may undermine democratic function by making tolerance between partisans more difficult to sustain (Levitsky and Ziblatt 2018). 
Societies split in political identity camps may become mutually exclusive in us versus them terms along strict in-group versus out-group antagonisms (Levitsky and Ziblatt 2018; McCoy and Somer 2019). Partisan-identity divisions may come to seem irreconcilable (Levitsky and Ziblatt 2018; Mason 2014), rigid and intolerant (Druckman, Peterson, and Slothuus 2013). The dynamics may still at times be fruitful for democratic development. From deep divisions over slavery to its abolition in early American democracy, norms of mutual tolerance and institutional forbearance wore down through frequent violent episodes on the US House and Senate floor between 1830-1860. One third of American states refused to participate in 1864 elections, leaving almost half of the Senate seats and over a quarter House seats vacant. Civil War broke after President Lincoln suspended habeas corpus and freed American slaves by executive order at the height of divisions (Levitsky and Ziblatt 2018). The "partisan animosity" endured after Union victory, but eventually ebbed as Democrats and Republicans "grudgingly accepted one another as legitimate rivals" (Levitsky and Ziblatt 2018, 123). Today, the consolidated US democracy under severe partisan-identity polarization may be vulnerable to deconsolidation trends. Though large-scale violence like Civil War or genocide are less likely for the now deeply ingrained regime, consequences may include gradual decline in quality of governance with creeping authoritarianism, or eventual democratic reforms.

\section{Partisanship and Deconsolidation Trends}

In sum, this thesis analyzes American party platforms to evaluate any changes in partisan-identity polarization and emphasize possible areas of concern for the longstanding US democratic regime. Therefore, I largely adopt framing of 'pernicious polarization' as in cases like the US that have underlying dynamics of a 'formative rift' around conceptions of the nationstate and matters of national belonging in the political community as possible fuel for politics 
amenable to democratic erosion (LeBas 2018; McCoy and Somer 2019; McCoy, Rahman, and Somer 2018). While economic factors may be of importance in broad de-democratizing trends, they are not the focus of this thesis (e.g., see Bonikowski 2017; Ercan and Gagnon; Hobson 2018; Waldner and Lust 2018). In particular, I adopt how severe partisan polarization in US politics may configure around "existential" rifts in matters of race and culture (Levitsky and Ziblatt 2018,9), as well as possible tensions over national identity and belonging, religion and secularism, or likewise salient discursive dimensions involving cultural values, cosmopolitanism and nationalism, and notions of citizenship (McCoy and Somer 2019). In general, recent cases including the US tend to involve populist leaders who leverage polarizing themes as electoral and political strategies, and frequently influence the mobilization of counter-movements (McCoy and Somer 2019).

Regime trajectories in severe polarization may hinge on the approach of opposing elites in either failing or succeeding to neutralize polarizing political appeals (McCoy and Somer 2019). For example, the Indonesian case of President Jokowi responding to Islamist-populist mobilization in late 2016 shows how elites might respond in deleterious ways despite goals to protect democratic institutions. Within key context that "religious polarization of elections in Indonesia, long believed to be on the decline, had reached new heights," the president chose to criminalize violators of established legal norms and pursue patronage policies towards aggrieved Muslims as ways to quash or accommodate radicals (Mietzner 2017, 272). The country is now arguably in the process of democratic deconsolidation. Political opponents whose responses to polarizing actors reciprocate rather than strategize with expressly pro-democratic reforms might aggravate problems. A ratchet response may drive political instability and "autocratizing tendencies" (263) under a hegemonic party, or regime conditions may turn to "alternation of 
power with diminishing quality of democracy, until one side gains the upper hand through court appointments and electoral law changes to enhance their electoral advantage" (McCoy and Somer 2019, 264). Granting the American democratic regime is more stable than other examples in the long view of history, this thesis highlights in its analytical approach the potentially destabilizing and therefore important dynamics in cases of polarization that may turn 'pernicious' along cross-cutting identity lines.

\section{Methods}

This thesis uses a qualitative methodology for its assessment of partisan-identity polarization, in part, because recent problems for democracies are typically "fine-grained" phenomena (Waldner and Lust 2018, 95). After two decades in scholarship on hybrid regimes, Mariam Mufti (2018) also encourages qualitative research driven by single case studies as well as comparisons based on in-depth field research and complimentary large-sample statistical analyses. While the latter may advance more generalizable findings, this thesis answers Mufti's (2018) call to contextualize deconsolidation trends and support mid-range theory building on possible influences. In addition, Stefan Foa and Yascha Mounk (2017) support the US case selection in this thesis, since it offers fresh grounds for studying deconsolidation trends in advanced liberal democracies. Accordingly, I present a content analysis of American party platforms. The aims of this methodological choice are thus twofold: First, it is to test theories of partisan-identity polarization as the issue may have consequential influence on the US democratic regime (see, e.g., LeBas 2018; Levitsky and Ziblatt 2018; McCoy, Rahman, and Somer 2018; McCoy and Somer 2019). Secondly, it is an effort to establish 'pernicious' polarization in the US case through examining qualitative data and then consider possible effects on democratic governance. 


\section{Content Analysis of Democratic and Republican Party Platforms, 1980-2016}

Over the period of 1980-2016, I use content analysis as a primary research tool to systematically assess changes in partisan emphasis on narrow cultural- or identity-based issues in contrast to universalist or common messaging in national politics. This timeframe is important because it generally overlaps with trends of increasing party polarization in American politics (see, e.g., Abramowitz and Saunders 2008; Bartels 2000; Hetherington 2001; Layman, Carsey, and Horowitz 2006), and broader trends of democratic erosion or stall over the last few decades (see, e.g., The Economist Intelligence Unit 2014; Freedom House 2019; Levitsky and Ziblatt 2018; V-Dem Institute 2020). The American Presidential Project is the chief archival resource for Democratic and Republican party platforms. These two major parties published 20 platforms over the 1980-2016 period, all on presidential election years. For the sake of resources against exhaustive and often lengthy party platforms, this content analysis spotlights changes from four 12-year increments, including 1980, 1992, 2004, and 2016. My choice of these four years in particular is meant to extend the content analysis from 1980-2016 coinciding with trends in increasing party polarization in American politics and democratic erosion to capture changes over a longer period. In total, eight party platforms comprise the research sample, four for each major party. I organize the content analysis of these voluminous texts to show whether partisan appeals may have diverged into a political-identity rift between Republican and Democratic party messages, then offer an assessment for how the dynamics might influence 'pernicious' or possibly gainful consequences for the American democratic regime.

\section{Identifying Shifts in Party Messaging on Universal and Identitarian Bases}

Under thematic consideration, the content analysis codes for 'universal' and 'identitarian' messaging to establish shifts in partisan attention towards or away from universal or narrower 
identity bases. Specifically, paragraphs in the party platforms are units of analysis in this thesis. There are 3,435 paragraphs or units of analysis in the sample. With involvement of two coders, the primary researcher and an assistant independently evaluate each paragraph in the eight party platforms to identify messages including appeals to one of three substantive themes, plus a fourth category for 'none of the above' or neutral messaging on any partisan-identity bases. Paragraphs with 'universal' expressions around a common purpose or collective identity of the American polity fall under category one. Category two covers party platform appeals to narrower political or 'identitarian' bases. The party platforms may sometimes reflect a common identity with concurrent appeals or messaging towards narrower identities or a subset rather than the collective polity, which is the basis for the third discrete category of universal-identitarian, hybrid partisan appeals. Most paragraphs are likely boilerplate or carryovers from past years, without regard to any of the discrete categories of universal, identitarian, or hybrid expressions that this thesis spotlights in its content analysis. Those paragraphs are a fourth category, coded 'none' for none of the above. In sum, the content analysis contains altogether four categories, with a table of definitions for coders in Appendix A.

I developed the content analysis after my initial review of the literature and survey of party platforms. Its four categories of analysis meet important criteria. They are exhaustive, mutually exclusive, and relevant to the theoretical grounding of this thesis (Benoit 2011). The categories are distinct, covering (1) universalist, (2) identitarian, (3) a combination of universal appeals and messaging to narrower identities, sub-groups or individual over collective or civic interests, and a final option for (4) none of the above. In other words, category one addresses party appeals to a common purpose or collective identity; two is the inverse as far as racial, 
religious, ethnic, socially specific or otherwise narrower appeals; and three captures an inclusive or universal message with simultaneous appeal to a narrower population(s) or sub-group(s).

The content analysis approach for this thesis is similar to the one used by Frank Baumgartner, Suzanna De Boef, and Amber Boydstun (2008) to the extent that it relies on subject categories $(\mathrm{x} 4)$ rather than computer processing keywords. In this way, the content analysis exhaustively captures its sample. It likewise follows suggestions in the Manifesto Coding Instructions for the Comparative Manifesto Project in content analysis for design and coder training (Werner, Lacewell, and Volkens 2015). Additionally, the approach is summative to the extent that the content analysis interprets context of units of analysis during data collection (Hsieh and Shannon 2005). I organize the data into graphical representations of coded text from Democratic and Republican party platforms, tracing any changes in universal and identitarian platform messaging between the two major parties from the 1980-2016 period. My contribution is thus uniquely establishing an empirical grounding for any changes to partisan-identity lines of polarization between Democratic and Republican party messages in recent decades.

\section{Managing and Reporting Intercoder Reliability}

Using content analysis as a research tool requires some way to address intercoder (or interrater) reliability. As such, the coding rubric in Appendix A develops the four categories for the thesis, with examples. The two coders use the coding rubric as key research participants. Involvement of multiple coders ensures a check on intersubjective analyses of content within the sample of party platforms for category judgements. The primary researcher has trained an assistant using the coding rubric as a guidepost. Both the researcher and assistant independently reviewed and coded every unit of analysis in the sample. Afterwards, using Cohen's Kappa, I calculated intercoder reliability of the content analysis to assess agreement between the two 
coders while accounting for agreement by chance (Lombard, Snyder-Duch, and Bracken 2010; Benoit 2011). This reliability test reflects the "extent to which two or more coders agree in their analysis of a common pool of texts" (Benoit 2011,273). I calculate and report Cohen's Kappa for each sample of party platforms in the content analysis and use Richard Landis and Gary Koch's (1977) Kappa scale for interpretation. Their scale ranges from 0 for poor agreement to 1 for almost perfect agreement. This reliability measure is useful in combination with percent agreement but goes further by accounting for agreement by chance and/or human error.

As a final assurance on intercoder reliability, Lombard, Snyder-Duch, and Bracken (2010) argue that all research strategies utilizing a content analysis should have more than one coder and report intercoder reliability among them. The content analysis follows these principles in addition to their six steps by (i) choosing a reportable reliability index (i.e., Cohen's Kappa); (ii) performing the reliability calculation after data collection, in this case by hand due to the nature of content and a summative approach based around categories instead of key words; (iii) establishing an appropriate minimum acceptable reliability, i.e., a Kappa score of at least 0.41 for "moderate agreement" (Landis and Koch 1977) to establish general patterns in partisan-identity or universal expressions; (iv) assessing reliability informally during training and test runs; (v) addressing coding disagreements; and (vi) carefully and clearly reporting intercoder reliability of the analysis (Lombard, Snyder-Duch, and Bracken 2010). 


\section{CHAPTER III: ANALYSIS}

This content analysis finds increasing salience of partisan-identity messaging in platform text from the two major parties over the last several decades in American politics. Both Democratic and Republican parties' share of hybrid or identitarian appeals peaks most recently in the 1980-2016 period for years in the content analysis (i.e., 1980, 1992, 2004, and 2016). At the same time, neutral themes from the parties are at their lowest point in a pattern of decline since 1980, a trend that the content analysis reveals as more intense in numbers for Democratic party platforms than Republican party counterparts. Identitarian themes in the Democratic party platforms grew in proportion of paragraphs over the sample from $10.62 \%$ in 1980 , although dipping in 1992 and 2004, to $32.36 \%$ in 2016. Republican party platforms remain relatively consistent in proportion of identitarian themes from 1980 (7.90\%), 1992 (7.05\%), and 2004 (5.82\%), until spiking in the same year as Democratic party platforms in 2016, although at a lower ratio (10.64\% for Republicans vs. $32.46 \%$ for Democrats). Hybrid messaging from Democratic party platforms overall increases from $2.09 \%$ in 1980 to $14.37 \%$ by 2016 . Hybrid messaging from Republican party platforms, like party appeals in the identitarian category, is relatively consistent, but remains in single digits from 1980 (2.66\%), 1992 (1.45\%), 2004 $(3.16 \%)$, and then similarly peaking in $2016(5.18 \%)$ in the same year that identitarian themes are highest from both party platforms. Neutral messaging in Democratic party platforms overall declines from a highpoint at $78.70 \%$ in 1980 to its lowest point at $36.57 \%$ in $2016(-42.13 \%)$. For the Republicans, neutral messaging to questions of American identity and belonging similarly declines in paragraph units of analysis from $73.47 \%$ in 1980 to $59.38 \%$ in 2016 (-14.09\%). See Figures 1 and 2 for a visual of these patterns. Importantly, as this chapter shows, party messages coinciding with these trends diverge between the Democratic and Republican 
party platforms for years in the content analysis. The findings suggest a polarizing dynamic that affirms claims of a deepening partisan-identity rift over the 1980-2016 period in American politics.

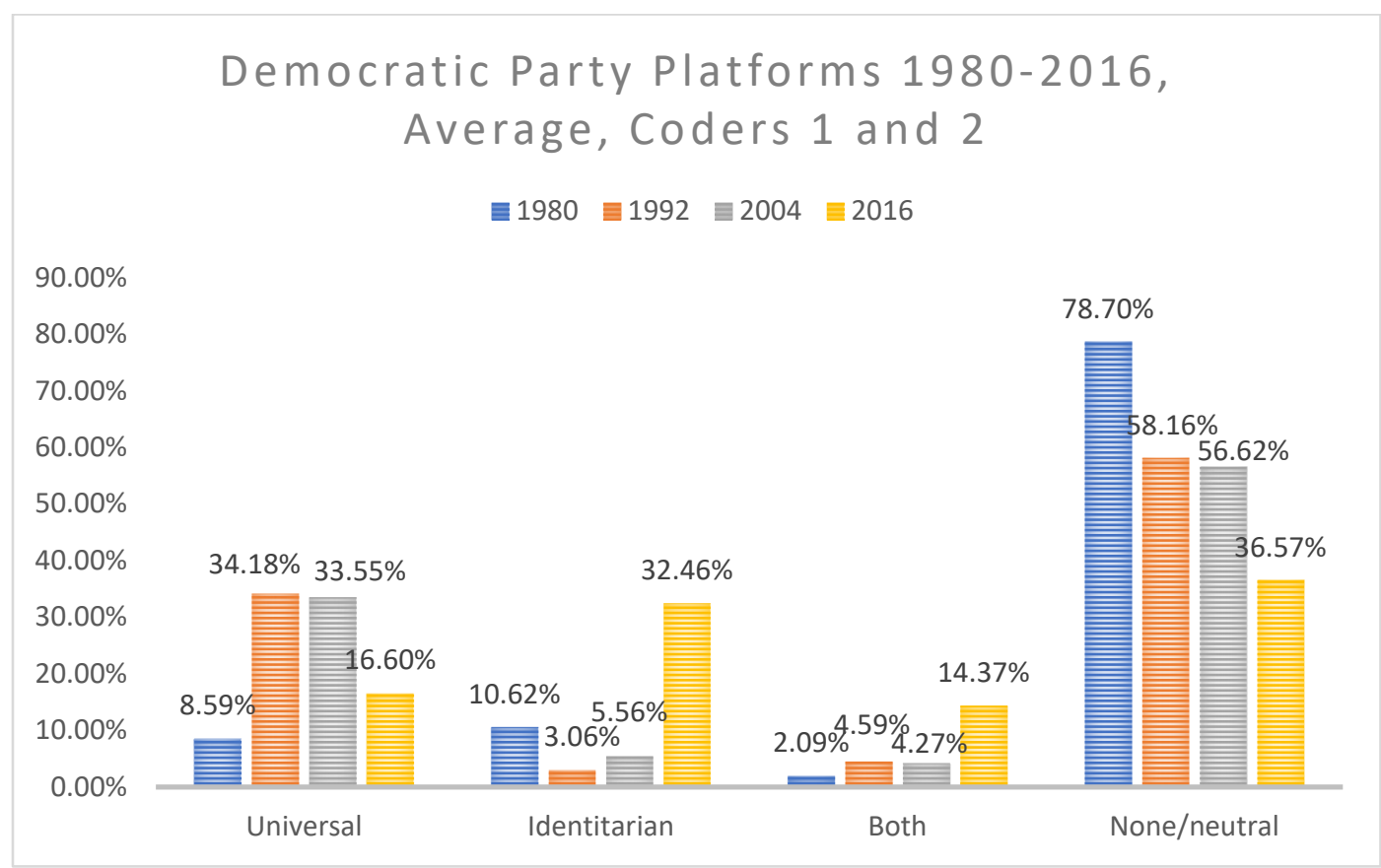

Figure 1. Democratic Party Platforms 1980-2016, Average, Coders 1 and 2, Grouped Bar

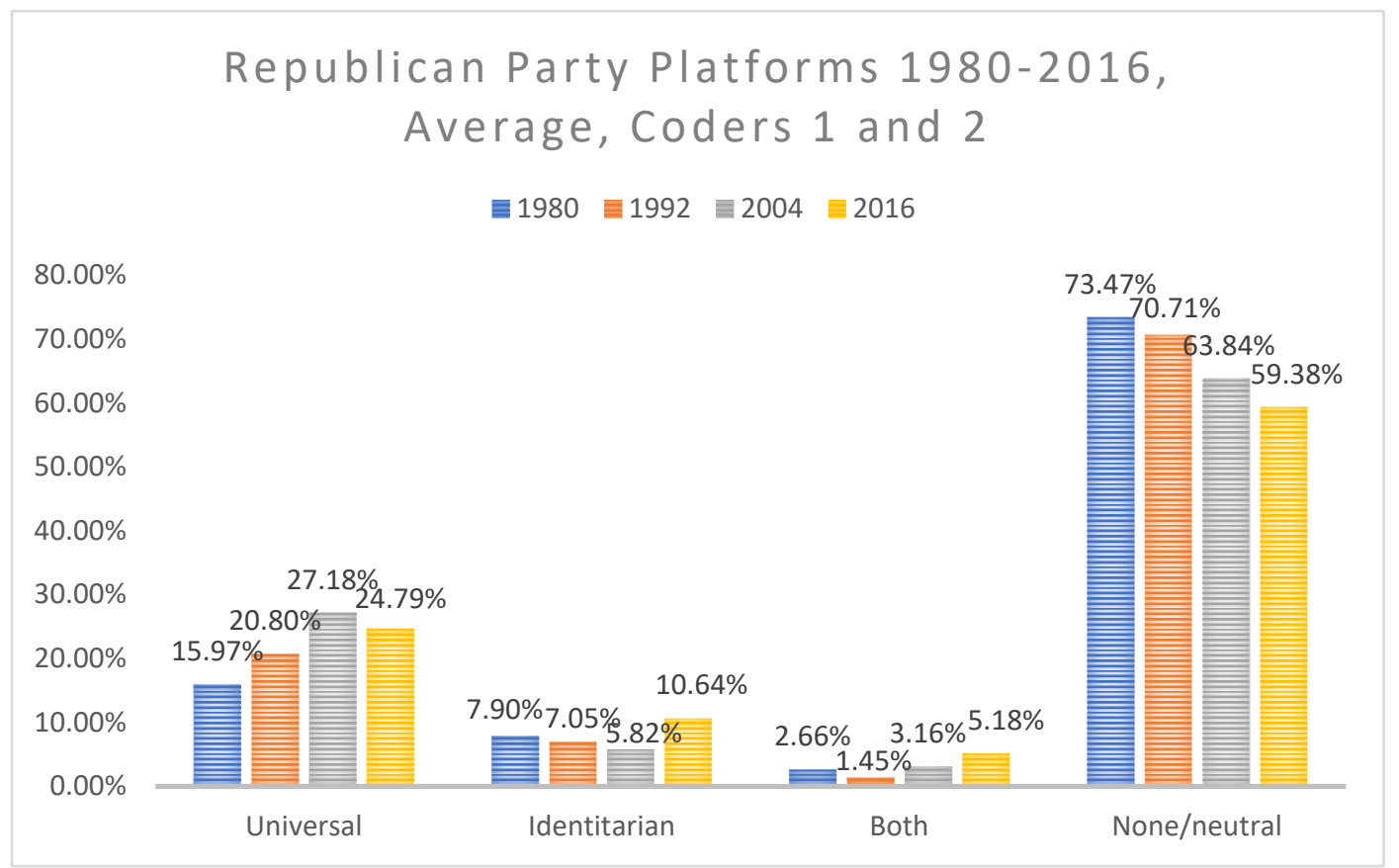

Figure 2. Republican Party Platforms 1980-2016, Average, Coders 1 and 2, Grouped Bar 
This chapter unpacks the content analysis. It begins with a summary of changes in proportionate percentages of universal, hybrid, or identitarian appeals in the party platforms. Secondly, key language and phrases from the content analysis help to identify common patterns and variations in party messaging in the substantive categories of universal, hybrid, and identitarian themes in the content analysis. In general, the findings suggest increasing partisanidentity polarization in American politics, at least between the two major party platforms, with less neutral messaging to identity considerations over time. In other words, a clear finding is reduction in neutral themes from both party platforms in a consistent trend across the four election years, as universal, hybrid, and identitarian messaging is variable but peaks most recently in 2016. From close examination of party platforms, the content analysis supports theories on 'pernicious' polarization and dynamics that advance severe partisanship in the US case. The trends may be consequential for the American democratic regime according to the framework of 'pernicious' polarization and comparable theories on cases involving partisanidentity rifts that have deep contestation over national values, identity, and belonging.

\section{Results in Numbers: Less Neutral, More Identity}

To start with the Democrats, the content analysis of party platforms suggests an overall decrease in political messaging neutral to identity considerations in the American community. ${ }^{1}$ In other words, the ratio of Democratic Party platform content agnostic to the makeup of the American polity, i.e., not specifically addressing either a common or subgroup identity interests,

\footnotetext{
${ }^{1}$ Data collection for this thesis began in a test run to evaluate the coding rubric in Appendix A. Successful testing gave a greenlight to continue this analysis after coders had moderate agreement. Appendix B shows a summary of intercoder reliability measures for the content analysis. For some years, Cohen's Kappa measures below the established minimum acceptable level of reliability (i.e., 0.41 ), with fair to slight agreement between the two coders in four of eight platforms in the thesis sample. There are nonetheless parallels in the coders' data output. They each find shifts in ratios of platform space between both major parties in the direction of either universal or narrower identity groups in appeals to the American polity. From the Democratic party platforms, there were 1,462 units of analysis (i.e., paragraphs); from the Republican party platforms, there were 1,973 units of analysis of the years in review, 1980, 1994, 2004, and 2016.
} 
falls markedly from 1980 to 1992 ( $20 \%$ decrease), remains stable, and then again falls from 2004 to 2016 ( $\sim 20 \%$ decrease). In context of this trending decline in neutral messaging to identity from the Democrats, the party gives more prominence to messages with universal emphases in years 1992 (34.18\%) and 2004 (33.55\%), which is more than threefold that of 1980 (8.59\%). Universal messaging from Democratic party platforms about halves from 2004 to 2016 ( $33.55 \%$ vs. $16.60 \%$, respectively), still roughly double from 1980 (8.59\%). Identitarian themes from 2004 to 2016 grow considerably from $5.56 \%$ to $32.36 \%$ in paragraph units of analysis.

There is meanwhile a steady rise from 1980 through its peak by the 2016 Democratic party platform in the hybrid 'both' category of universal themes in combination with appeals to subgroup or narrower interests. ${ }^{2}$ For example, figure 3 shows the average between coders 1 and 2 .

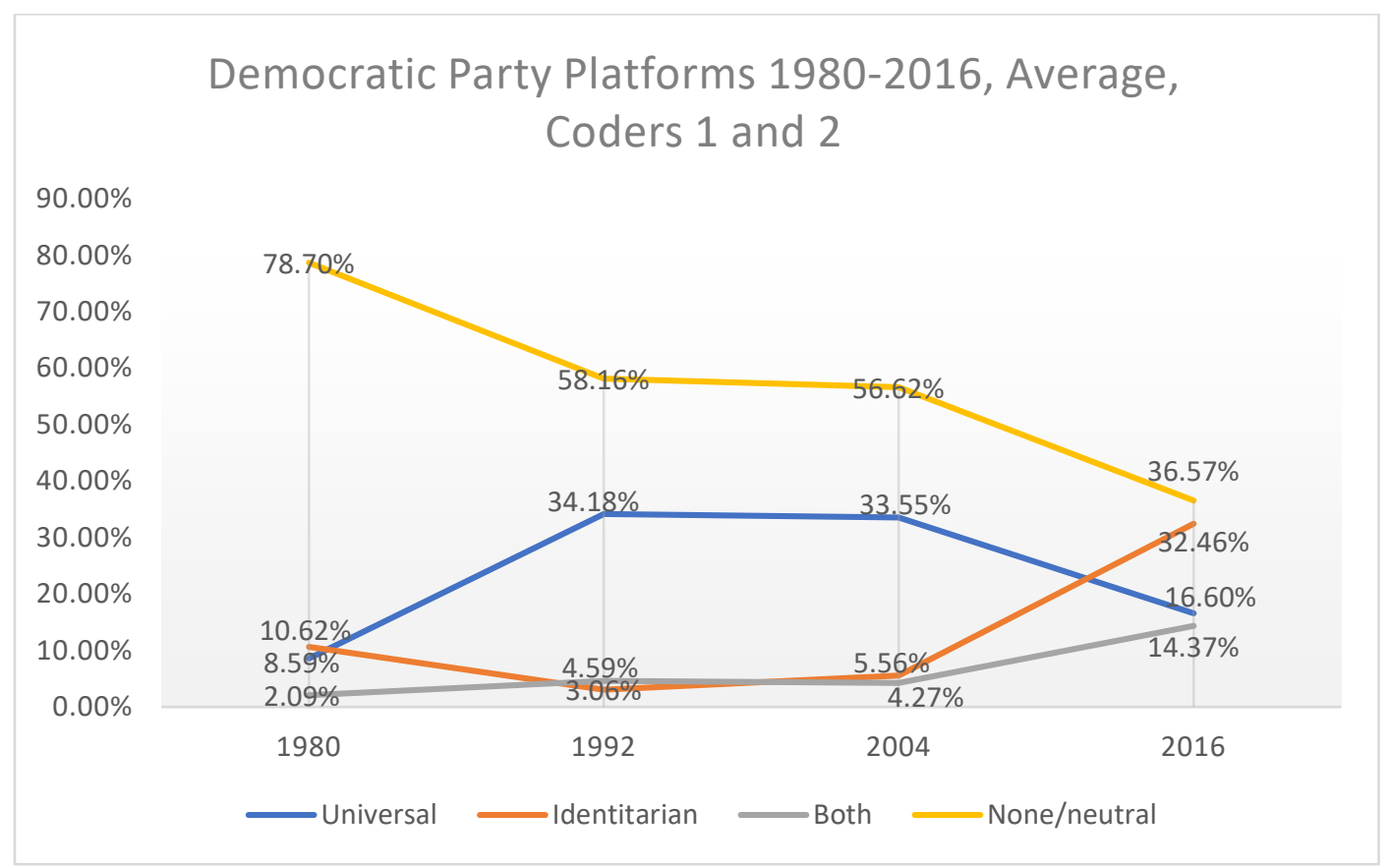

Figure 3. Democratic Party Platforms 1980-2016, Average, Coders 1 and 2, Line

\footnotetext{
${ }^{2}$ It is important to note that data output from coders 1 and 2 in the content analysis varies by degree of intensity with which they exhibit changing proportions of appeals for the Democrats, as well as for the Republicans, since intercoder reliability is imperfect and subject to human error in a manual coding process. There are nevertheless resemblances between patterns of data output that may help to ground assumptions of increasing partisan-identity appeals in Democratic party platforms over the 1980-2016 period. For example, see Appendix C for coder 1 and 2 comparisons for the Democratic party messaging.
} 
In short, Democratic party platforms overall decline with respect to neutrality in messaging on ideas of American nation or community belonging. Universal themes are second to neutral messages in 1992 and 2004 (34.18\% and 33.55\%, respectively). By 2016, the Democratic party platform gives most weight to identitarian themes, nearly as much as neutral messaging (32.46\% vs. $36.57 \%$, respectively). In comparison, Universal and hybrid themes are at highpoints over the 1980-2016 period but still less than half by 2016 (16.60\% vs. $14.37 \%$, respectively).

By contrast, trends from the content analysis of Republican party platforms are not as drastic as far as intensity of changes across the four election years in the 1980-2016 period. However, like the Democrats, the ratio of platform messaging with ideas in one of the three identity categories grows over time but fluctuates — notably as neutral themes are in clear decline for both parties. The latter finding from both parties suggests that there may be contestation over identity issues in increasing prominence for platform messaging.

The results in numbers for Republican party platforms are similar to Democratic party counterparts, except in their intensity. Beginning from $73.47 \%$ in 1980 , Republican party platform weight to neutral themes decreases an average of roughly $5 \%$ for each period in the sample. In other words, by 2016, the percentage of neutral messages in Republican platforms is down to $59.38 \%(-14.09 \%$ since 1980$)$. Meanwhile, the three identity categories of the content analysis increase accordingly for Republican platform messaging. Comparing start and end years in the sample, i.e., 1980 and 2016, universal themes in Republican party platform messaging rise by $8.82 \%$ in paragraph units of analysis, from $15.97 \%$ in 1980 to $20.80 \%$ in 1992 , and to $27.18 \%$ in 2004, before leveling off to $24.79 \%$ in 2016 . Interestingly, identitarian themes in Republican party platforms start as a somewhat higher percentage of content space in 1980 and 1992 at $7.90 \%$ and $7.05 \%$, respectively, before a dip in 2004 to $5.82 \%$ and subsequent spike to $10.64 \%$ 
by 2016. Hybrid, universal-identitarian, themes from Republican platforms follow a similar trajectory, although marginally. In 1980, for example, the Republican platform includes $2.66 \%$ hybrid messaging in paragraph units of analysis, which shrinks slightly by 1992 to $1.45 \%$, rises to $3.16 \%$ in 2004 , and then reaches a relative high point by 2016 at $5.18 \%$. Figure 4 shows the averages in identity categories between coders for Republican party platforms in sample years. ${ }^{3}$

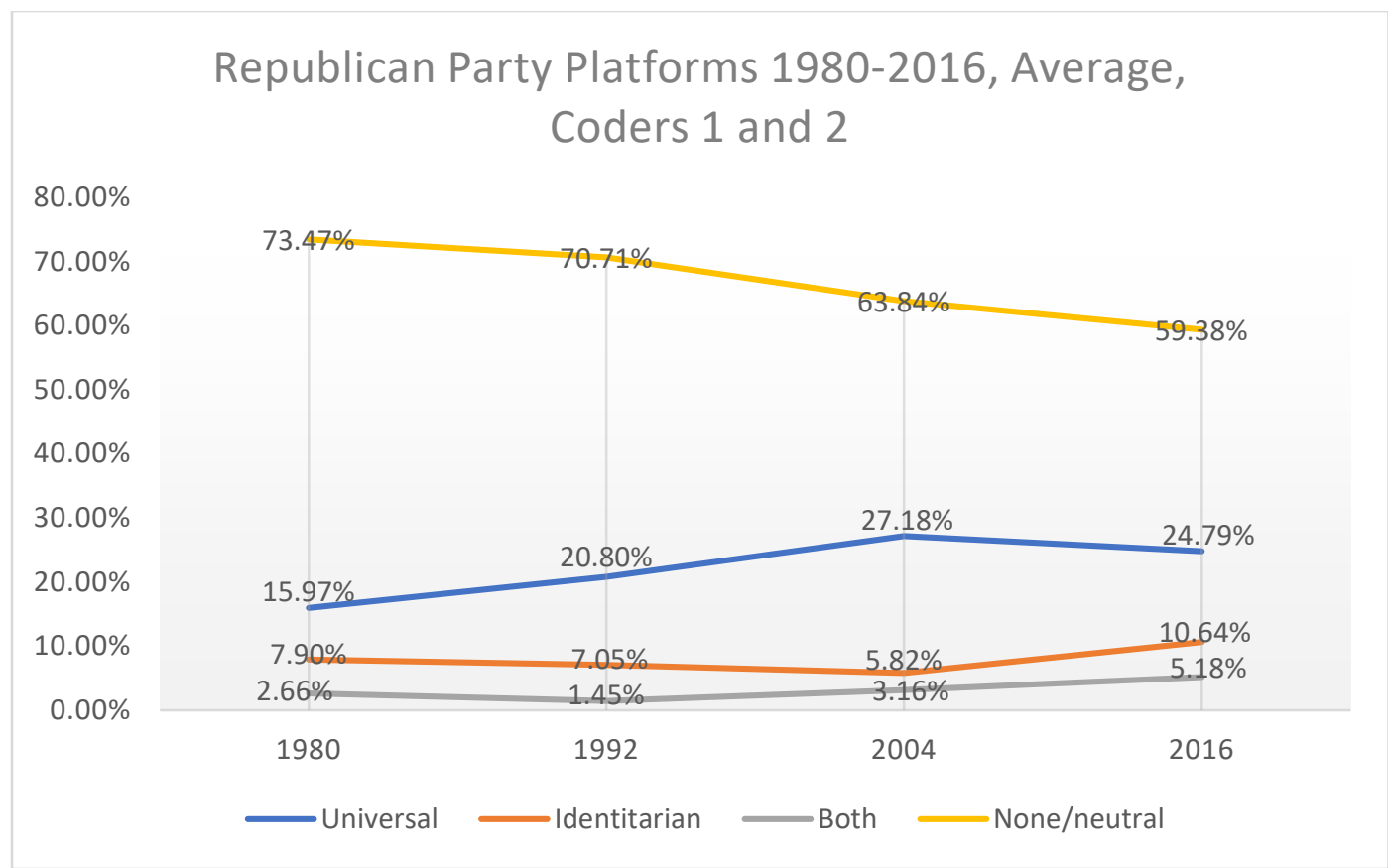

Figure 4. Republican Party Platforms 1980-2016, Average, Coders 1 and 2, Line

One notable difference in numbers for Republican party platforms, unlike Democratic party platforms in the sample, is that the proportion of messaging with hybrid themes remains fairly marginal across all years. For Republicans, this category fluctuates before a growth pattern from 1992 to 2004 (1.45\% increasing to 3.16\%). It then peaks (5.18\%) by 2016 like their party counterparts. Although both parties have variance for years in review, trends of decline in neutral messaging against positive trends for identitarian, universal, or hybrid messaging around identity are generally consistent results that suggest increasing salience of partisan-identity politics.

\footnotetext{
${ }^{3}$ See Appendix D for coder 1 and 2 comparisons for the Republican party messaging.
} 
Another clear difference in numbers from the content analysis is in changing ratios from the two major parties by 2016. The Democratic party platform's emphasis on identitarian appeals around American identity increases nearly sixfold between 2004 and 2016 from $5.56 \%$ to $32.46 \%$. Overall Democratic party platform messaging in the identitarian category roughly triples from $1980(10.62 \%)$ to $2016(32.46 \%)$. Hybrid themes from Democratic party platform messaging likewise spike in the most recent period of the sample, with an increase from $4.27 \%$ in 2004 to $14.37 \%$ by 2016 . Since the starting year in the sample of $1980(2.09 \%)$, a slow and variable increase in hybrid messaging through 1992 (4.59\%) and 2004 (4.27\%) spikes by 2016 (14.37\%). The Republican party platform's identitarian and hybrid messaging increases more modestly. It begins from $7.90 \%$ in 1980 and reaches a highpoint at $10.64 \%$ by 2016 , with marginal dips in $1992(7.05 \%)$ and 2004 (5.82\%). This pattern of variability from Republican party platform messaging is similar for the hybrid category, which begins at $2.66 \%$ in 1980 and peaks in 2016 at 5.18\%, with a small dip in $1992(1.45 \%)$ as the start of an upward trend evident by $2004(3.16 \%)$.

Furthermore, in contrast to Democratic party platforms, the Republican party platforms are generally more consistent in relative proportion of universal messaging over all four years in the 1980-2016 period. However, later years still show more prominence in the category than earlier years (e.g., $15.97 \%$ in 1980 and $20.80 \%$ in 1992 , then $27.18 \%$ in 2004 and $24.79 \%$ in 2016). Democratic party platforms by comparison roughly double in the universal category from $1980(8.59 \%)$ to $2016(16.60 \%)$, while middle years of $1992(34.18 \%)$ and $2004(33.55 \%)$ are more prominent in universal identity themes from the sample of years in the 1980-2016 period.

Both Republican and Democratic parties with respect to platform content have patterns of relative decline in neutral content while messaging more to identity across the 1980-2016 period. 
Much like Democratic party platforms even if more gradual, there is an overall drop in proportion of neutral messaging from the Republican party with regard to American community or 'nation' and belonging in matters of either composition or emphasis on universal versus specific subgroup interests. ${ }^{4}$ With declining neutral party messaging on American identity or subgroup considerations, the results suggest shifts in party messaging towards partisan-identity appeals in recent decades for American politics.

Accordingly, this thesis next evaluates keywords and phrases from the texts for partisanidentity polarization to better appreciate the importance of these changes in relative proportion of identity messaging from the two major parties' platforms. With increases from both parties in platform attention to identity considerations, plus the important finding of common trends in decline in neutral messaging between the parties, I assess variations and common themes in messaging across universal, hybrid, and identitarian categories for each party across the 19802016 years in the sample. Findings of contrasting party messages tracking with growth in partisan-identity themes may indicate a growing rift or polarization along partisan-identity lines. ${ }^{5}$

\section{Democratic Party Platforms (1980, 1992, 2004, 2016)}

Without a doubt, both parties underwent many changes over the 1980-2016 period with differing social and political contexts. Themes in party platforms move with such vagaries. As follows, I trace categories of universal, hybrid, and identitarian messaging on American identity across the two major parties' platforms in the content analysis for years 1980, 1992, 2004, and

\footnotetext{
${ }^{4}$ Despite lower agreement in data classification between coders against the sample of Republican party platforms than for the Democratic party platforms, trends from Republican appeals have similarities over the 1980-2016 period. One difference between the coders is clear, however. In the hybrid 'both' category for Republican platforms, coder 1 finds relative consistency in the ratio of hybrid messaging from Republicans, while coder 2 finds modest growth reaching a highpoint in 2016, like the Democrats. The average between the coders reflects a trend of modest growth from the small dip in 1992 through 2004 and 2016 election years in the sample.

${ }^{5}$ These examples in keywords and phrases offer an exhaustive, yet practical attempt to convey fine details of themes within the party platforms over the sample of election years in the 1980-2016 period from Democratic and Republican parties.
} 
2016, starting with the Democrats. The Democratic party in 1980 gave the preponderance of platform space to messaging absent of appeals to American identity, nation, or community. It was largely neutral (e.g., 78.70\% of paragraphs), next to identitarian, universal, and hybrid themes, which are correspondingly lower. All identity categories in the content analysis are higher by 2016, though universal phrases peak in 1992 and 2004. As neutral framing declines since 1980, universal themes vary somewhat as hybrid and identitarian messages grow in breadth of themes as well as prominence in the texts by 2016 .

\section{Universal}

In universal messaging on "the American people," the 1980 Democratic party platform emphasizes "equality for all citizens." It rejects a "deeply divided" nation in favor of one that is "stronger" and meets the "basic needs of all the American people" and "all sections of the nation" (see Table 1). The "ideals of the American people" are analogous to the "aspirations of mankind." American "values" include people around the world associating the US with “widespread human aspirations." Twelve years later, the 1992 platform stresses universal notions of American identity, community, and national interests conspicuously more than 1980, as reflects a leap from $\sim 9 \%$ to $\sim 34 \%$ of paragraphs. In universal appeals to the "American people," the platform stresses the "spirit of the American Revolution," and "citizen activism that has always been the touchstone of a free and democratic society." In other words, appeals to civic identity underscore a universal "common good" with interests of all Americans tied to a "social contract" and "mutual dependence." The 1992 Democratic party platform even criticizes Republicans for their identity politics: "by playing racial, ethnic and gender-based politics they have divided [Americans] against each other, created an atmosphere of blame, denial and fear, and undone the hard-fought battles for equality and fairness." 


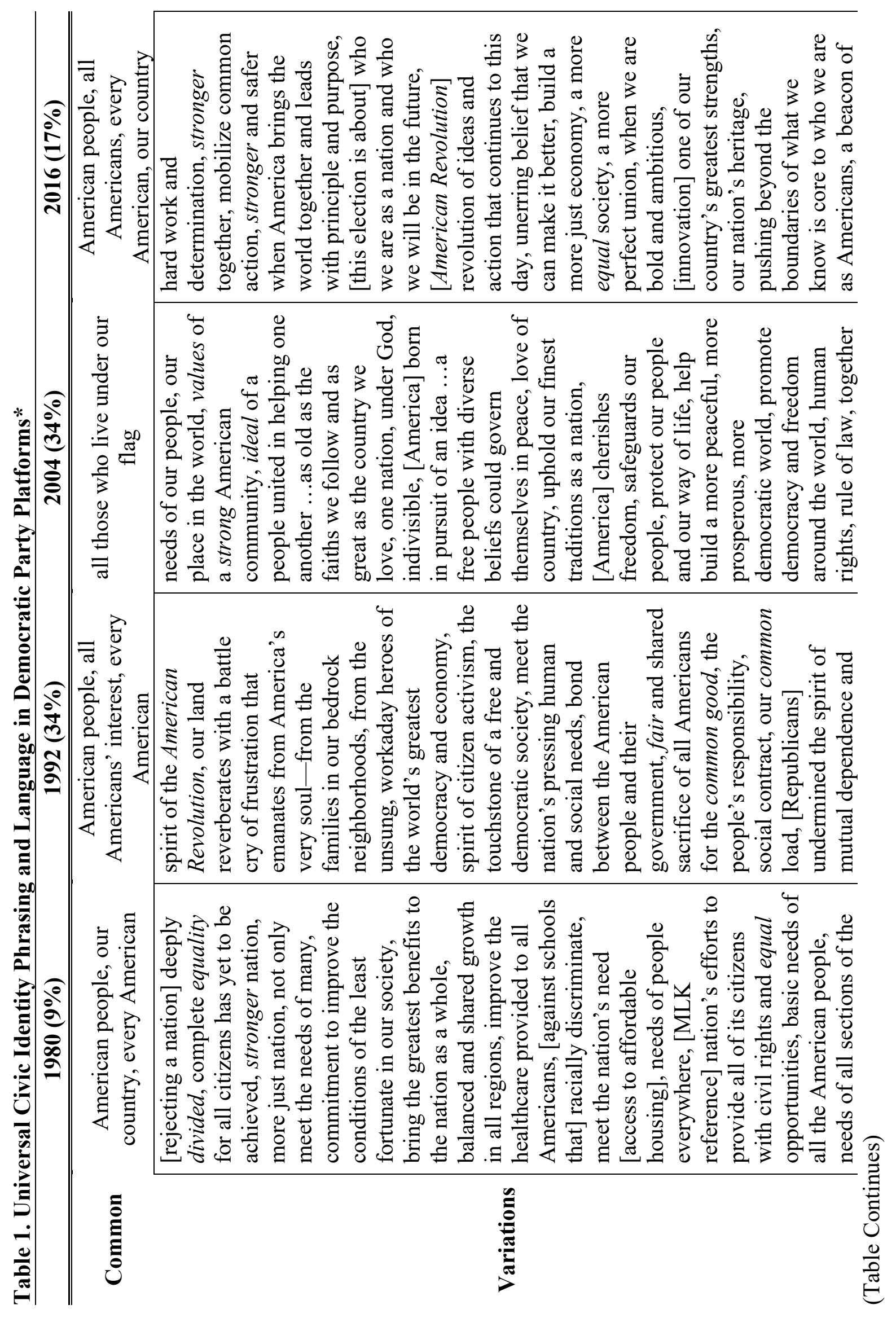




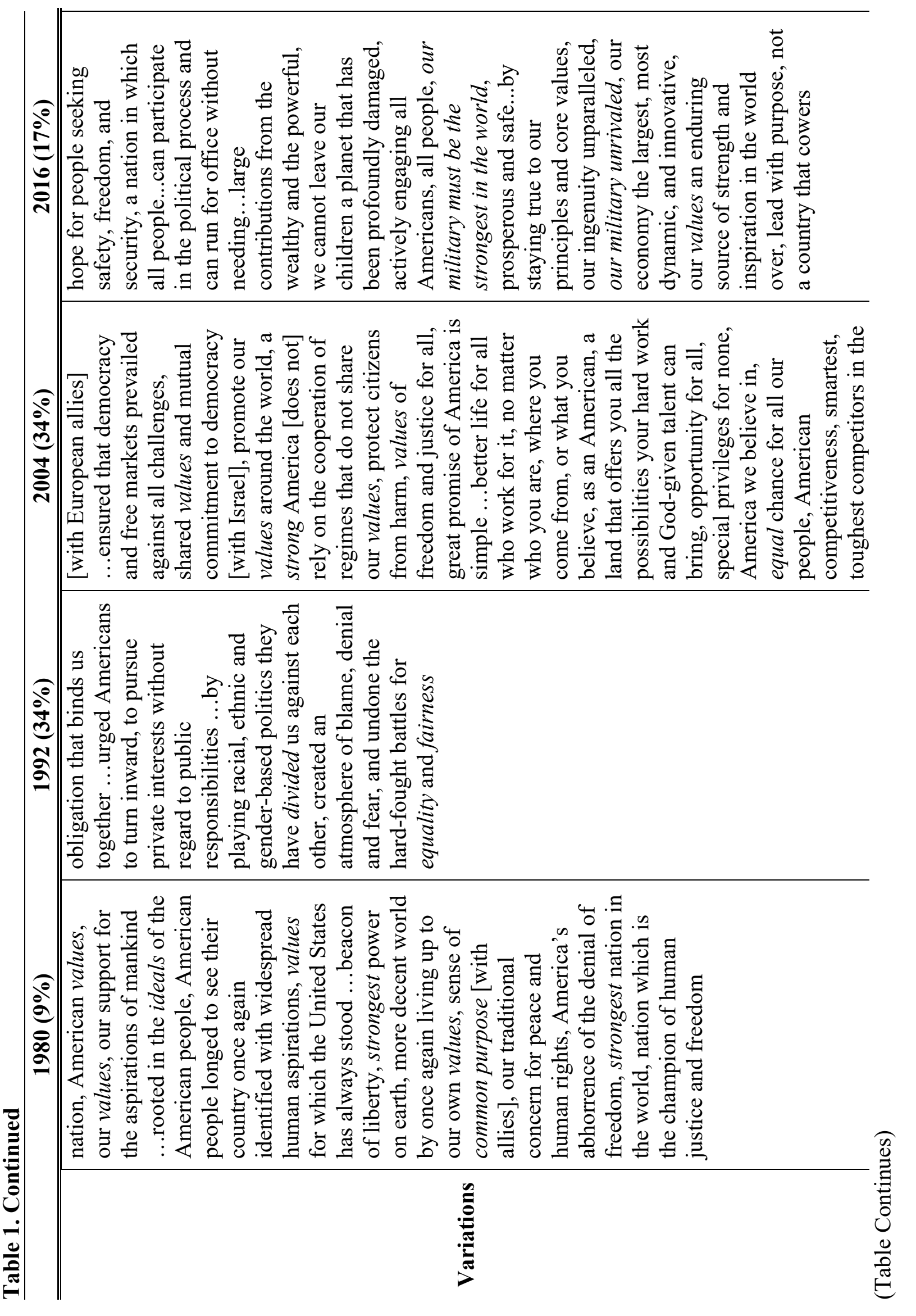




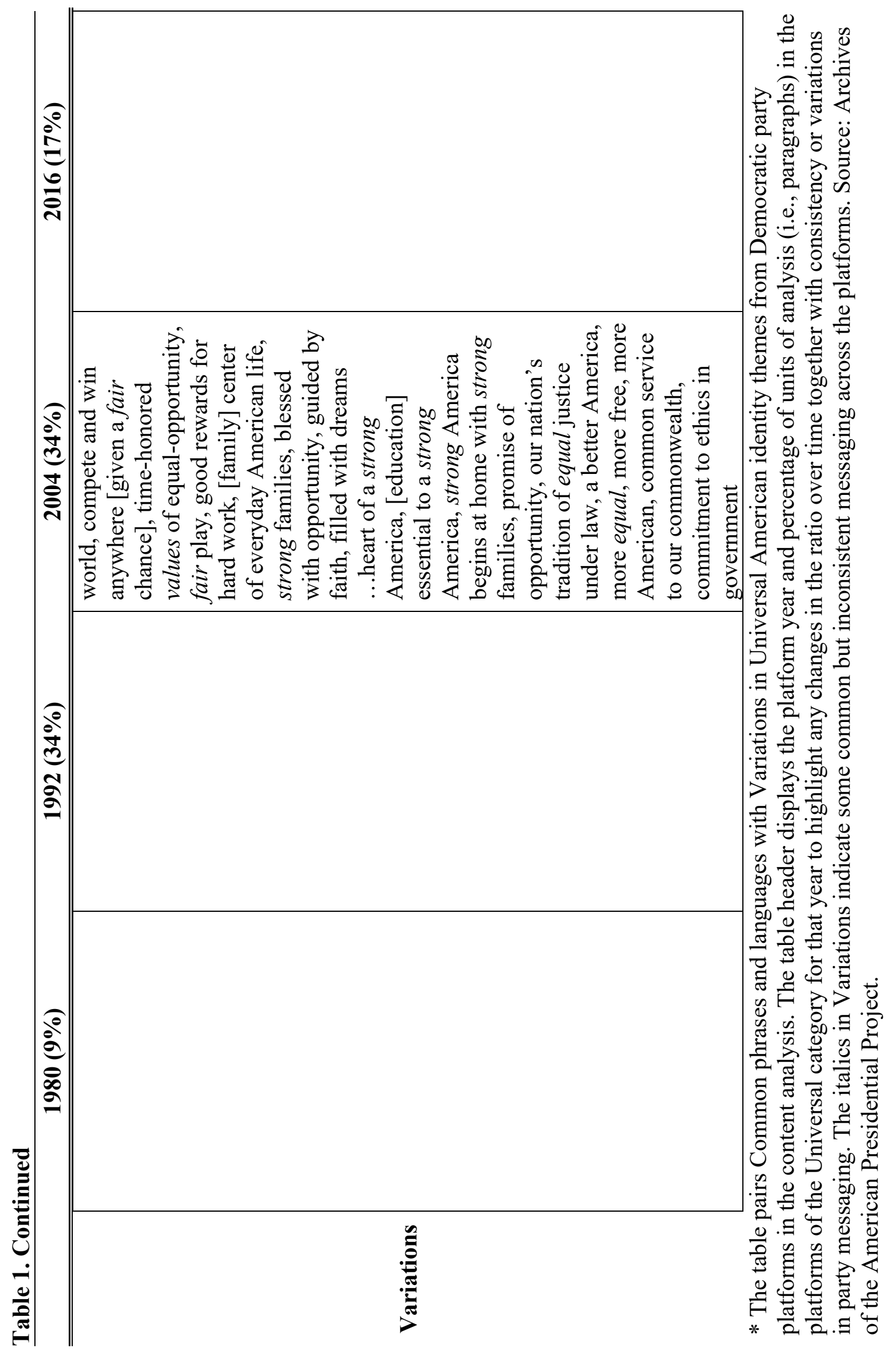


By 2004 , written only a few years after 9/11 terrorist attacks, the Democratic party platform in its universal civic themes reflect a patriotic message, including around democracy and freedom as American ideas as well as promotion of such values as American tradition. The 2004 platform emphasizes the "ideal of a people united in helping one another" and "a strong American community," in addition to one where "a free people with diverse beliefs could govern themselves in peace." With "love of country," the Democratic party platform further appeals to "an America that cherishes freedom." America's path is to "help build a more peaceful, more prosperous, more democratic world," to "promote democracy and freedom around the world," as well as human rights and rule of law for the sake of ensuring that "democracy and free markets prevailed against all challenges." The phrasing speaks to "American competitiveness," smart and tough Americans who "compete and win anywhere" if given a fair chance and equal opportunity. Accordingly, appeals to conceptions of American community, identity or nation are mostly universal around a civic identity, not unlike Republican counterparts in most years. In contrast to earlier years in the content analysis, the 2004 Democratic party platform is more ideological by way of democracy promotion in conjunction with free markets, both inwardly as well as abroad, i.e., a global project rather than one kept to the local or national community. This framing comes in the context of roughly a year after the US-led invasion of Iraq and overthrow of the government of Saddam Hussein, when a 'rally around the flag' patriotic wave was noticeable in opinion polls and war dominant headlines.

In 2016, universal themes around American community remain present in the Democratic party platform's recurrent emphasis on "hard work and determination of the American people," and likewise, with American "innovation" as a great strength. Phrases like "our nation's heritage," with roots in actions and ideas of the American Revolution, culminates in a "belief 
that [Americans] can make it better," that Americans can "build a more just economy, a more equal society" and "a more perfect union." With regard to immigration, the 2016 platform further distinguishes America as “a beacon of hope for people seeking safety, freedom, and security." In contrast to 2004 messaging, language of democracy and free market promotion is absent. Neither does the 2016 Democratic party platform articulate presence abroad as clearly as 2004, although it sustains "always coming together to stand up to terror" as a matter of "who we are as Americans" in appeals to values, strength, inspiration, dynamism, and prosperity in American identity.

To summarize, phrases in the universal civic identity category are mostly consistent in presence, but only sparingly have commonalities across Democratic party platforms from 19802016. These common messages include references to "the American people," "our country," and "every" or "all" Americans "who live under our flag." Variations in universal phrases are plenty. In 1980, "nation" is frequent in rejection to one that is "deeply divided." The platform pushes for a "stronger nation" to "meet the needs of many," to "reaffirm...commitment to improve conditions of the least fortunate," and achieve "complete equality for all citizens." The universal phrases shift the emphasis to the "spirit of the American revolution," and "spirit of citizen activism...the touchstone of a free and democratic society in 1992." It further speaks to the "soul" of America and its "social contract" of "fair and shared sacrifice of all Americans for the common good," from "families" to "workaday heroes of the world's greatest economy." By 2004, language move towards patriotism in "love of country," a "great" country because of its ideals - i.e., "values of a strong American community," as "one nation, under God, indivisible." The universal civic identity emphasis in 2004 is an America "born in pursuit of an idea." It is that "a free people with diverse beliefs could govern themselves in peace." Alluding to the onset 
Iraq war in 2003, the 2004 platform accentuates protecting American people and their way of life, including democracy, freedom, and free markets, as well as promoting "our values around the world." The variations by 2016 underscore an America "stronger together," and "safer when America brings the world together and leads with principle and purpose." These facets, it states, are "who we are as a nation and who we will be in the future." The 2016 platform emphasizes American values and ideas - a universal civic identity of "purpose" and "principles" as a "source of strength," while continuing an outward message, like 2004, as "beacon of hope" for the world. Hybrid

The least weight from the 1980 Democratic party platform is to the hybrid, universalidentitarian phrases and appeals. For example, it addresses "equal opportunity and full voluntary participation in the military regardless of sex." It reiterates the party goal of "eliminating discrimination in education because of sex," and "embraces a recognition of the right of every citizen—Black and Hispanic, American Indian and Alaska Native, Asian/Pacific Americans, and the majority who are women.” The 1980 platform also pleas to end discrimination against "language minorities," and describes American society as "analogous to a beautiful mosaic," mentioning the same "mosaic" descriptor in 1992. A hybrid theme for the 1980 Democratic party platform, which is increasingly prominent over the 1980-2016 period, incorporates universal appeals to American community as well as subgroup interests or identity(ies) (see Table 2).

Like in 1980, the 1992 Democratic party platform stresses rejection of discrimination and an assurance of equal rights for all Americans without exception for "race, gender, language, national origin, religion, age, disability, sexual orientation, or other characteristics irrelevant to ability." Within such framing, the platform maintains a civic identity notion of shared values not unlike that in its universal language except for the stress on anti-discrimination among various 


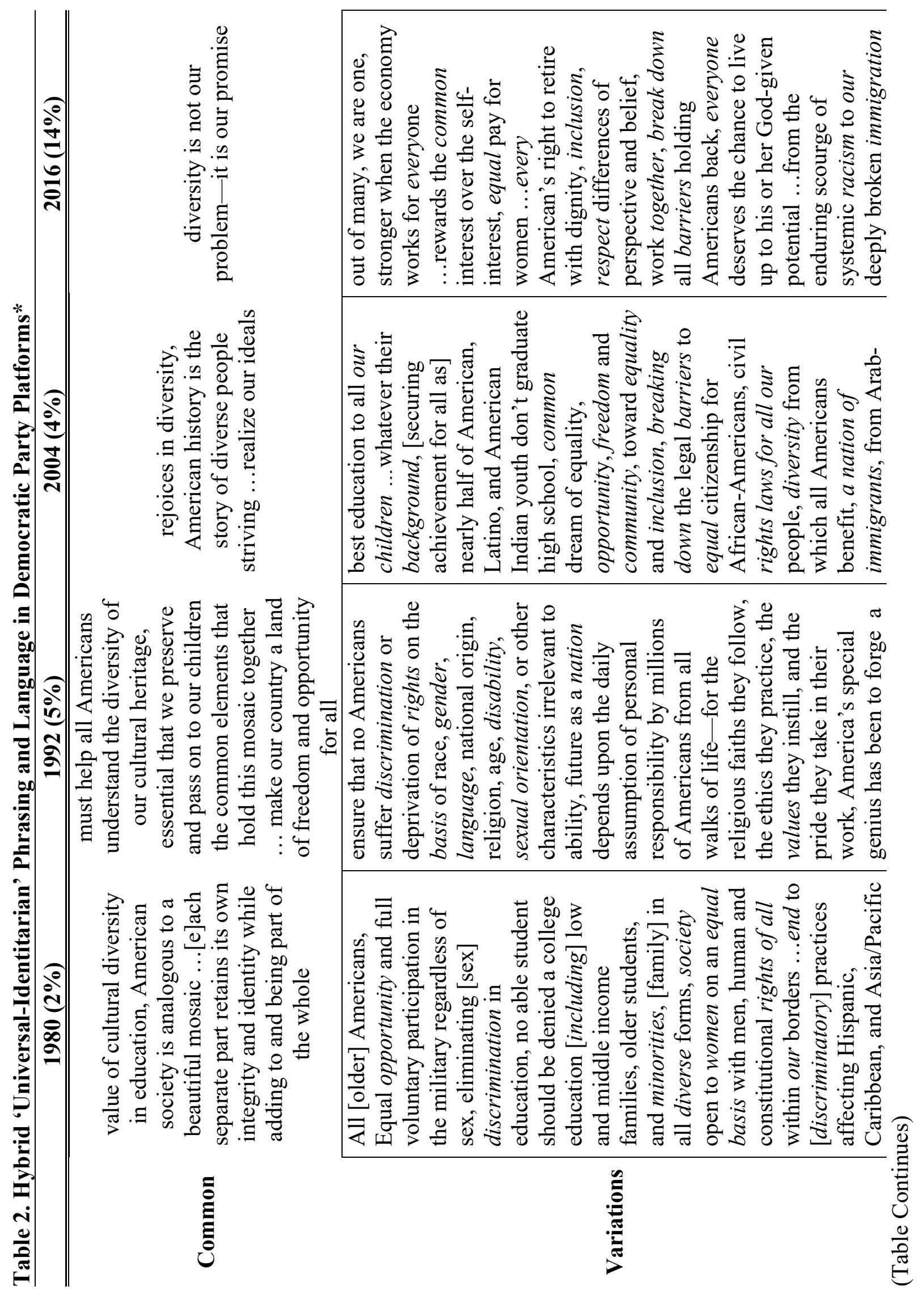




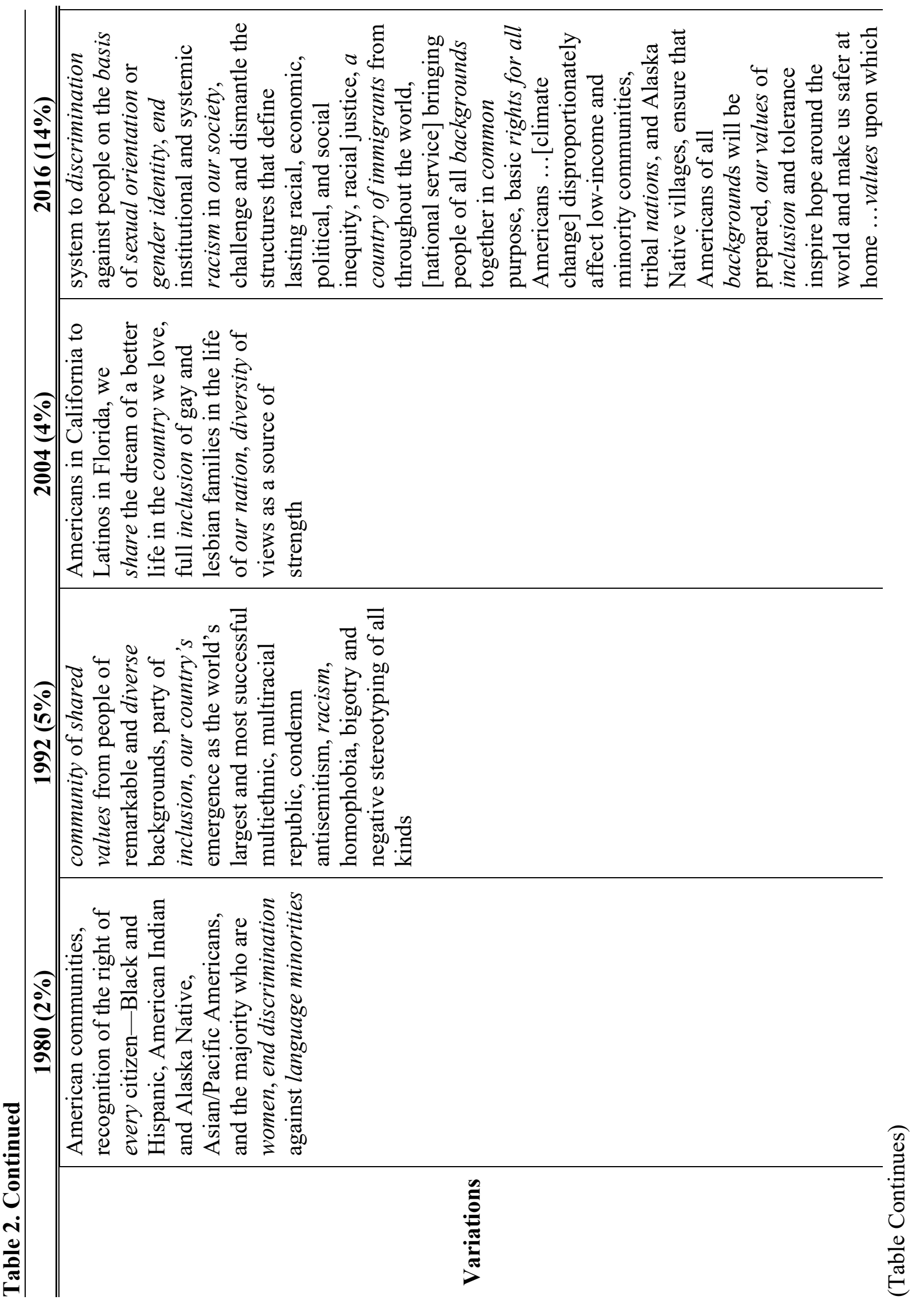




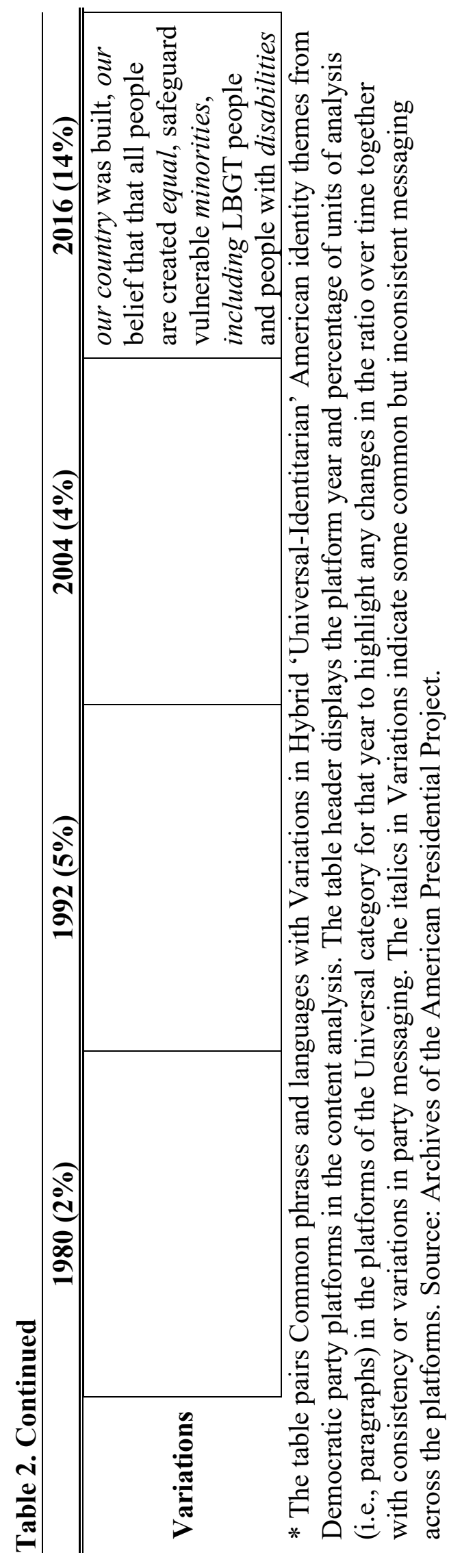


subgroup categories. The 1992 platform underscores the diverse background of Americans, a nation of "the world's largest and most successful multiethnic, multiracial republic," and the party's vision to “condemn antisemitism, racism, homophobia, bigotry and negative stereotyping of all kinds." Moreover, it appeals to the individual as an integral part of the American community to the extent that "a nation depends upon the daily assumption of personal responsibility by millions of Americans from all walks of life—-for the religious faiths they follow, the ethics they practice, the values they instill, and the pride they take in their work." Hybrid messaging in the Democrats' 2004 platform continues similar themes as earlier years in the content analysis. It highlights American opportunity while stressing that the nation "rejoices in diversity" - that "American history is the story of diverse people striving." These appeals are comparable to hybrid, universal-identitarian themes of the 1992 party platform, which might suggest changes coming about in globalization and the de facto diversifying American 'community' comprising the US population and American citizenry. For example, it describes America as "a nation of immigrants," together "from Arab-Americans in California to Latinos in Florida." The platform frames a hybrid identity of Americans as including immigrants as part of a common "dream of a better life in the country we love," in addition to "full inclusion of gay and lesbian families in the life of our nation," unlike earlier years in the content analysis. In other words, the 2004 Democratic party platform frames belonging for "all Americans" as specifically including diverse backgrounds and identity subgroups in American culture. It is similar to language in the 1980 Democratic party platform, which describes "American society" as "analogous to a beautiful mosaic," although more expansive and prominent themes in the text.

More common than past years, the 2016 Democratic party platform features hybrid themes invoking identitarian appeals that describe American oneness, such as "out of many," of 
"everyone," and including "Americans of all backgrounds." In other words, it distinctly stresses social inclusion, diversity, and anti-discrimination in hybrid, universal-identitarian themes. The platform pleas to "break down barriers," in phrasing that continues from 2004, as an American promise to eliminate anything holding them back. However, this theme by 2016 adds new language of an "enduring scourge of [institutional and] systemic racism," plus lamenting "our deeply broken immigration system." The 2016 Democratic party platform explicitly invokes the word 'identity' in terms of subgroup appeals for the first time for years in the content analysis. Since 2004, it further presents a message in rejection of "discrimination against people on the basis of sexual orientation and gender identity." It stresses America not as a 'nation' necessarily but a place "bringing people of all backgrounds together in common purpose," and as a guarantor of "basic rights for all Americans." Language of American values in "inclusion and tolerance" are central themes in 2016 Democratic party platform messaging in the hybrid category. Such values are foundational beliefs underpinning why Americans must "safeguard vulnerable minorities, including LGBT people and people with disabilities." Growth in hybrid themes trails identitarian trends for the 1980-2016 period in the content analysis, though both peak by 2016 at $14.37 \%$ and $32.46 \%$ of paragraph units of analysis in the platforms, respectively. Their growth comes at the expense of neutral and universal messaging, which have steep declines from 2004 to 2016 (decreasing from $56.62 \%$ to $36.57 \%$ for the former, and from $33.55 \%$ to $16.60 \%$ for the latter).

In short, hybrid language and phrasing have subtle growth in prominence for Democratic platform space, beginning at the margins (2.09\%) before peaking (up to $14.37 \%$ ) most recently from the 1980-2016 period for years in the content analysis. Diversity is a common phrase in terms of American culture and identity from hybrid language. It is a theme that grows more 
expansive and prominent as most evident by 2016 in its breadth and salience in the platform text. In particular, diversity and inclusion messaging, with laments against "systemic racism," a “deeply broken immigration system," and discrimination towards subgroups, is key to the Democratic party platform's hybrid, universal-identitarian appeals by 2016 . These themes are less prominent in 1980 (2.09\%), while subtle in the texts from 1992 (4.59\%) and 2004 (4.27\%). The variations of hybrid wording noticeably change in 2004 with the inclusion of "gay and lesbian families in the life of our nation," which expands by 2016 to "sexual orientation" and "gender identity." Throughout, the platforms maintain anti-discrimination sentiments in ethnic or racial terms for the $1980-2016$ period. In 1980, messaging against discrimination in the Democratic party platform is more frequently for issues of sex and women's rights. The subgroup languages in 1992 are less specific for the "party of inclusion." There are mentions of persons of a "diverse background" and differing "sexual orientation" as part of shared American values, as well as stances against "homophobia" and "racism." The 2004 platform is suggestive for paving the way for a stronger message along similar terms in 2016, as subgroups in Latino, African, gay, lesbian, immigrants, American Indian youth, and others are features in appeals to “equality" and eradicating "barriers" for "all Americans.” A key variation by 2016 in the Democratic party platform, besides peaking for years in the content analysis (increasing from $2.09 \%$ in 1980 to $14.37 \%$ by 2016 ) is language of "systemic racism" in its emphasis on subgroup identity and the various issues regarding minority inclusion in the de facto American community.

\section{Identitarian}

Identitarian messaging from the 1980 Democratic party platform $(10.62 \%)$ is second to neutral themes (78.70\%) for phrases or language regarding American civic identity, community or belonging. There are appeals to American subgroups and minorities, including women and the 
disabled, in large part around job growth and training, disproportionate burdens of economic downturn, and representation issues such as trial juries and jobs in the federal government. By comparison, there is less in relative proportion of text in the 1992 Democratic party platform messages in the identitarian category (decreasing to 3.06\%). There are still some appeals to American subgroups, particularly to the "people of" US territories relating to "just and fair treatment under federal policies," in addition their "rights and self-determination." Besides this one narrow and infrequent theme, the 1992 platform also stresses the cultural issue of abortion. For example, the text asserts "the right of every woman to choose" whether or not to have the procedure, while conceding the "goal of our nation must be to make abortion less necessary." The framing of abortion issues develops over later years. For example, in 2004, the platform advises that abortion should be "safe, legal, and rare." In 2016, it expands on the issue of "safe and legal" abortion with regard to judicial appointments influencing the direction of the country's policies, in addition to "Securing Reproductive Health Rights and Justice" by supporting a reproductive healthcare organization, Planned Parenthood. The 2016 platform frames such issues as against Republican efforts to oppose them. It supports access to such facilities for women "regardless of where she lives, how much money she makes, or how she is insured," including "legal abortion throughout the developing world." The issue garners more attention in the 2016 platform relative to earlier years, as the platform now further explains that similar issues of "family planning" will "thereby also reduce the need for abortions." This trend in the text mirrors changing numerical ratios. The proportion of text in 1992 with identitarian themes is the low point for the content analysis. By 2004, it grows slightly (from 3.06\% to $5.56 \%)$ as other categories are relatively stable in proportion of Democratic party platform text from 1992-2004. Identitarian text is prominent by 2016 (32.46\%) (see Table 3). 


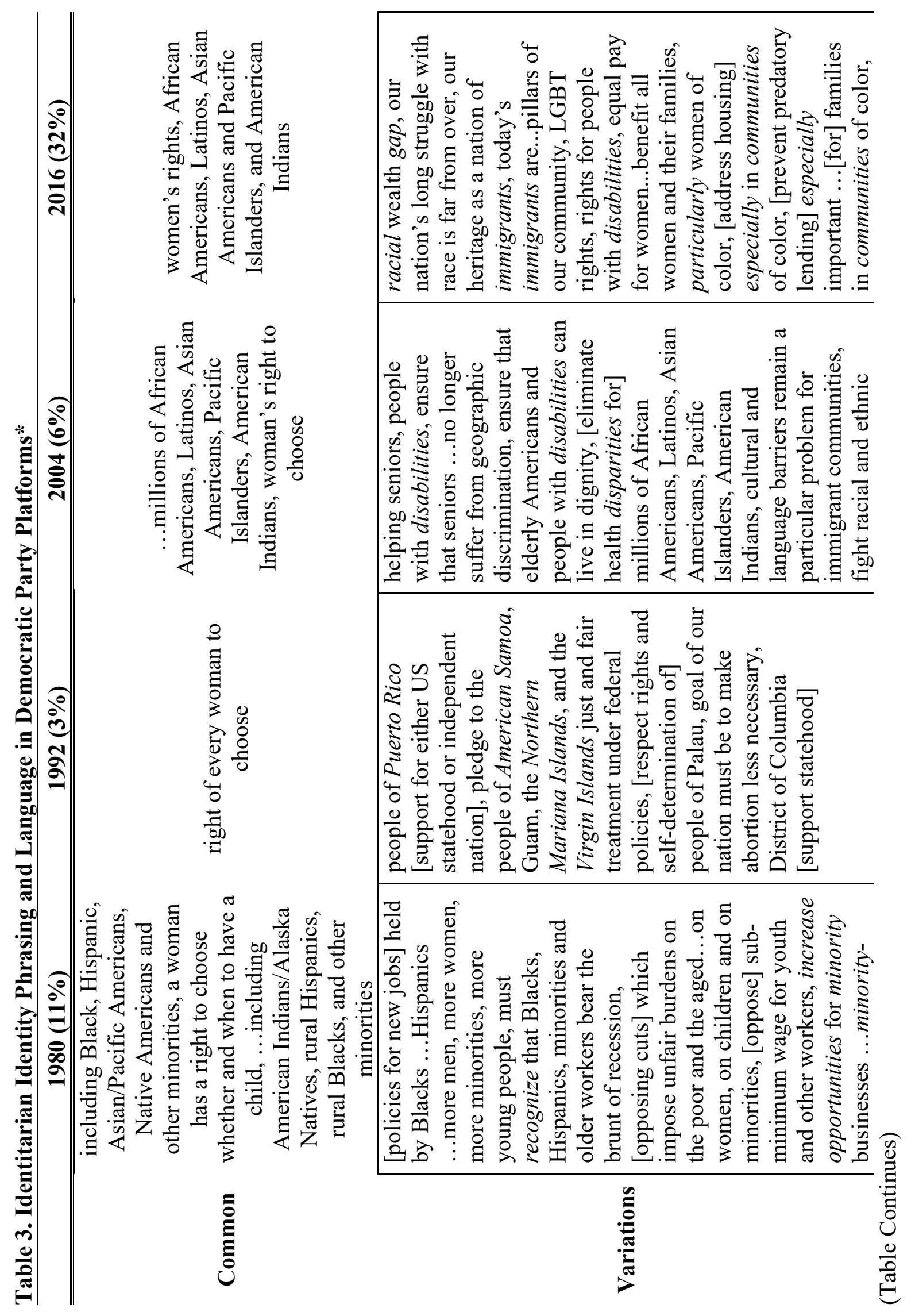




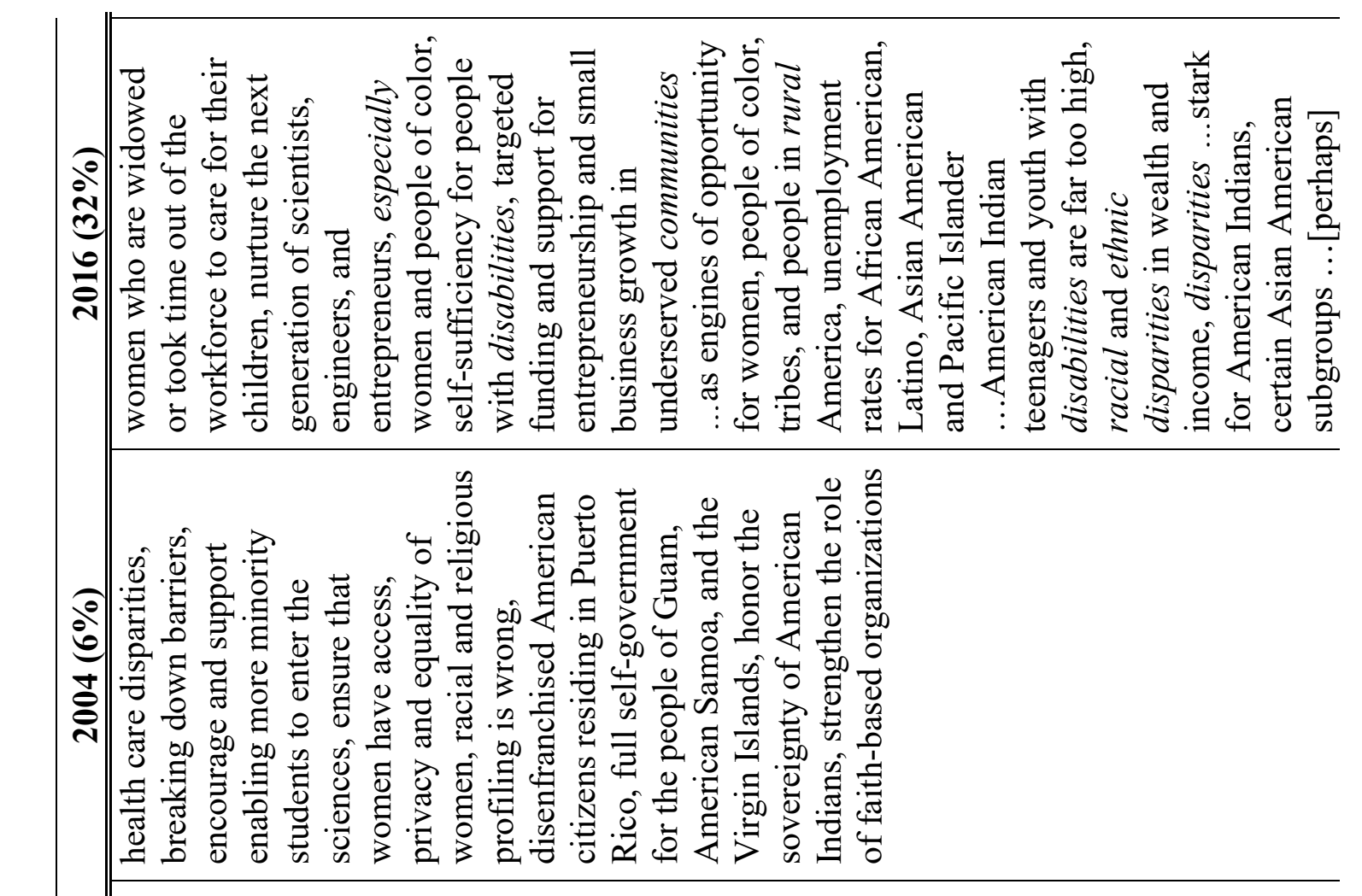

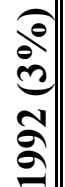

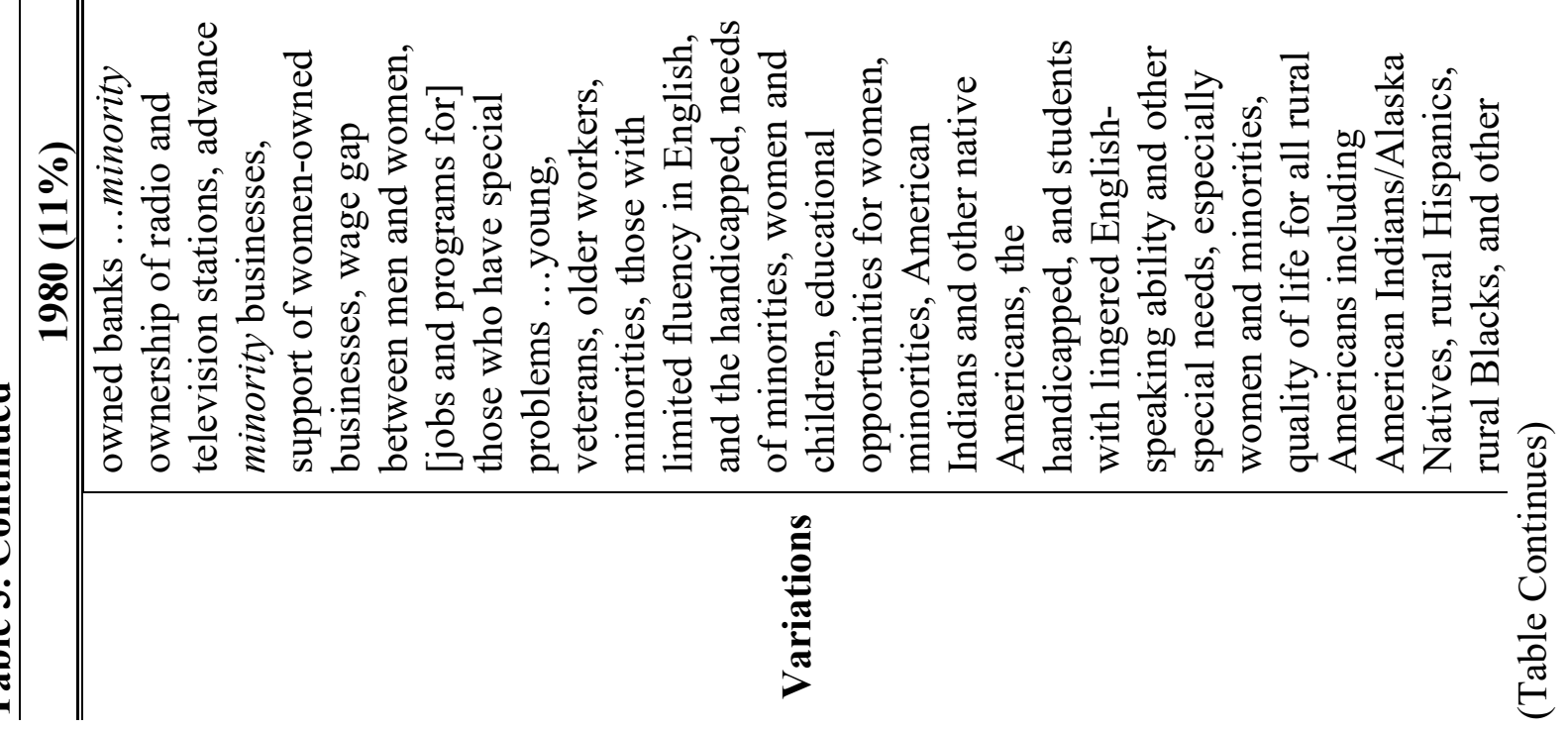




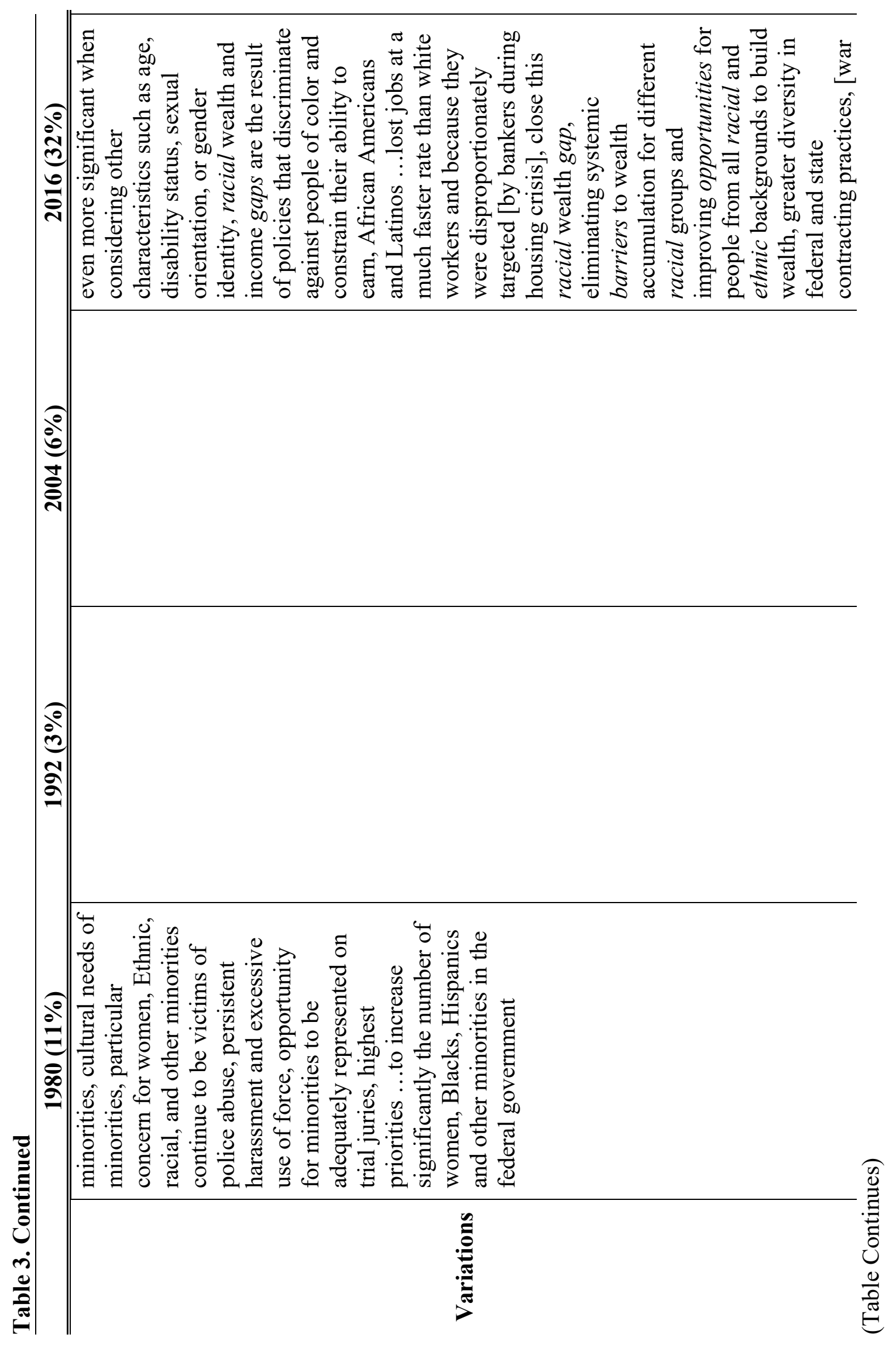




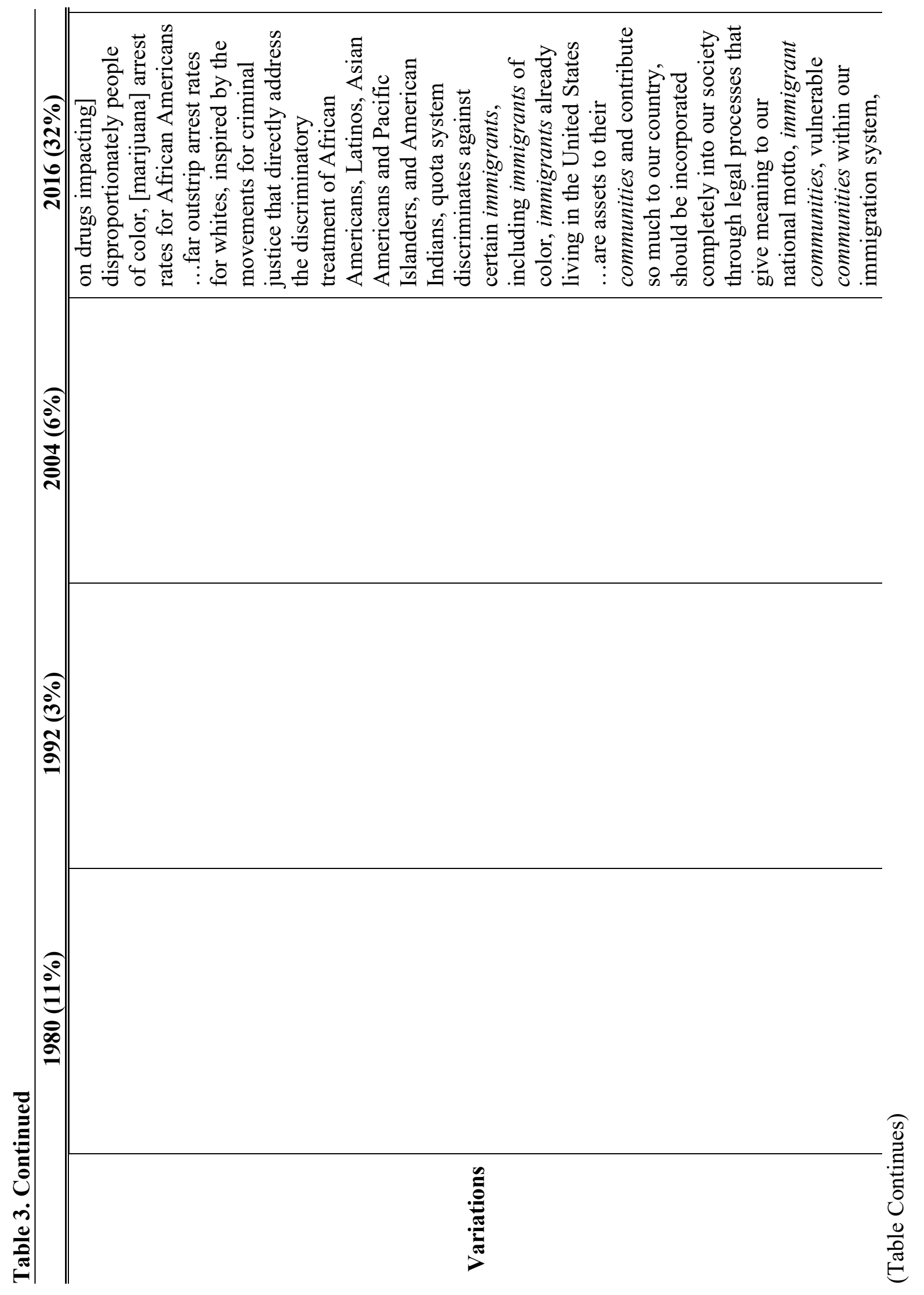




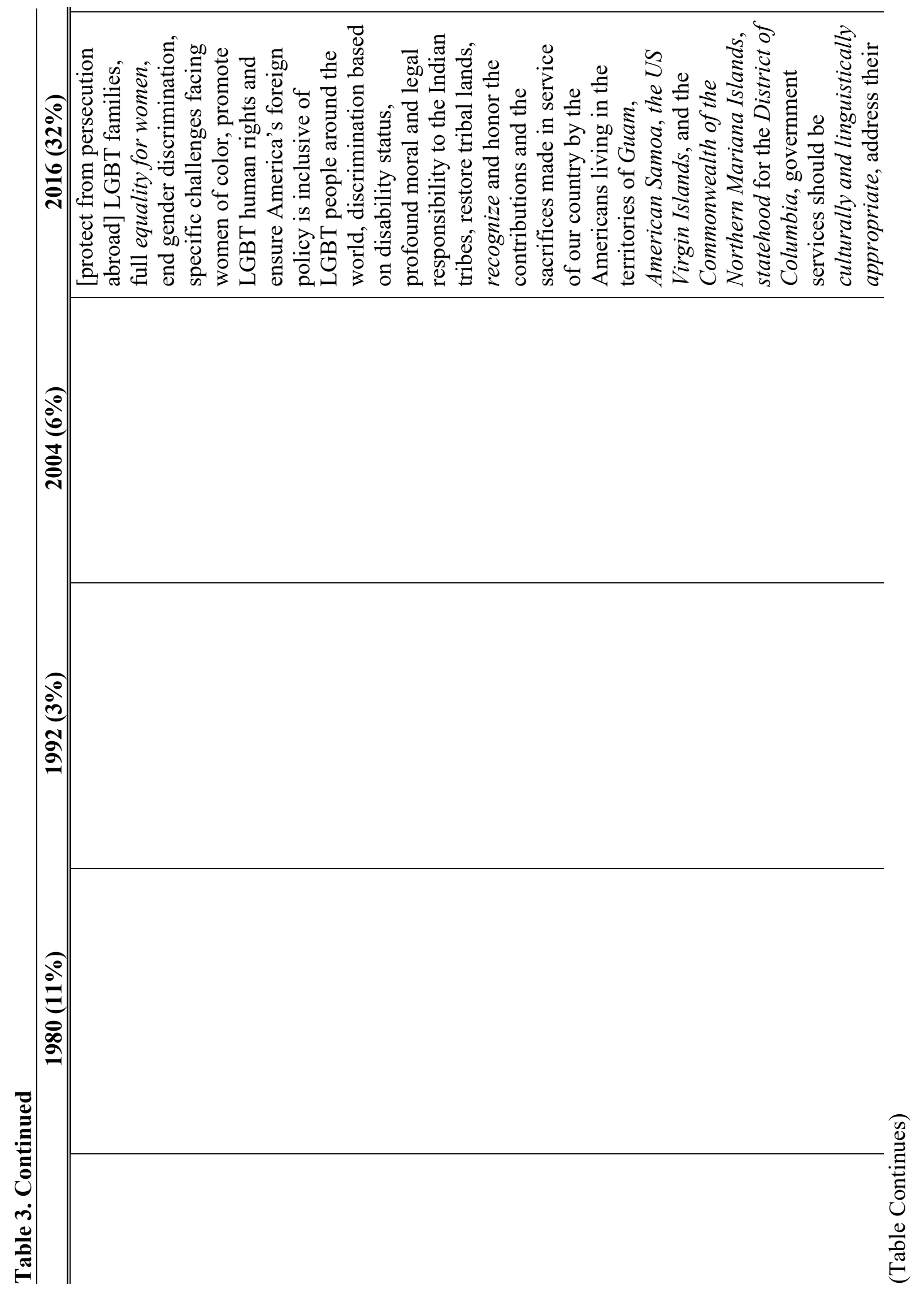




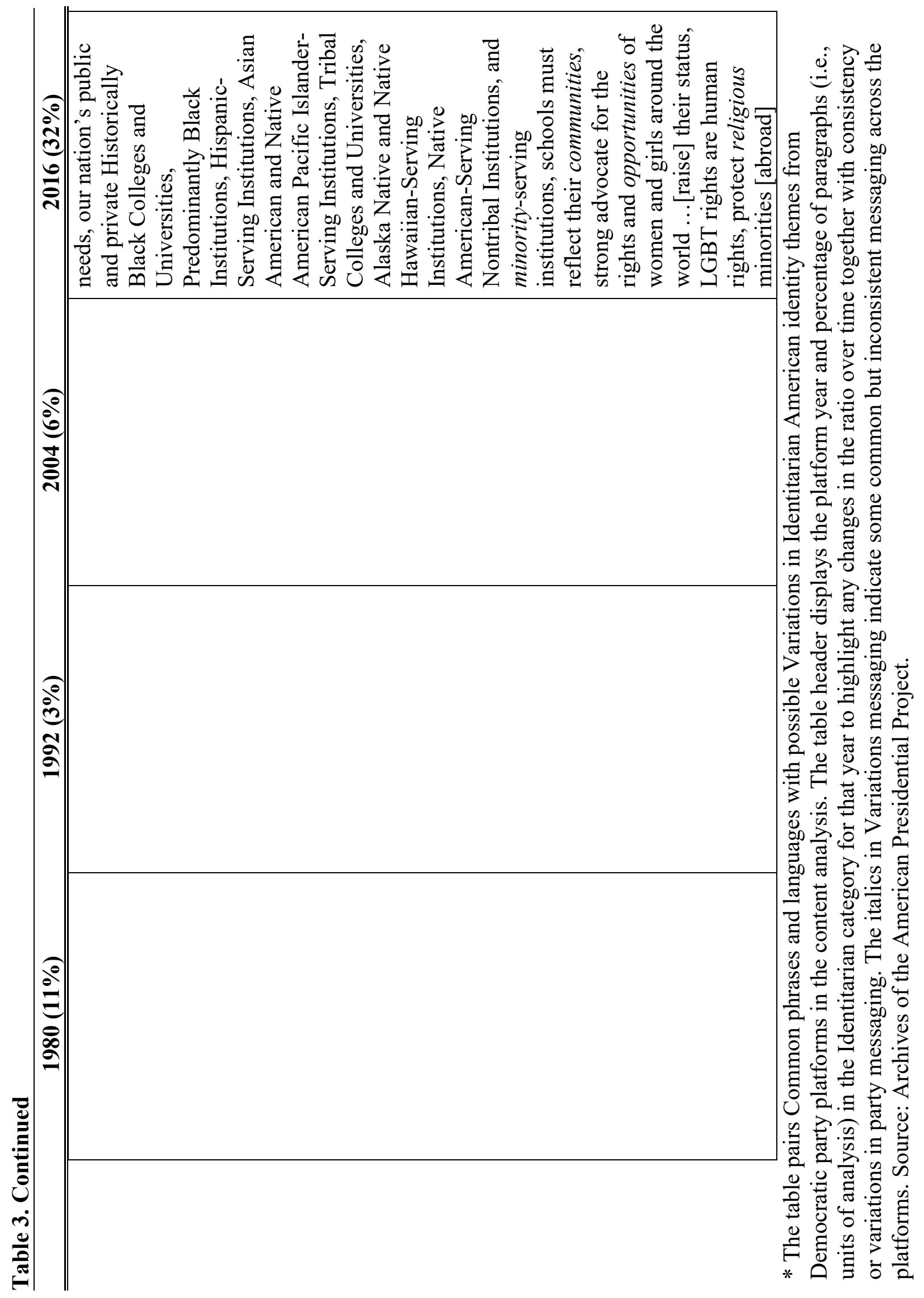


Moreover, along with women's issues, from 1992 to 2004 the Democratic party platform expands identitarian themes on minority subgroups. For example, the 2004 platform speaks to elimination of health disparities for "millions of African Americans, Latinos, Asian Americans, Pacific Islanders, and American Indians," and how "cultural and language barriers remain a particular problem for immigrant communities." It further appeals to "breaking down barriers" for women and minorities in education, jobs, and health. From 1992, 2004, and 2016 years in the content analysis, the platforms reiterate a "woman's right to choose" over abortion, while in 1980 the platform acknowledges as much but qualifies that it "fully recognize[s] the religious and ethical concerns which many Americans have about abortion."

Identitarian themes in the Democrats' 2016 party platform are most expansive of all years in this category from the content analysis, as it recites various subgroups throughout its political messaging. The 2016 platform largely draws on group disparities and discrimination, diversity and inclusion, and "our nation's long struggle with race," which it laments as "far from over." Reiterating "our heritage as a nation of immigrants," the 2016 Democratic party platform affirms "today's immigrants...are pillars" of the American community. Particularizing the basic rights of "all Americans," it further develops political issues to narrower subgroups within the American community; in messages to "women's rights," "particularly women of color," "LGBT rights," "rights for people with disabilities," "families in communities of color," "especially in communities of color," "people in rural America," "immigrants, including immigrants of color," "LGBT human rights...LGBT people around the world," in unemployment rates for various ethnic identities, African Americans and Latinos with lost jobs compared to "white workers," racial and social disparities in wealth accumulation, government contracting, and arrest rates, ...etc. The takeaway message is primarily rectifying social inequalities for racial, ethnic, sex, and 
gender minorities, appealing to inclusion, non-discrimination, and equalizing subgroup disparities. In short, the extent of issues the 2016 platform devotes to narrower identities within the US is noticeably more prominent and throughout the text than any of the prior Democratic party platforms in the analysis, as also seen in ratios (from $10.62 \%$ in 1980 to $32.46 \%$ in 2016).

On the whole, Democratic party platform language and phrasing shifts away from neutral messaging towards identity framing in the 1980-2016 period for years in the content analysis. Neutral messaging has clear decline in salience for proportional text by paragraph units of analysis $(78.70 \%$ in $1980,58.16 \%$ in $1992,56.62 \%$ in $2004,36.57 \%$ in 2016$)$. While universal themes show overall growth ( $8.59 \%$ in 1980 to $16.60 \%$ in 2016), they peak in 1992 and 2004. By contrast, hybrid messaging start at the margins (2.09\%) and rise to salience most notably by 2016 (14.37\%). The identitarian category becomes more expansive in phrases and language while increasing overall from $10.62 \%$ in 1980 to $32.46 \%$ by 2016 . The years 1992 and 2004 are likewise exceptional for the identitarian category as the phrases and language are less prominent in 1992 (3.06\%) and rising slightly by 2004 (5.56\%), before a substantial rise by 2016 (32.46\%). Universal messaging remains somewhat consistent, varying in word choices and proportion of text with emphasis on "diversity," which is especially the case for 1980 and 2004, then most of all by 2016. The 1992 Democratic party platform is lesser in identitarian messaging and, interestingly, rejects Republican counterparts for "playing racial, ethnic, and gender-based politics" for its divisive political strategy. This lowest year for the identitarian category from Democratic party platform messaging is exceptional in that sense. Moreover, hybrid themes that increase steadily from 1992-2004, and then peak in 2016, parallel changes in messaging in the identitarian category. While the latter has the most expansive messaging and proportional text, both show language and phrases of increasing importance to women, LGBT, inclusion of 
immigrants and minorities or subgroup interests, as well as appeals to belonging in the de facto American community over the 1980-2016 period. Lastly, in 2016, the Democratic party platform goes further to identify "systemic racism" and issues of social disparity and inequalities. These themes are central in intensifying identitarian themes expressive of ideas in American identity.

\section{Republican Party Platforms (1980, 1992, 2004, 2016)}

The Republican party platform trends are similar to their counterpart insofar as changing appeals over the 1980-2016 period for years in the content analysis. However, the two parties have different underlying narratives in the texts. Unlike Democratic party appeals, Republican party platforms across the four categories are relatively consistent. Still, ratios of different categories of appeals between the parties similarly show general decline in neutral messaging from the content analysis. Universal, hybrid, and identitarian categories become more expansive and salient. For Republican platforms, changes are more mixed and gradual. Unlike Democratic party platforms, aside from similarities in neutral messaging decline, Republican party platforms devote most text among categories in the content analysis to universal themes (from $15.97 \%$ in 1980 to $24.79 \%$ in 2016 , peaking in 2004 at $27.18 \%$ ), second to the identitarian category ( $7.90 \%$ in $1980,7.05 \%$ in 1992 , dropping to $5.82 \%$ in 2004 , and up to $10.64 \%$ by 2016 ), with little for hybrid appeals except marginally and light peaking in 2016 (from $2.66 \%$ in 1980, down to $1.45 \%$ in 1992 , up to $3.16 \%$ in 2004 , and then rising to $5.18 \%$ by 2016 ). Accordingly, Republican and Democratic party platforms seem to increasingly diverge in partisan-identity appeals. Both party platforms emit gradually more contestation in messaging on American nation, community or identity considerations of interests and belonging. As Democratic party platforms increasingly stress a pluralistic message around various forms of minority inclusion and against "systemic racism," appeals from Republican counterparts are divergent in historical majoritarian appeals as 
far as identity and group interests, cultural and religious belonging in the American nation or community. The Republican party platforms nevertheless maintain a universal, civic identity message of American values. They repeat themes of "optimism," equal rights before law, and "hopes and aspirations" of "the people" or "nation." Still, the recounting of subgroups in identity interests and non-discrimination increasingly contrast with Democratic party platforms.

To preface, the 2016 Republican party platform is noteworthy because the party readopted it for the 2020 presidential election. The exceptional resolution reaffirms that the "Republican Party has and will continue to enthusiastically support [then-President Trump's] America-first agenda" (Republican National Committee 2020). The party leader may thus be more important now than party principles. With that said, a declining ratio of 'neutral' platform text, i.e., political messaging impartial to contestation or framing of American civic identity, community or belonging continues over the 1980-2016 period for years in the content analysis.

Moreover, modest decline in universal appeals coincides with the highest ratio of identitarian and hybrid messaging among Republican platforms in the content analysis by 2016 .

\section{Universal}

While the 1980 Republican party platform appeals are mostly neutral $(73.47 \%$ compared to $78.70 \%$ for the Democratic party platform in the same year), the category of universal language or phrases $(8.59 \%)$ begins second to identitarian themes $(10.62 \%)$. The former is expressive of American identity in mutual "hopes and aspirations," as well as in shared "talents and resources" that are imperatives to realize. The 1980 Republican party platform further expounds universal ideas of American identity with its calls to "restore the family, the neighborhood, the community, and the workplace as vital alternatives in our national life to ever expanding federal power." As Table 4 displays in common versus variations in messaging, the platforms reliably express a civic identity basis in universal appeals to American community. 


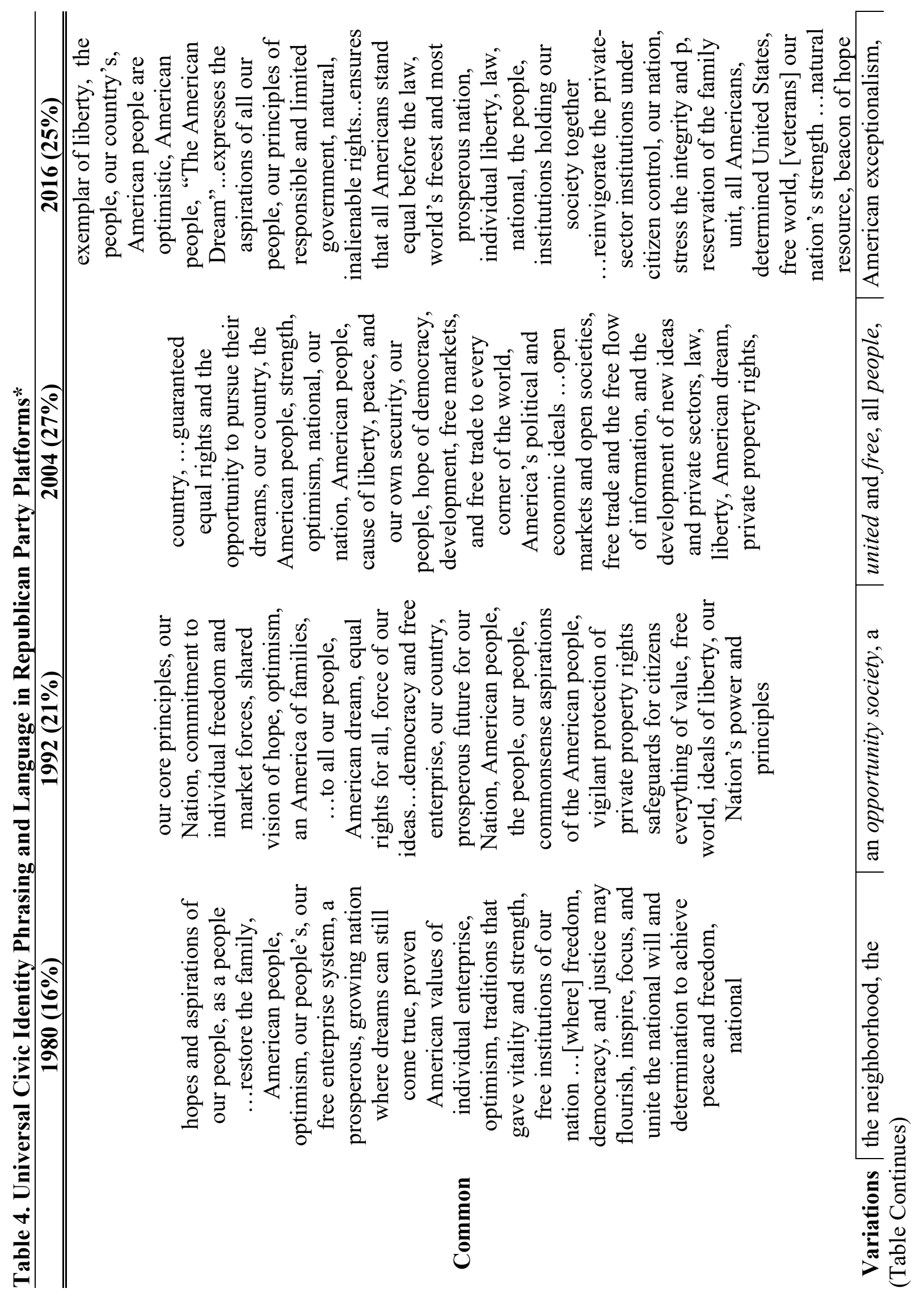




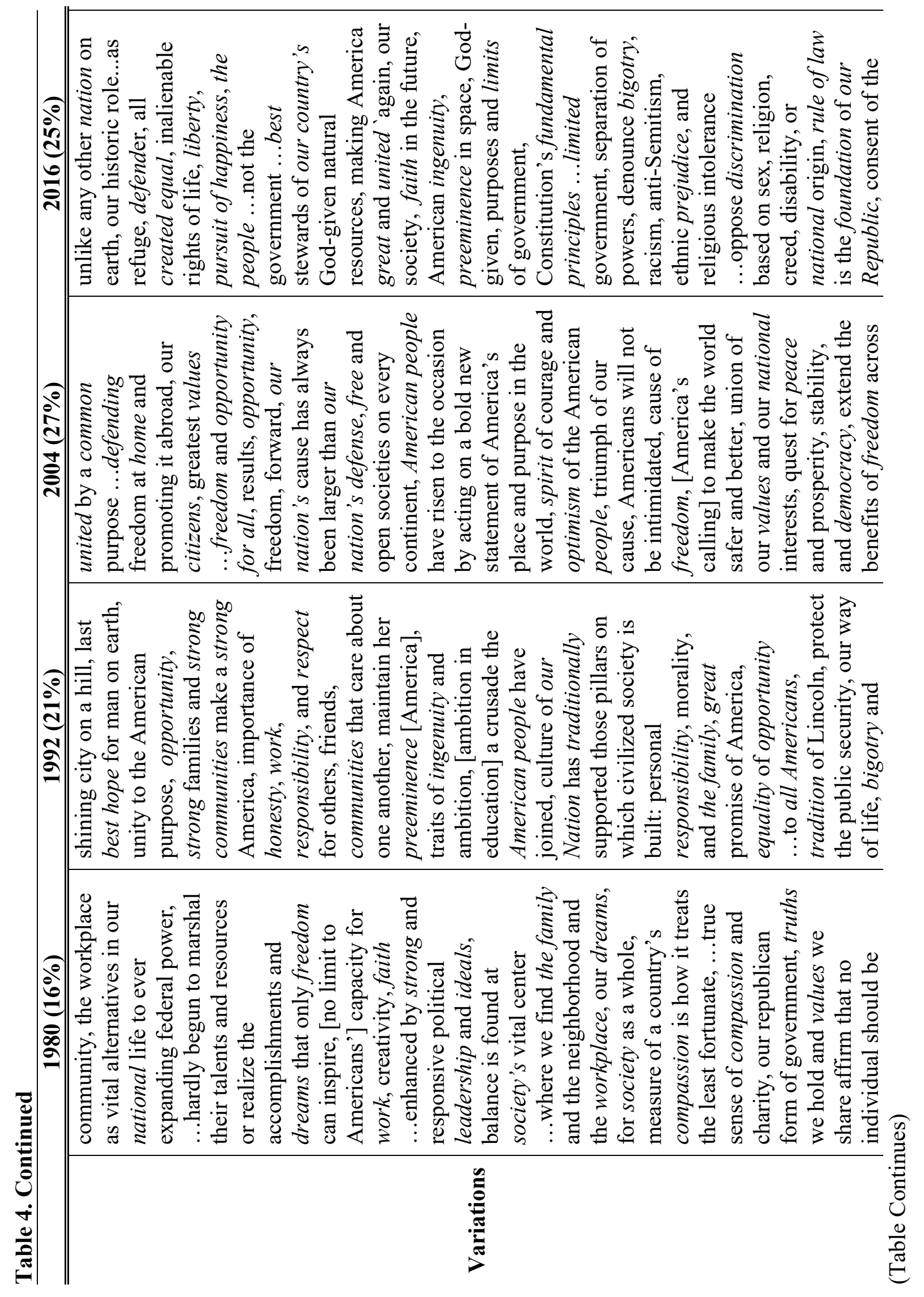




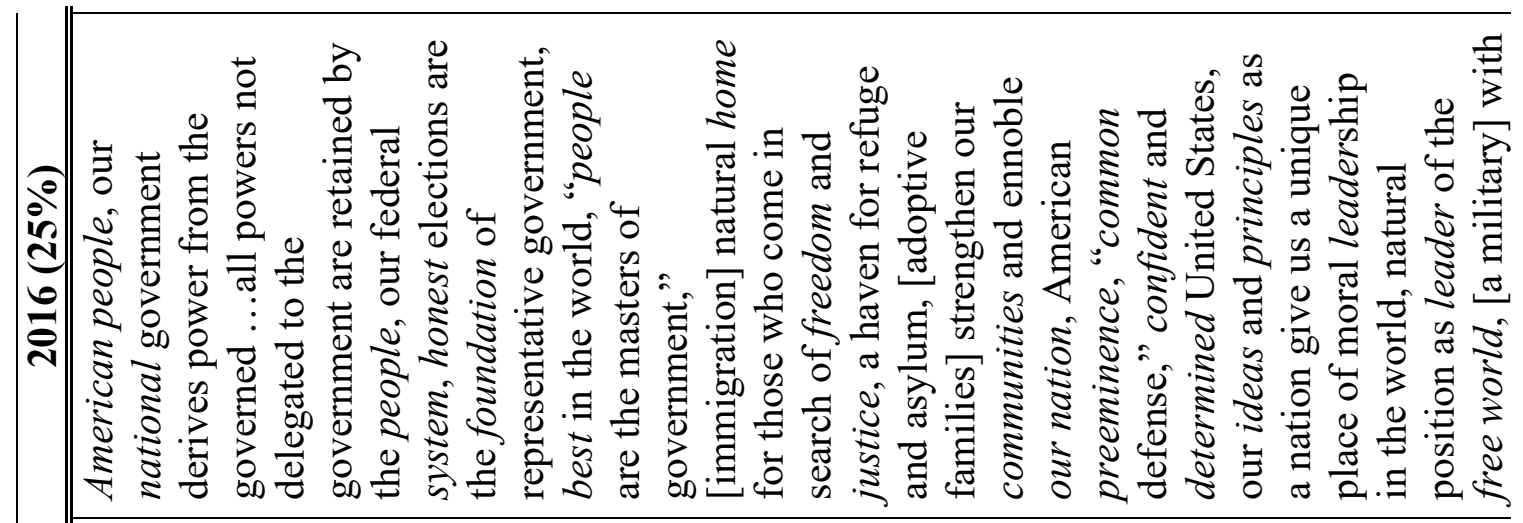

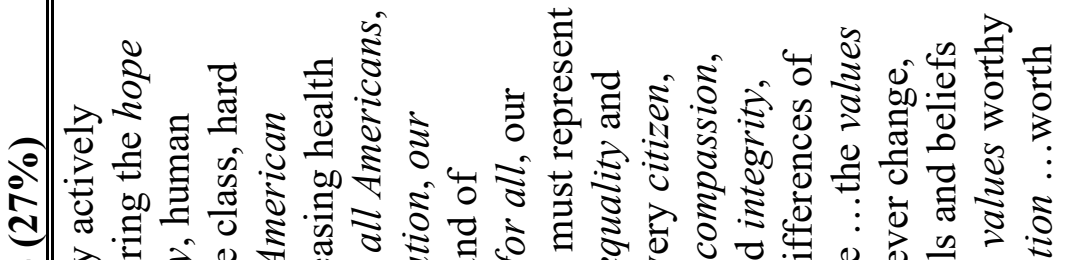

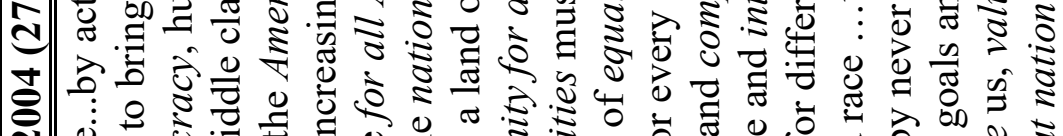

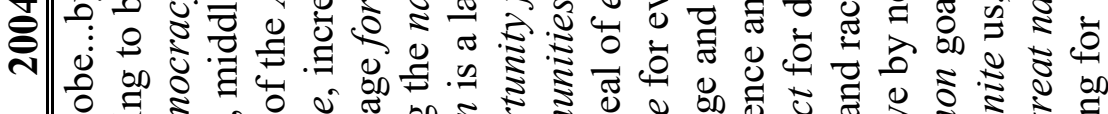

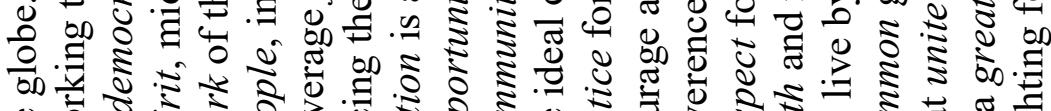

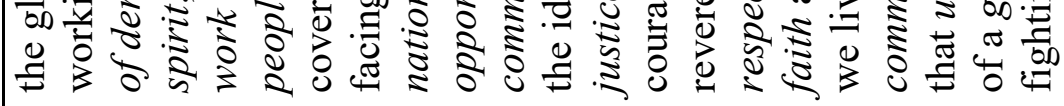

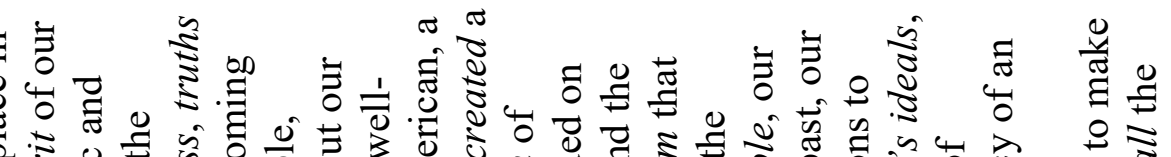

จी

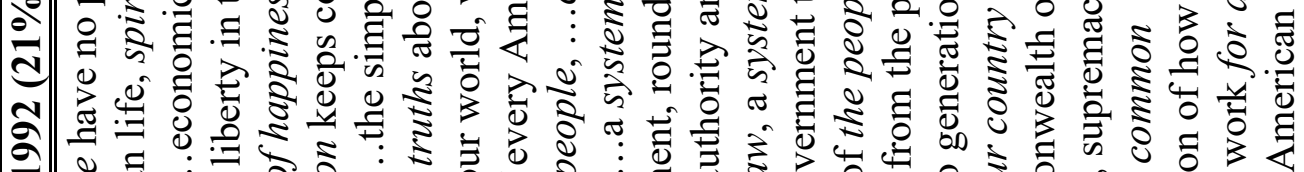

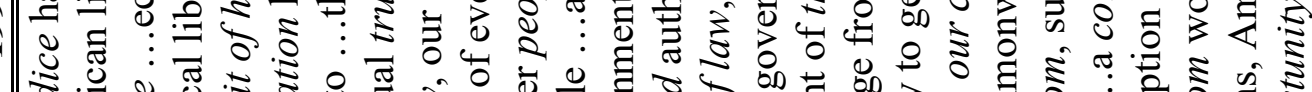

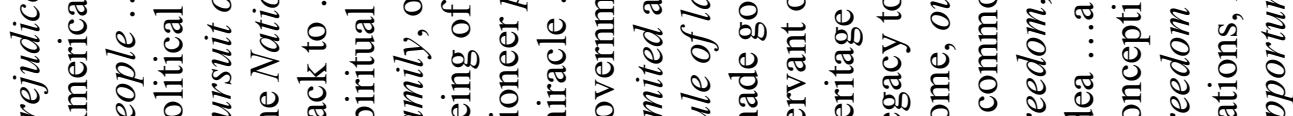

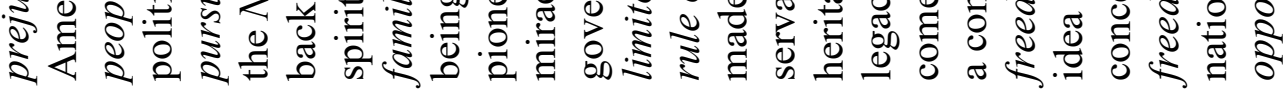

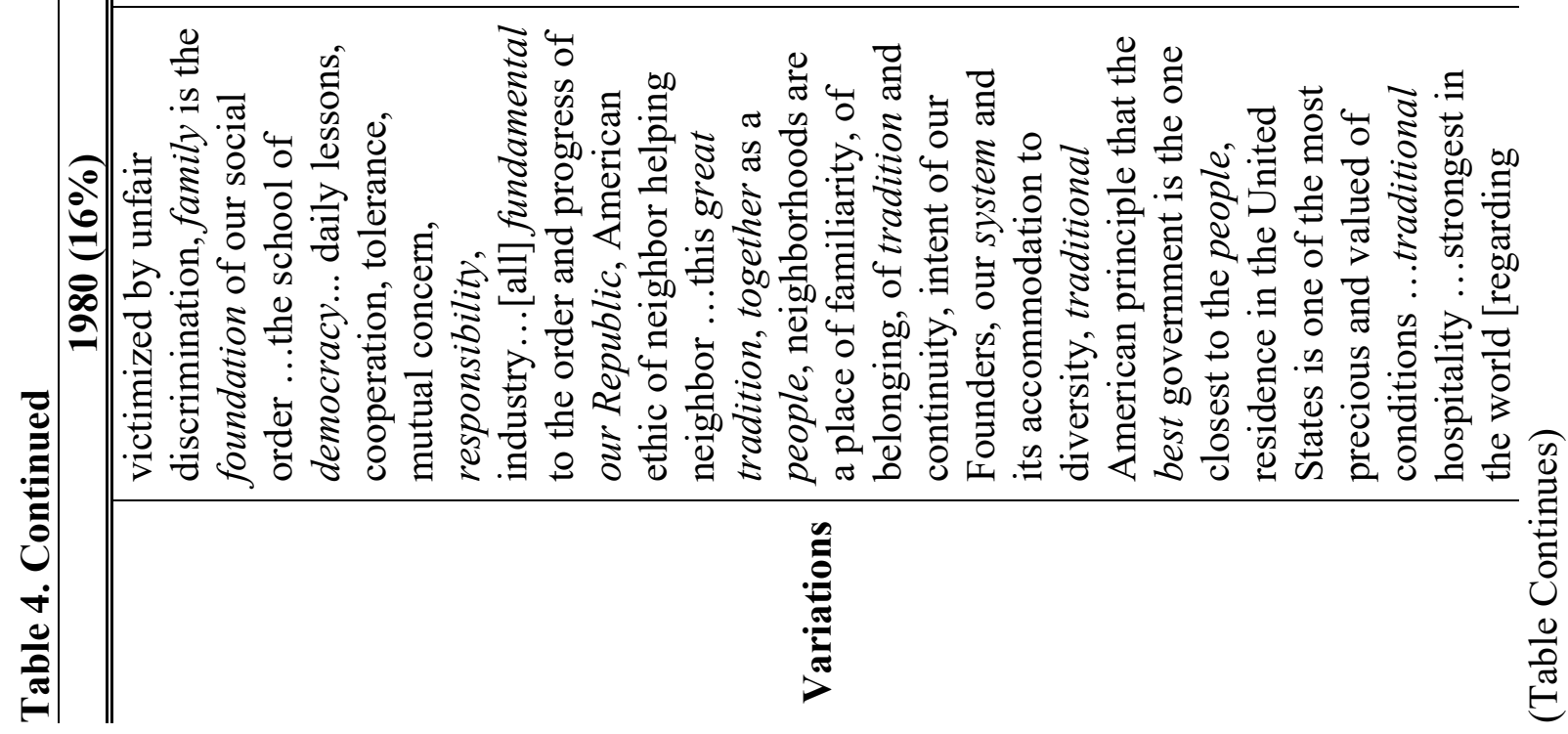




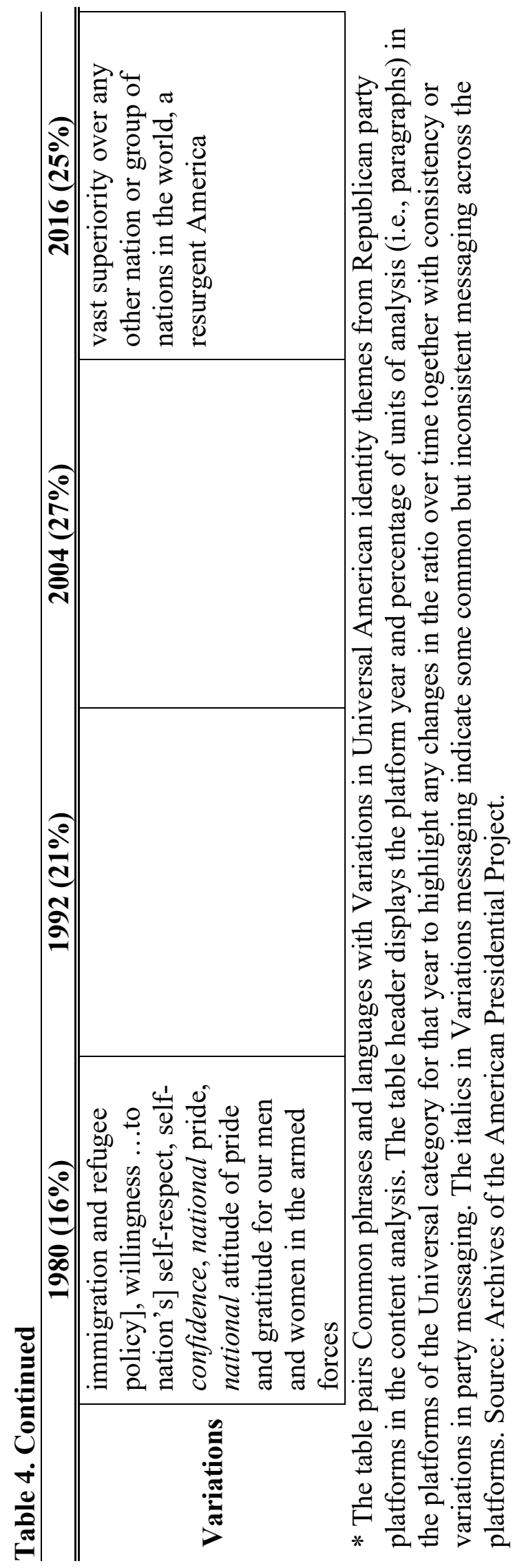


For example, the Republican party platform in 1980 roots a universal idea of American identity in "our republican form of government," in which power is local and freedom is the means to bolster the family, i.e., "the foundation of our social order." It affirms that American "truths we hold and values we share" include non-discrimination, "our free enterprise system" and "our sense of compassion and charity." They enshrine the "school of democracy" as part of American identity, including “cooperation," "tolerance," "mutual concern," "responsibility," and an accommodative system of diversity. The 1980 Republican party platform further refers to a "great tradition" as well as "continuity" of the American people. It underscores the "intent of our Founders" as a source of American values binding "the people." Ideas of an American dream are evident throughout the 1980 platform, from a government at its "best" when closest to the people to reiterating "neighborhoods" as places of "familiarity" and "belonging" as part of meaning in America. Its "free institutions" and "freedom" and "democracy" are all chief to the universal civic identity conception of America from the 1980 Republican party platform, together with local emphasis of neighborhood and family comprising American nation and social order.

By 1992, the content analysis finds little movement in Republican party appeals as a proportion of messaging with considerations of American identity, subgroup interests, or ideas of community belonging. Exceptions are the universal and neutral categories, where the former increases in proportion from $15.97 \%$ to $20.80 \%$, and the latter declines from $73.47 \%$ to $70.71 \%$. The ideological foundations to universal notions of American identity continue in the 1992 Republican party platform in its "commitment to individual freedom and market forces." It describes America as "an opportunity society" and as "the last best hope for man on earth," with its "purpose" in the "supremacy of an idea... [as well as] a common conception of how to make freedom work for all the nations." Its message of American identity pushes "hope, optimism, and 
opportunity." Such features bind Americans together in "preeminence," with its "strong families and strong communities," plus its "honesty," strength, and "democracy and free enterprise" in "limited government." The latter appeals to liberal democracy and free markets are more overt in contrast to the 1980 Republican party platform appeals to its ideological civic identity of American community in the universal category from the content analysis. Like the 1980 Republican party platform, a free market system and democratic government are prominent in 1992 universal themes of American community, except more stress to "American opportunity," economic liberty, and private property rights that altogether "safeguards for citizens everything of value" in the "free world." In 1992, the Republican party platform again highlights family as part of "truths the Nation keeps coming back to...the simple, spiritual truths." Moreover, it adds that American life has no place for "bigotry and prejudice." Indeed, the platform stresses that American life is about both equality of rights and "opportunity" to all.

In 2004, not unlike the Democratic party platform in the same year soon after the 2003 onset of the US-led invasion of Iraq, wartime patriotism in rhetoric from the Republican party is salient in the universal category according to findings in the content analysis. The 2004 Republican party platform appeals to "a country united and free" are similar to their Democratic party counterpart. Recurrent from earlier years are appeals to civic identity on the bases of America as "united by a common purpose," where "all people are guaranteed equal rights and opportunity to pursue their dreams." In context, the ideal of unity in common purpose is defense of "freedom at home and promoting it abroad." Republicans and Democrats each generally agree in their respective 2004 platforms on this sentiment. Furthermore, the 2004 Republican party platform notion of "American people" is one of "strengths," "results," "optimism," "opportunity" and "freedom." It repeats in slight variation from the 1992 Republican party platform in 2004 
that the "nation's cause has always been larger than our nation's defense," which includes "free and open societies on every continent" as a feature of "America's place and purpose in the world." This message of American resolve goes further to describe a 'nation' of values, and a calling "to make the world safer and better." In short, America's aims are pursuant to its "political and economic ideals... [of] open markets and open societies." The 2004 platform appeals to American destiny as a matter of bringing democracy together with "free trade to every corner of the world." Universal themes from Republican party platforms peak in 2004 for years in the sample (from $15.97 \%$ in 1980 to $20.80 \%$ in $1992,27.18 \%$ in 2004 then dropping slightly to $24.79 \%$ by 2016). In other words, the universal appeals to American identity in 2004 are much more prominent than hybrid $(5.82 \%)$ or identitarian $(3.16 \%)$ categories as a ratio of content in the Republican party platform. Still, both of the latter categories rise to peak levels by 2016 (respectively to $10.64 \%$ and $5.18 \%$ ) as neutral language and phrases follow a gradual decline (from $73.47 \%$ in $1980,70.71 \%$ in 1992 , and $63.84 \%$ in 2004 , to $59.38 \%$ by 2016 ).

Most recently for years in the content analysis, the 2016 Republican party platform reiterates a belief in "American exceptionalism" and limited government each as key to the “American Dream” in universal appeals to 'nation' or American identity. As a place "unlike any other nation on earth," it stresses the United States as serving a "historic role... as refuge, defender, and exemplar of liberty." It also repeats appeals to "limited government" in echoes to the 1980 Republican party platform's disparaging of “expanding federal power.” Moreover, in addition to the "hopes and aspirations" and "opportunity" of Americans, a key characteristic of the American people in the 2016 platform is "optimism." Through language of "making America great and united again," it steeps universal messages to American community in having "faith in the future." Like earlier years, it stresses an "American Dream" as a mutual expression of the 
people, which like past years includes "our principles of responsible and limited government," and "God-given" and "natural...inalienable rights" that ensure equality before law for all Americans. In a universal appeal comparable to that of 1992, the 2016 Republican party platform message proclaims to "denounce bigotry, racism, anti-Semitism, ethnic prejudice, and religious intolerance," and "oppose discrimination based on sex, religion, creed, disability, or national origin." It further emphasizes rule of law as foundational to the US republic, a government under the "consent of the American people." Indeed, the "people" are frequently subject of universal appeals in 2016, e.g., as "masters of government." The 2016 Republican party platform repeats ideas from past texts in the content analysis like American "preeminence," and stresses "integrity and preservation of the family unit." It also emphasizes universal appeals to American exceptionalism again through importance of "ideas and principles as a nation" in a form of civic identity for universal themes from 2016.

In short, universal appeals from Republican party platforms overall rise in prominence by 2016 (from $15.97 \%$ in 1980 to $24.79 \%$ of paragraph units of analysis by 2016), but peak in 2004 (27.18\%). As the universal language and phrases are somewhat consistent in the Republican party platforms for years in the 1980-2016 years in the content analysis, the messages grow more expansive over time with rising emphasis on a universal, civic identity ideal of American community and belonging. In 1980, the words "neighborhood" and "national" appear frequently. The "people" and "nation" are common in 1992. By 2004, "freedom" is recurrent next to American "nation," "values," and "people." The "nation" and limits on government are prominent by 2016. Republican party platforms maintain a tailored universal message that contrasts with Democratic party platforms, especially with emphasis on civic identity around 
freedom and democracy as "institutions holding our society together," above counterpart appeals to equality in "our nation's heritage" as a common theme in the 2016 Democratic party platform. Hybrid

Considering the 1980 Republican party platform message as a whole, hybrid as well as identitarian appeals may be implicit in a typical or majoritarian type of family from ostensibly universal messages like "traditional family values." However, this inference is circumstantial. For example, a central component to the 'nation' is in the 1980 platform's account of America as "steeped in Judeo-Christian ethic and in Anglo-Saxon theories of law and right." This appeal has a specific ethnic and religious-cultural origin story. Yet the platform goes on to qualify the message in ideas of a system of government over which power derives from "the people of multifarious heritage." In any case, hybrid themes in the 1980 Republican party platform, differ from later platforms, like those in the identitarian category in the content analysis.

Hybrid appeals from the 1980 Republican party platform tend to recite subgroups among "all Americans" as well as unity in common aspirations, e.g., for "blacks and whites," "women and men," "rural and urban," "ethnic," "cultural" and "regional diversity of our people," and so on. The 1980 Republican party platform stresses that the answer to economic issues for "black Americans" is the same for "all Americans," which includes "equality of rights for all citizens, regardless of race." It explicitly recognizes the Hispanic American population as a burgeoning minority group of Americans, and "one of the major pillars in our cultural, social, and economic life" within a proud heritage that enriches the "American melting pot." The 1980 Republican party platform also underscores that the values of Americans with "Eastern, Central, and Southern Europe[an]" and Asian-American heritage should no longer face neglect, i.e., given praise only in election years, and instead made an "integral part of government" (see Table 5). 


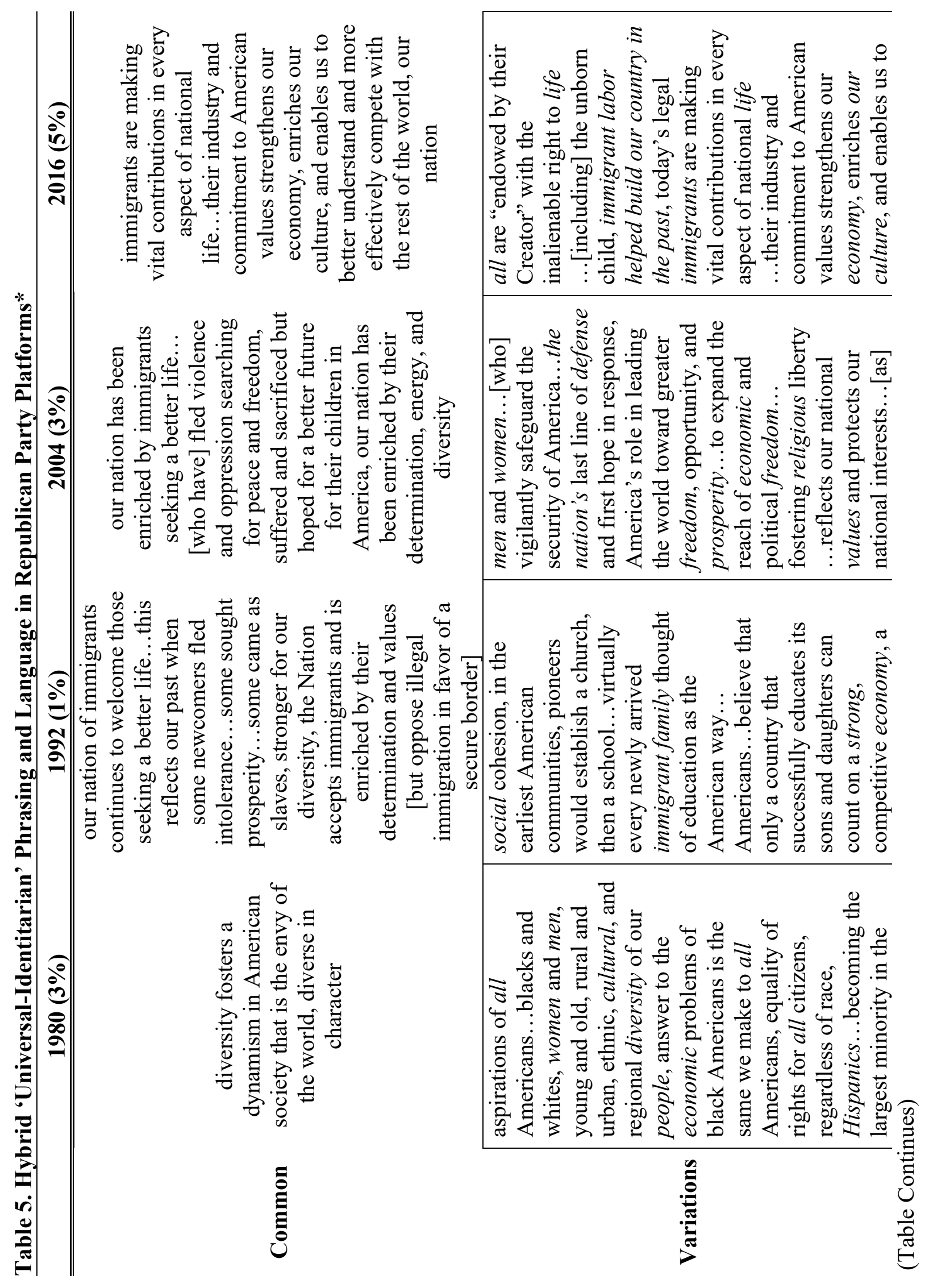




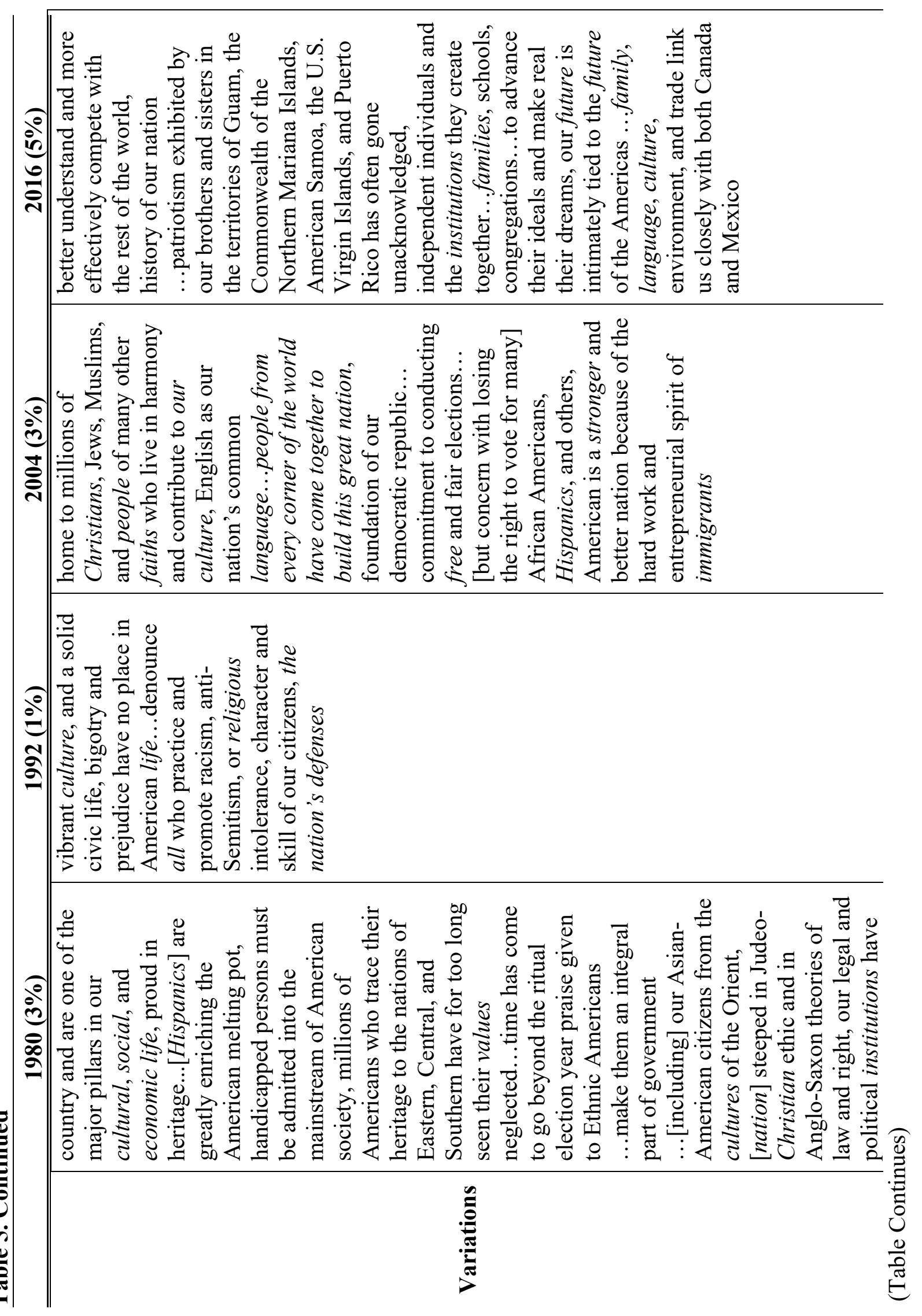




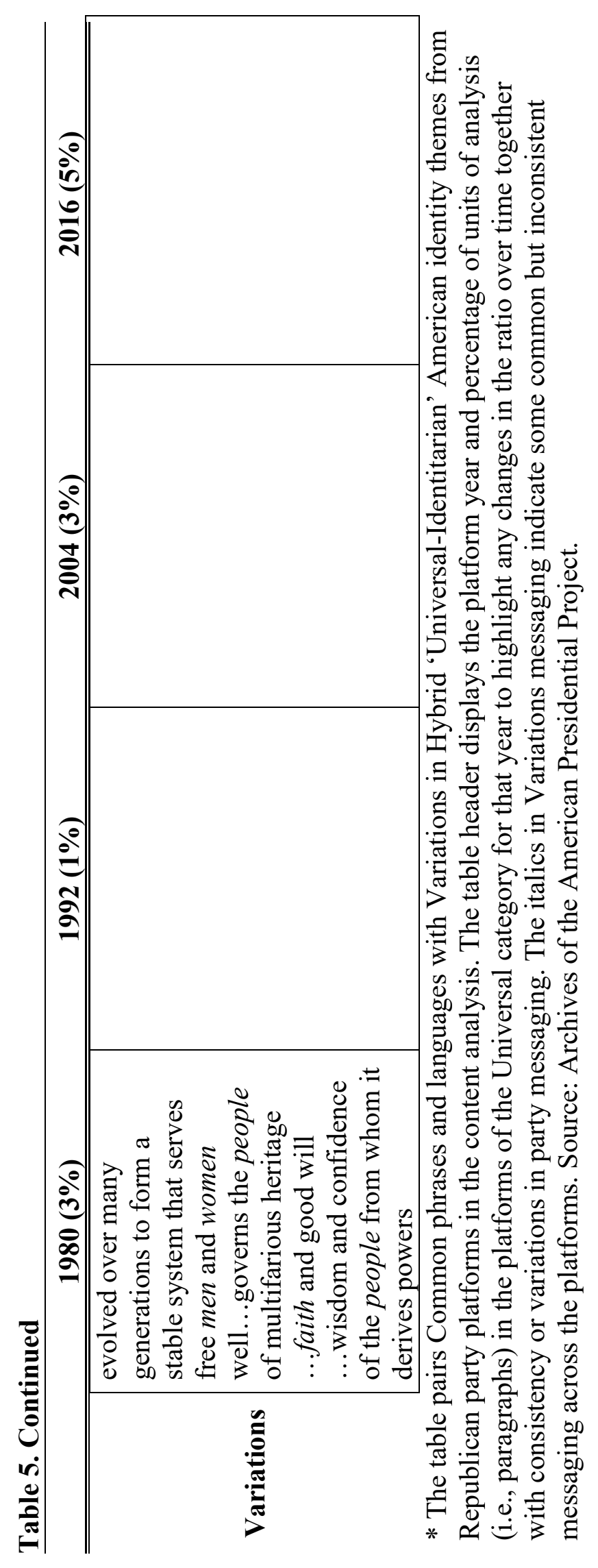


Themes in the hybrid category from the 1992 Republican party platform, again like that found in identitarian themes as later shown, have some modifications since 1980. For example, traditional "family" with "fathers and mothers in the home" are a "vital element of social cohesion." Hybrid messages, in general, are less prominent (down from $2.66 \%$ in 1980 to $1.45 \%$ by 1992). The 1992 Republican party platform no longer recites different subgroups of minority demographics in the de facto American community, who were subjects to hybrid as well as identitarian appeals in the 1980 platform. Still, hybrid wording and phrases in the 1992 Republican party platform continue appeals to "a vibrant culture," an America "stronger for our diversity," and an America as "a nation of immigrants [that] continues to welcome those seeking a better life." It repeats that American life rejects bigotry and prejudice.

By 2004, there is more salience in both hybrid and identitarian categories of messages in the Republican party platform to concerns of American identity, or whose interests and what values comprise 'we the people' of the United States. The hybrid themes in the 2004 Republican party platform largely reflect an American 'melting pot' mythology that highlights the role of immigrants in formation of the political community. For example, America is a story of how "our nation has been enriched by immigrants seeking a better life." Owing to their "determination, energy, and diversity," the "hard work and entrepreneurial spirit" of immigrants makes the American 'nation' stronger and better. In addition to universal wartime appeals, Republicans' 2004 platform celebrates American promotion of "freedom, opportunity, and prosperity" around the world because it reflects "our national values and protects our national interest...[as] home to millions of Christians, Jews, Muslims, and people of many other faiths who live in harmony and contribute to our culture.” The 2004 Republican party platform distinguishes English as the common language of America, adding that it is a nation built by 
"people [who have come together] from every corner of the world." It also raises some concerns over lost voting rights for many "African Americans, Hispanics and others" in appeals to America as a "democratic republic" committed to "free and fair elections." Hybrid language and phrasing in 1992 differs from 2004 such that there is no reciting of subgroups in the former, while there is some mix of it in 1980, which suggests some fluctuation in messaging.

Unlike in 1992, the 2004 Republican party platform makes hybrid appeals to minorities and various subgroups of Americans. In addition to earlier support for minority entrepreneurship, the 2004 Republican party platform presses the "goal of increasing the number of minority homeowners." Women are also more prominently the subject of appeals with respect to healthcare, particularly "our mothers, daughters, grandmothers, and granddaughters," whose needs are unique. The 2004 platform similarly rejects disparities in "health and health care based upon race, ethnicity, socio-economic status, or geography" as unacceptable. It "encourage[s] qualified minorities to enter the fields of science and medicine." More so than 1992, the cultural wedge issue of abortion continues in the 2004 Republican party platform. It declares opposition to "destruction of human embryos," which is more colorful language than the past. It likewise expresses defense of religious organizations and groups facing "barriers that have prevented... [them] from applying for government grants on an equal footing with secular organizations." It also appeals to end "discrimination against faith-based organizations." The 2004 Republican party platform further reiterates an extension of the "American dream" to Native Americans, in preservation of tribal governments, culture, and lands.

The hybrid category of universal-identitarian appeals from Republican platforms peaks in 2016 for years in the content analysis over the $1980-2016$ period. It is still relatively peripheral at $5.18 \%$, up from $2.66 \%$ of paragraph units of analysis in 1980 . Past language of a "melting pot" 
and of immigrants "enriching" the American nation shows rewording. The appeals are instead to "immigrant labor" for helping to "build our country in the past," and specifically to "today's legal [emphasis added] immigrants...[for] making vital contributions in every aspect of national life." The 2016 Republican party platform underscores that immigrants' "commitment to American values strengthens our economy, enriches our cultures, and enables us to better understand and more effectively compete with the rest of the world." Moreover, the cultural matter of abortion is again a feature of the Republican platform with hybrid appeals to "all," who are "endowed by their Creator" to the "right to life," which is to include "the unborn child." In other words, the 2016 Republican party platform frames abortion as a universal issue to safeguard life, while appealing to particular religious or cultural values against the practice. In contrast to past years in the content analysis, there is noticeably less emphasis from hybrid appeals as far as reciting subgroups and interests of American identity or community in the 2016 Republican party platform. As will be seen, the same is true of identitarian messaging from the party. By comparison, it is also much less weight than hybrid appeals in the Democratic party platform for the same year. The 2016 trends in hybrid messaging as far as expansive themes from Republican party platforms are somewhat comparable to dampening of such appeals in 1992, despite a higher ratio in total paragraphs. This pattern may result from declining space to neutral appeals ( $73.47 \%$ in $1980,70.71 \%$ in $1992,63.84 \%$ in 2004 , and $59.38 \%$ by 2016 ).

To summarize for hybrid appeals from the 1980-2016 period for years in the content analysis, common language of "diversity" as part of American identity evolves until it is not so explicit in language by 2016. In 1980, diversity is a value fostering "dynamism in American society," in 1992 for making America "stronger," and in 2004 for immigrants "seeking a better life... [to enrich America] by their determination, energy, and diversity." To be sure, the 2016 
message still appeals to immigrants as "making vital contributions in every aspect of national life,” including that “...their industry and commitment to American values strengthens our economy, enriches our culture, and enables us to better understand and compete more effectively with the rest of the world." Throughout all years except 1992, the Republican party platform messaging in the hybrid category of appeals recites subgroups in American identity or community in interests or belonging. Regardless, in the same year the party platform disavows "bigotry and prejudice" as having "no place in American life," and rejects "racism, antiSemitism, or religious intolerance." In 1980, the Republican party platform stresses an American "melting pot," while in 2004 it appeals to "people from every corner of the world" as having “come together to build this great nation." In 2016, it continues to appeal to people of the American territories. The words "people," "heritage," "women," and "nation" appear frequently in 1980. As for 1992, there is no distinct phrasing that appears more frequent than others in hybrid appeals. By 2004, "freedom," "nation," "values," and "American people” appear more so in hybrid language and phrasing. Then in 2016, the words "family," "culture," and "future" are frequent. The identitarian category further illuminates these changing messages over the 19802016 period for years in the content analysis. While hybrid messaging is relatively marginal across all years, peaking only at $5.18 \%$ by 2016 , the identitarian category is more prominent. It starts at $7.90 \%$ in 1980 and fluctuates down to $5.82 \%$ by 2004 , then peaks at $10.64 \%$ by 2016 in total paragraph units of analysis. The changes may signal rising partisan-identity contestation.

\section{Identitarian}

In the identitarian category of language and phrases, the 1980 Republican party platform makes particular appeals to subgroups. For example, it recites issue interests “...especially so for blacks and Hispanics," minorities, and women, from poverty and unemployment to new jobs and 
other opportunities. It similarly tailors a message to the "Hispanic community," which is an absent phrase in reference to subgroups for future platform years over the 1980-2016 period from the content analysis. As other patterns hint at some changes, the 1992 and 2016 platforms in fact completely skip any references to the word "Hispanic" altogether, while the 2004 platform is more similar to the 1980 messaging towards subgroups in this way. Otherwise in 1980 , the Republican party platform calls for "elimination of discrimination against women," and decries problems of an "America today...[where] especially women must be stressed."

Identitarian themes in the 1992 Republican party platform are distinct from Democratic party counterparts. Taking a turn from 1980, the 1992 messaging more intricately ties "traditional family" and "Judeo-Christian heritage that informs our culture" to the "American people." It stipulates that Americans are those who are "free men and women with faith in God," and that the ideal family is "built on...spiritual foundations." Rather than reciting subgroups in various appeals to interests or identity in the American community as it did in 1980, from "black Americans" to "Hispanics," the 1992 Republican party platform proclaims the American ideal according to the party as "color-blind" in distinction from Democrats. Some could argue this messaging may have better placement in the universal civic identity category. The 1992 Republican party platform from the identitarian category of the content analysis nevertheless presents an overall message in cultural-political contestation over partisan-identity ideals to American identity and community. For "our country's Judeo-Christian heritage" and in standing up for "family values," it asserts opposition to abortion, same-sex marriage, and pornography. It instead favors a set of "common moral values that bind us together as a nation." The 1992 Republican party platform further expresses a clear stance for "exclusion of homosexuals from the military as a matter of good order and discipline" (see Table 6). 


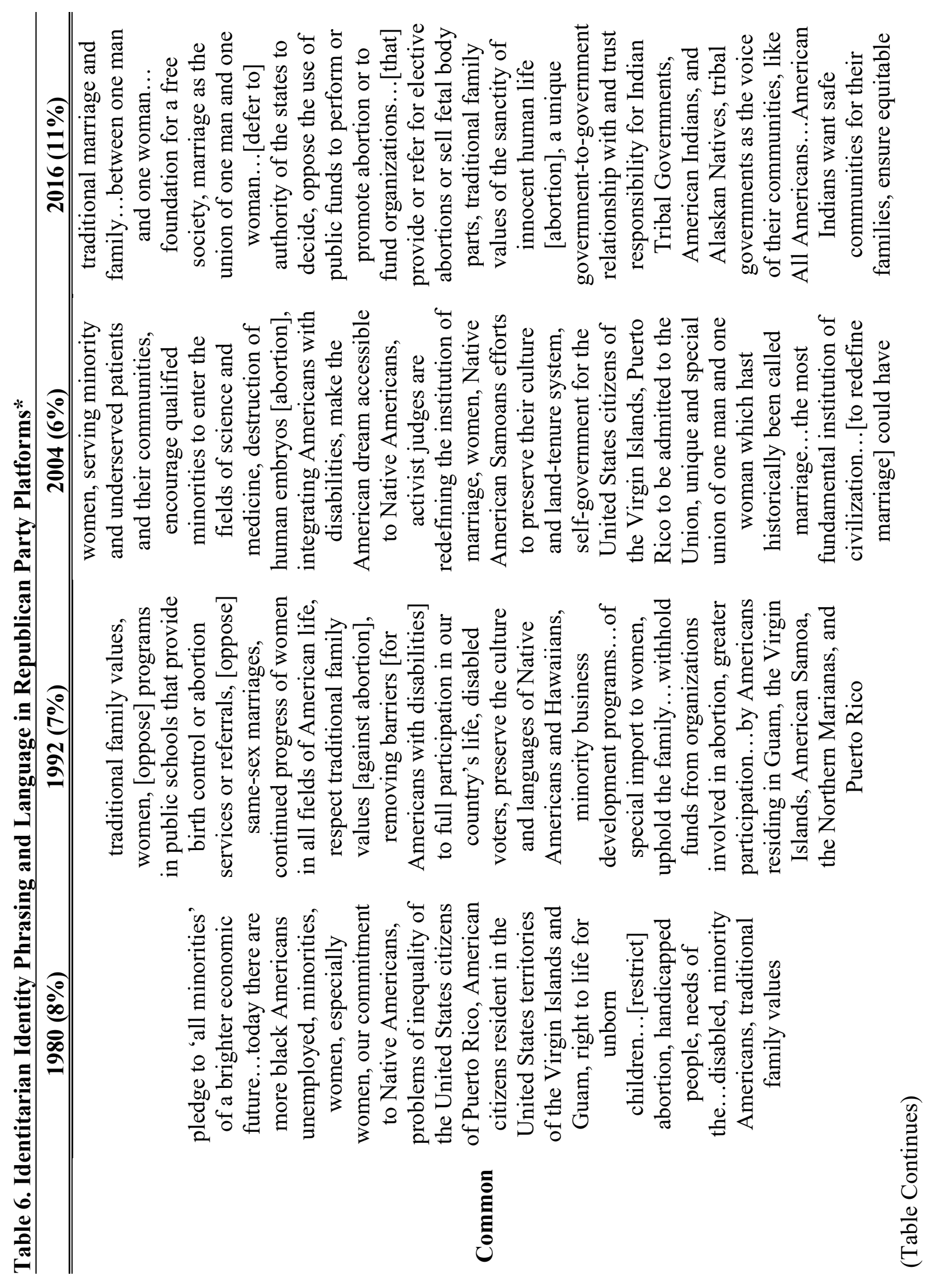




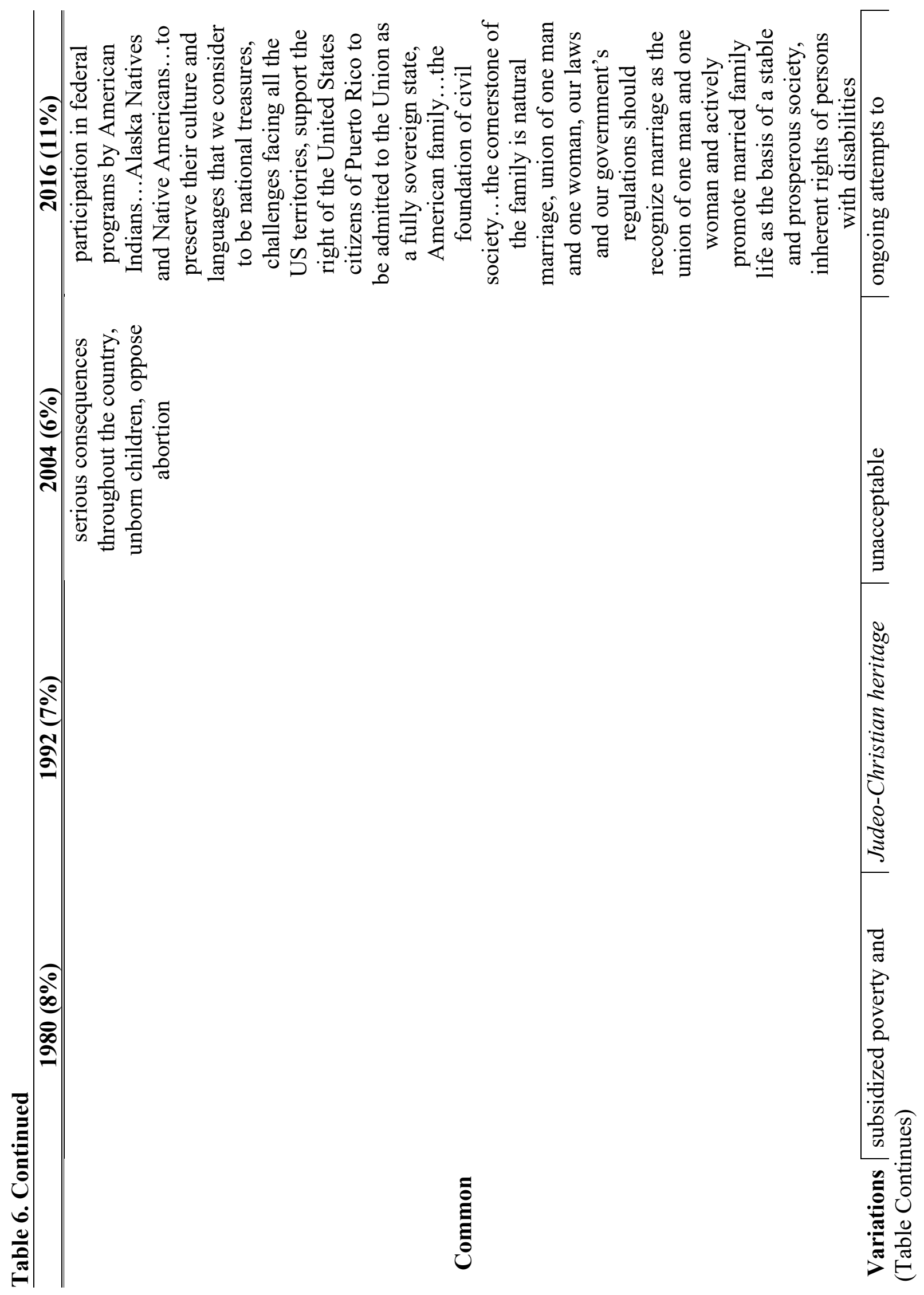




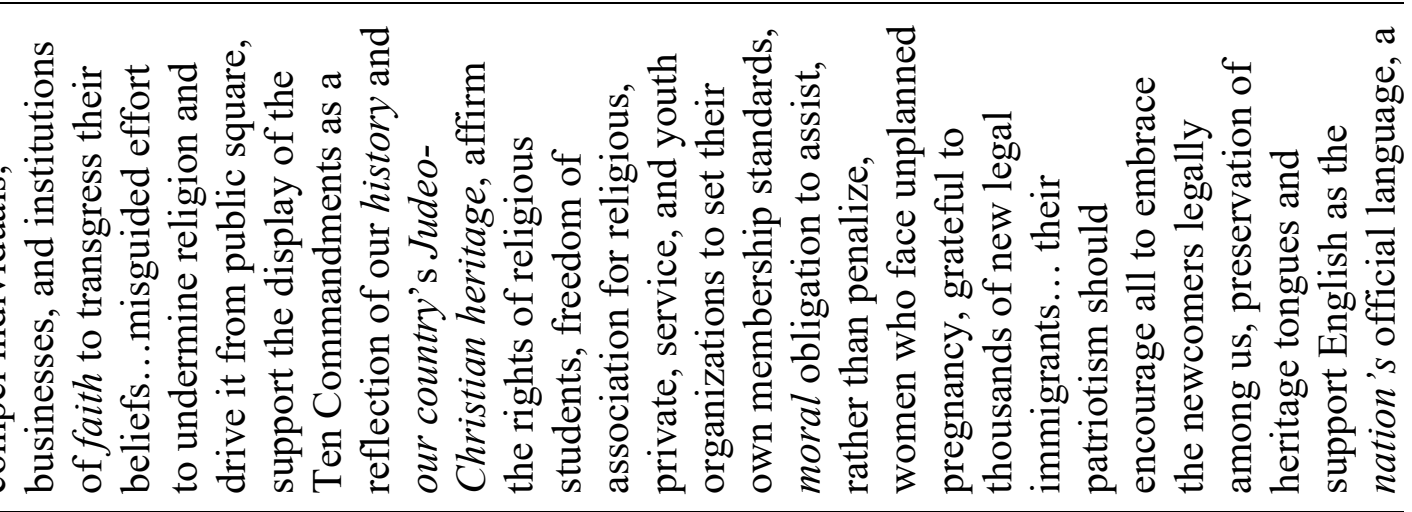

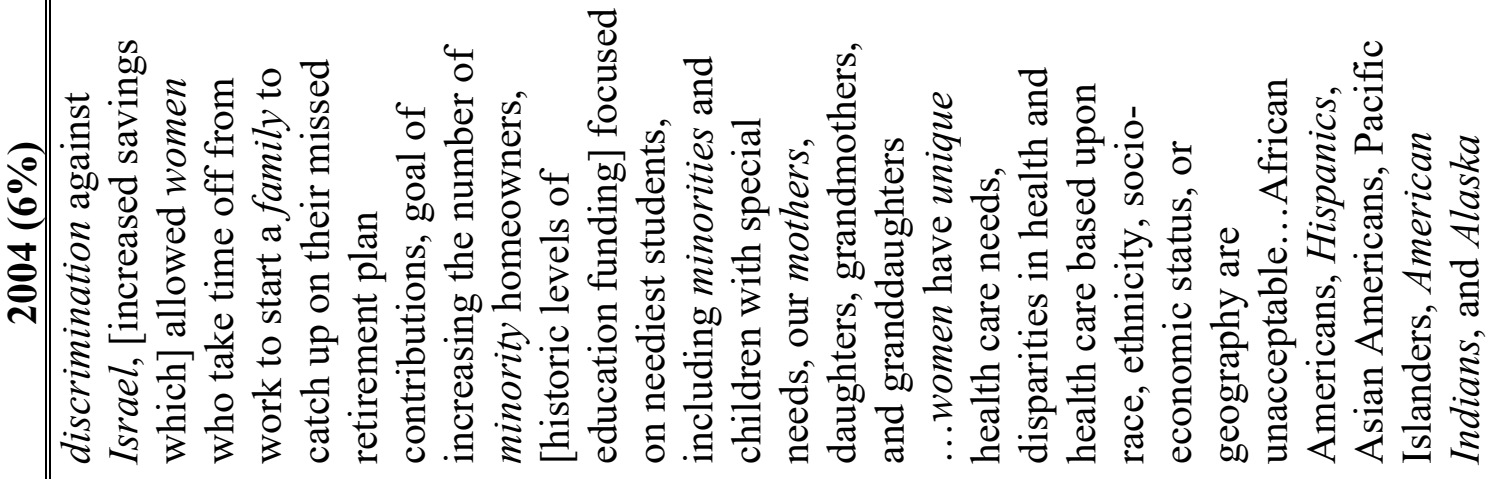

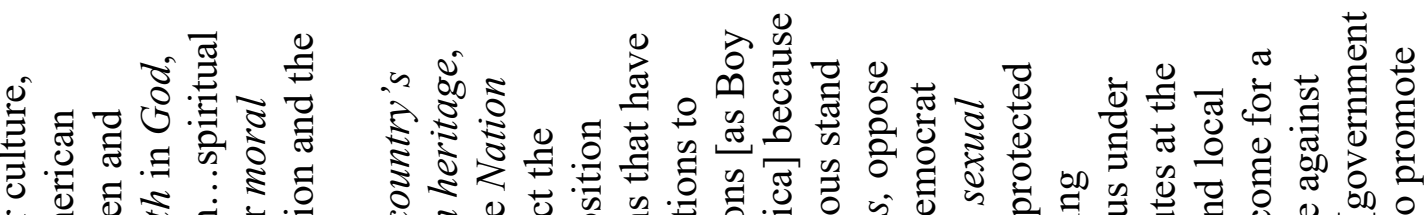

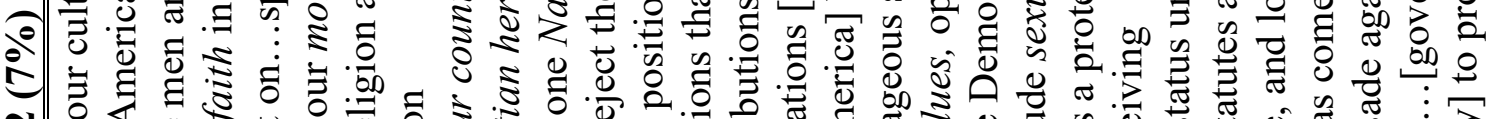
a

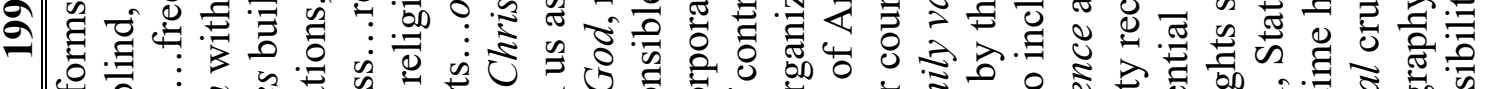

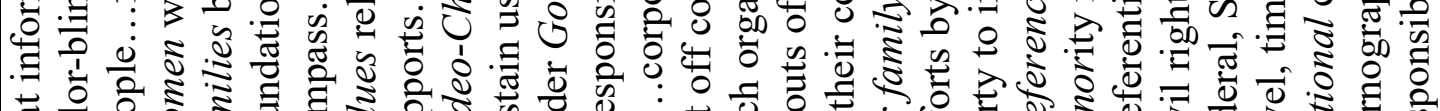

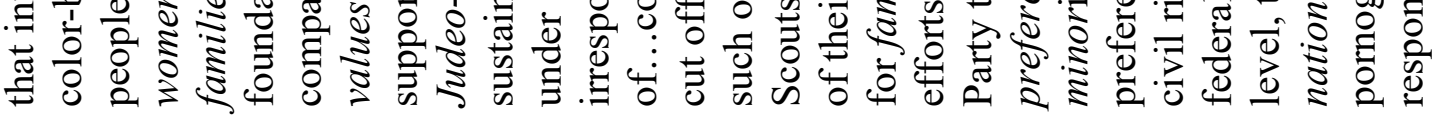

㤩焉

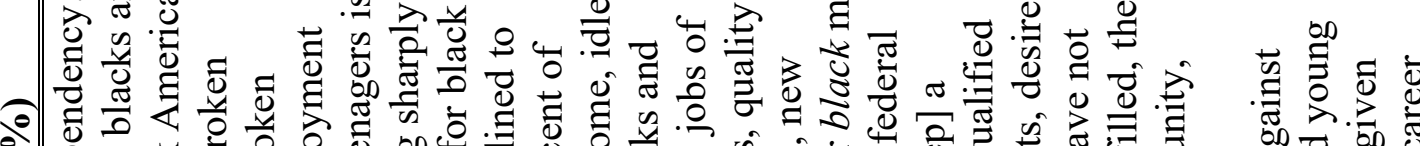

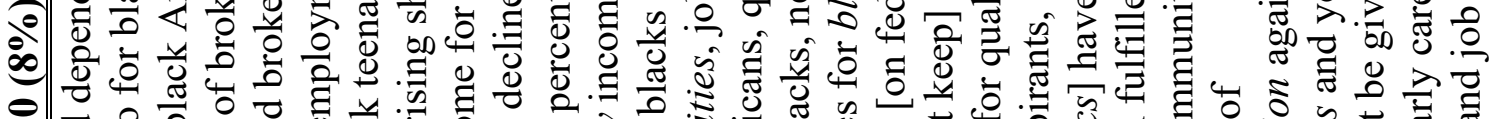

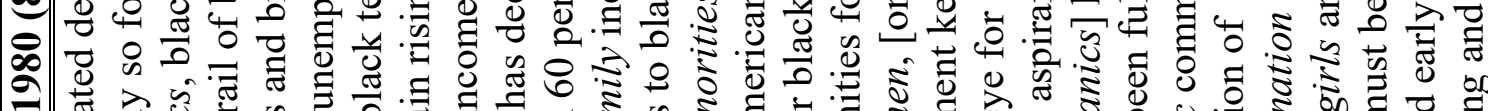

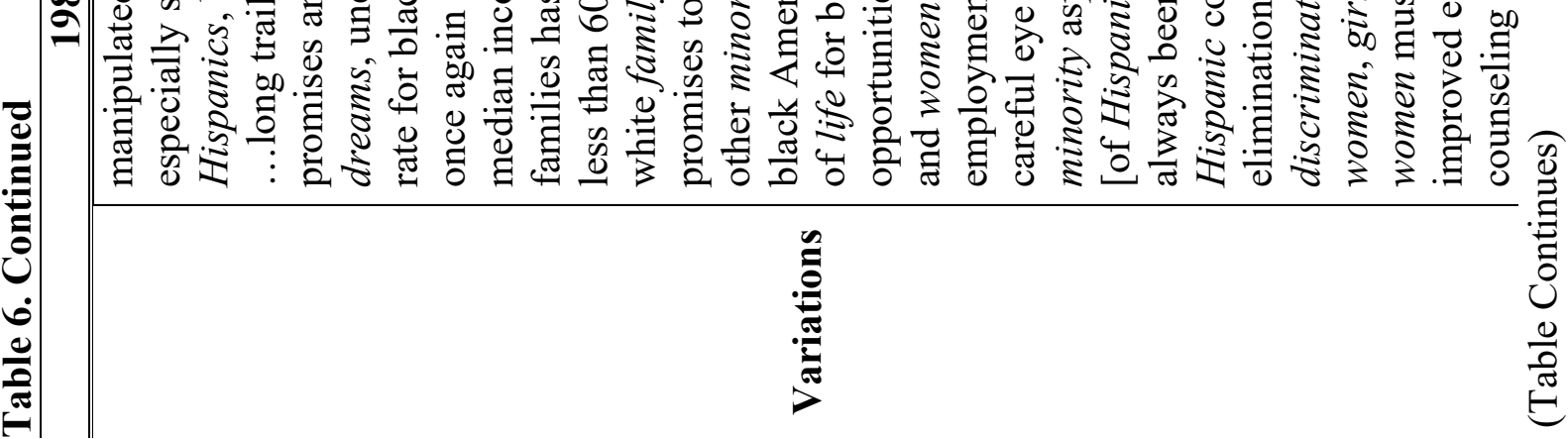




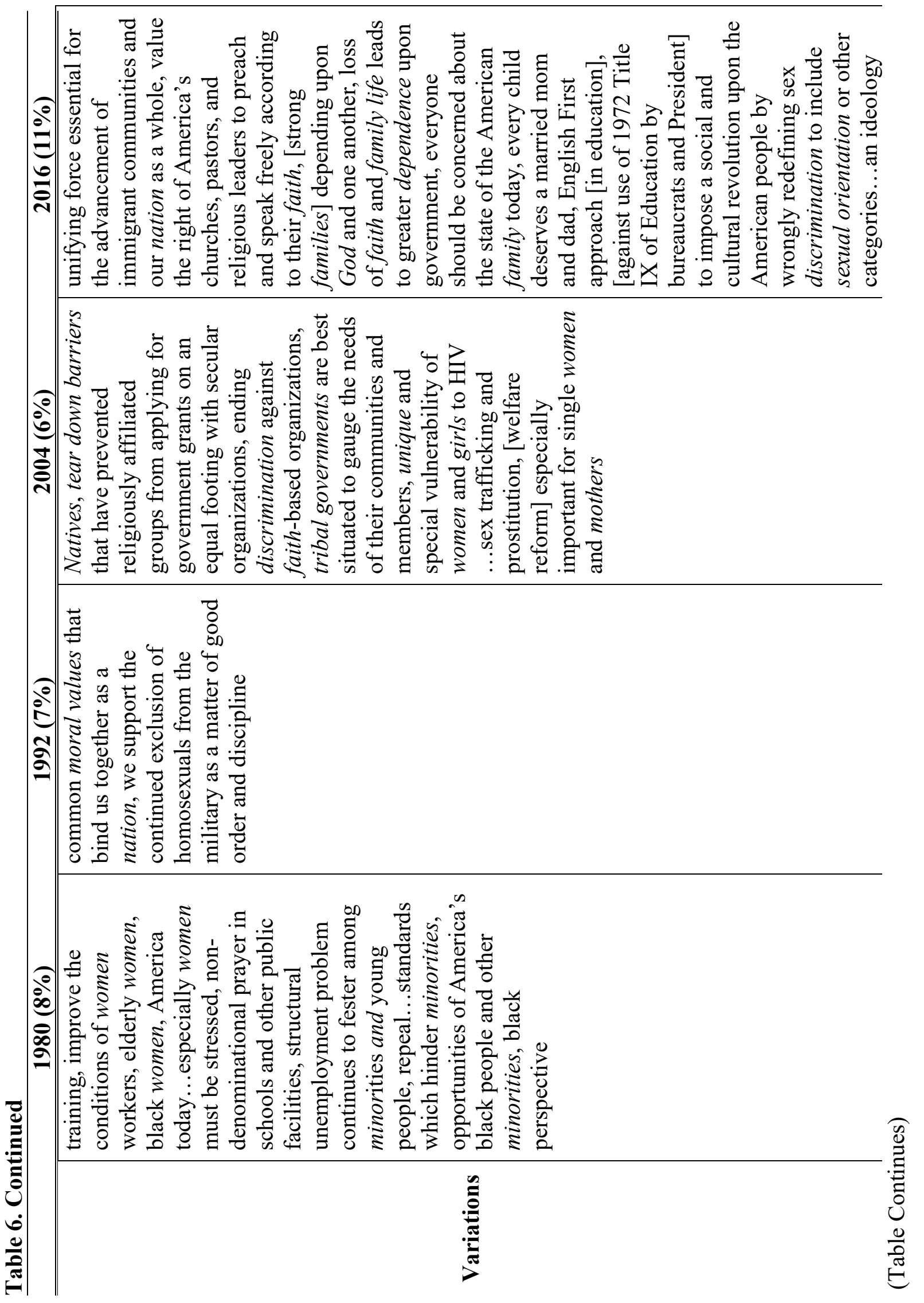




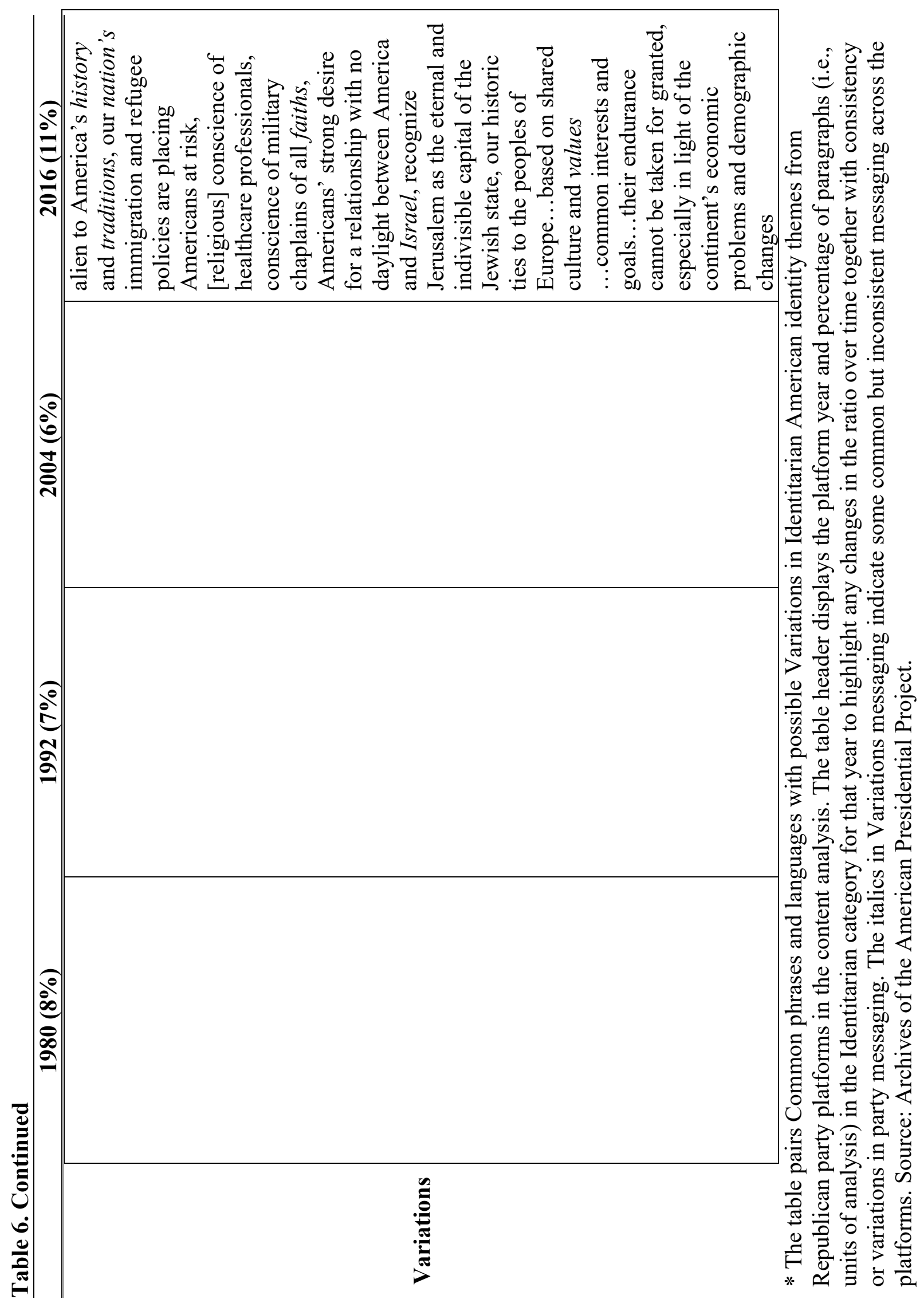


Among similarities in language and phrases from the Republican party platform in 1980, the 1992 platform speaks to subgroups to the extent of "continued progress of women in all fields of American life," because women "uphold the family." It also appeals to the subgroup of Americans with disabilities. It further makes distinct calls to preserve "culture and languages of Native Americans and Hawaiians." It supports business development programs targeted at minorities (in contrast to specifically "black" or "Hispanic" Americans like in 1980) and recites American territories insofar as interests of Americans residing among them and support for greater participation. The latter phrasing is common through 2016 for years in the content analysis, and the former messaging to "minorities" continues in 2004 but is absent by 2016, with subtle changes to subject matter in all. For example, the 2004 Republican party platform presents interests that correspond to "serving minority and underserved patients and their communities," in addition to variations like the "goal of increasing the number of minority homeowners." It also underscores the need to eliminate health care disparities "based upon race, ethnicity, socioeconomic status, or geography" because they "are unacceptable." These appeals around social disparities are more comparable to 2016 Democratic party platform messaging than that of the Republican party platform by 2016. Notably, this example shows a clear assimilationist or inclusionary distinction of identitarian appeals versus the Republicans' hegemonizing or exclusionary messaging around "Judeo-Christian" heritage or ethic.

While phrases more clearly defining the American community in identitarian appeals sharpen from 1980 to 1992, the 1992 Republican party platform maintains some space for appeals to minorities and women as a proportion of text. The language and phrases are still marginal by 1992, as the identitarian category of appeals in the content analysis from Republican party platforms dips slightly from $7.90 \%$ in 1980 to $7.05 \%$. This small change is comparable to 
the decline of hybrid appeals from $2.66 \%$ in 1980 to $1.45 \%$ by 1992 . However, neutral messaging from 1980 to 1992 platforms declines somewhat more from $73.47 \%$ to $70.71 \%$ over the same period that universal civic appeals show growth (from $15.97 \%$ to $20.80 \%$ ). The narratives to American identity and belonging also appear to be changing.

There may be fluctuating narratives from the identitarian category over the 1980-2016 period for years in the content analysis. In one clear example, any reference to American "JudeoChristian heritage" from the Republican party platform — to which it alludes in 1980 and expressly states in 1992 - is absent by 2004 . On the other hand, identitarian appeals from the 2004 Republican party platform claim staunch opposition to "discrimination against Israel." Like earlier years in the content analysis from the identitarian category, the 2004 Republican party platform continues its appeals to women. For example, it stresses support for family-oriented policies to help those who "take time off from work to start a family to catch up on their missed retirement plan contributions." Additionally, in combination with past positions, the 2004 platform rejects "activist judges" in America for "redefining the institution of marriage." There is similar messaging against same-sex marriage as in 1992, which is absent in 1980 among years in the content analysis. A change in historical understanding of marriage "could have serious consequences throughout the country," warns the 2004 Republican party platform. As will be seen, this phrasing and language towards sexual (as well as gender) identity becomes more salient in the Republican platform by 2016 for years in the content analysis. By this time, it also brings back the appeal to American "Judeo-Christian" roots.

Variations in Republican party platform messaging from 1980 and 1992 to 2004 may be an indicator of developing contestation over belonging and values in meaning of the American 'nation,' identity, or political community. In comparison, differing weight between the parties to 
neutral and particular subgroup interests or identitarian appeals is evident from the content analysis results in numbers. As a reminder, the 1980 Democratic party platform began with $78.70 \%$ in the neutral category, and the Republican party counterpart at $73.47 \%$ for total paragraph units of analysis. They respectively decline by 2004 to $56.62 \%$ and $63.84 \%$. In the same year, universal appeals peak in the Republican party platforms and remain at a relative highpoint among Democratic party platforms over the 1980-2016 period for years in the content analysis ( $\sim 27 \%$ and $\sim 34 \%$, respectively). Meanwhile, hybrid and identitarian categories of messaging seem in flux from 1980 until 2004, before ascending their highest point in proportion of platform paragraph units of analysis as evident by 2016 , and as neutral messaging continues in decline to its lowest point from both parties (i.e., [1] the identitarian category reflects $10.64 \%$ by 2016 in the Republican party platform, up from $7.90 \%$ in 1980, and $32.46 \%$ by 2016 in the Democratic party platform, up from $10.62 \%$ in 1980 ; [2] the hybrid category reflects $5.18 \%$ by 2016 in the Republican party platform, up from $2.66 \%$ in 1980, and $14.37 \%$ by 2016 in the Democratic party platform, up from $2.09 \%$ in 1980; [3] the neutral category reflects decline from $73.47 \%$ in 1980 to $59.38 \%$ by 2016 for the Republican party platform, and from $78.70 \%$ in 1980 to $36.57 \%$ by 2016 for the Democratic party platform; and [4] the universal category fluctuates in platforms over the years from both parties, from $15.97 \%$ in 1980 to $24.79 \%$ by 2016 for Republicans, and from $8.59 \%$ in 1980 to $16.60 \%$ for Democrats, with highpoints for each midway over the $1980-2016$ period, at $27.18 \%$ for Republicans in 2004 and at $34.18 \%$ for Democrats in 1992).

Like the Democratic party platforms, identitarian appeals pick up as a proportion of party messaging from the Republican party platform by 2016. It is clear in the extension of phrasing and language that the 2016 Republican party platform leans into cultural-identity messaging and 
issues trending in the direction of appeals to American subgroups and identity interests in matters of community and belonging. However, appeals contrast as less inclusionary (or more exclusionary) than the Democratic party counterpart in terms of the de facto American community with an increasingly multicultural and diversifying appeal to cultural and demographic characteristics. In other words, narrower appeals to the meaning and composition of American identity and values are more prominent by 2016 in the Republican party platform in comparison to earlier years in the content analysis. For example, the platform hones into "JudeoChristian heritage," support for the "traditional marriage and family...between one man and one woman," and defense of "faith" for businesses and institutions as well as sustaining religious presence in the American "public square." It further asserts party support for public display of the "Ten Commandments as a reflection of our history" and American heritage in Christian faith. Moreover, its defense of various religious freedoms is more conspicuous than prior years, including protecting religious speech, "conscience of healthcare professionals," and rights of churches. The 2016 Republican party platform also declares ardent objection to abortion, in favor instead of "traditional family values of the sanctity of innocent human life" in an appeal that more readily implies a narrower idea of American family than prior years in the content analysis. It distinguishes family tradition as built upon "natural marriage," or the "union of one man and one woman," in evidence of contestation over sexual orientation matters of American identity, community, and belonging., The 2016 Republican party platform laments that "dependence upon government" is certain without such a family life and faith.

Likewise, in their 2016 party platform Republicans stress that the "state of American family today" ought to be a universal concern. It is a concern that requires regulation to recognize "traditional" marriage and "actively promote married family life as the basis of a 
stable and prosperous society." Furthermore, the platform states clear opposition to imposition by the then-current Democrat administration of a "social and cultural revolution upon the American people by wrongly redefining sex discrimination to include sexual orientation or other categories." ${ }^{6}$ It opposes Democratic party efforts "to reshape our schools—and our entire society—to fit the mold of an ideology alien to America's history and traditions."

What was first evident by 2004 for years in the content analysis, the Republican party platform by 2016 most prominently among years in the content analysis for the 1980-2016 period underscores Israeli-American ties. It stresses that having "no daylight" between the United States and Israel is a "strong desire" of the American people. Such American values in the 2016 Republican party platform include embracing recognition of "Jerusalem as the eternal and indivisible capital of the Jewish state." In a symbolic political appeal, this messaging on US ties to Israel alludes to Judeo-Christian heritage and cultural significance to Americans from the Republican party perspective. Lastly, the 2016 Republican party platform distinctly draws on the American nation's "historic ties to the peoples of Europe," from culture and values to common interests and goals. In short, language and phrases from the 2016 Republican party platform in the identitarian category appeal to a narrower slice of the de facto increasingly multicultural and diverse American population and identity representation since 1980.

Still, like the past among years in the content analysis, the 2016 Republican party platform messaging maintains some weight in appeals to other subgroups. There are some similarities and additional variations. For example, the 2016 Republican party platform briefly appeals to American Indians, Alaska Natives and Native Americans in support of preserving "their culture and languages that we consider to be national treasures." It also appeals in small

\footnotetext{
${ }^{6}$ In June 2020, the United States Supreme Court incidentally ruled against Republicans on the issue Title IX protections for LGBTQ.
} 
part to citizens of the US territories for their patriotism, including to citizens of Puerto Rico in support for full recognition of their territory as an American state. These sorts of appeals are common over the 1980-2016 period for years in the content analysis. Moreover, 2016 platform appeals to "legal immigrants" and "newcomers legally among us" are messages that continue to stress American control over national borders for determining who is welcome to join the political community. The 2016 platform phrasing of "legal immigration" is consistent with messaging against "illegal aliens" in 2004, support for immigrants except for "[i]llegal entry" in 1992, and party opposition to aid for "illegal aliens" in 1980. In general, the 2016 Republican party platform message that "America's immigration policy must serve national interest of the United States" is also consistent with the 1980 platform message that "United States immigration and refugee policy must reflect the interests of our national security and economic well-being." In a similar way, the 1992 Republican party platform opposes "illegal entrants" as undermining "the social compact on which immigration is based." Likewise, the 2004 Republican party platform states that immigration must be "structured to address the needs of national security." However, there is a qualifying message around immigration in support of diversity specifically for fostering "dynamism in American society that is the envy of the world" (1980), for making America "stronger" (1992), or as "a source of strength" (2004) in all years except 2016 over the 1980-2016 period for years in the content analysis. The word "diversity" is notably absent from the 2016 Republican party platform in any such context (i.e., except unrelatedly in reference to financial markets). The 2016 Republican party platform nevertheless concludes its immigration message by describing America as "[f]rom its beginning... a haven of refuge and asylum." Yet it goes on to qualify this practice "should continue_-but with major changes," limiting the practice to "political, ethnic or religious persecution" as a matter of national security. As a further 
message to immigrant subgroups, not unlike earlier years in Republican party platforms-i.e., for all but 1992 for years in this content analysis - the 2016 Republican party platform reiterates support for "English as the nation's official language." It stresses that English is a "unifying force essential for the advancement of immigrant communities and our nation as a whole," while encouraging "preservation of heritage tongues" in an appeal to the "legal immigrants" for which it is "thankful."

Frequent phrases from the identitarian category of the content analysis from the 1980 Republican party platform consist of women, minority, black American, jobs, and Hispanic. By 1992, phrases shift in frequency with focus of identitarian appeals to recurrent language of women and minorities, albeit bringing Christian heritage, God, family, religion, and nation to the fore. The high-frequency words in 2004 show additional fluctuation in identitarian messaging over the years for Republican party platforms as women, health, mother, and discrimination are frequent. Lastly, recurrent words from the 2016 Republican party platform are faith, nation, and values, without mention to racial categories of past Republican party platforms over the 19802016 period for years in the content analysis. These shifting themes in phrases and language from Republican party platform messaging tend to correspond to trendlines from content analysis results in numbers (i.e., [1] steady decline in neutral messaging from $73.47 \%$ in $1980,70.71 \%$ in 1992 , and $63.84 \%$ in 2004 , to $59.38 \%$ by 2016 ; [2] steady increase in universal messaging from $15.97 \%$ in $1980,20.80 \%$ in 1992 , and $27.18 \%$ in 2004 , before levelling out at $24.79 \%$ in 2016 ; [3] a variable uptick in identitarian messaging from $7.90 \%$ in $1980,7.05 \%$ in $1992,5.82 \%$ in 2004, and peaking at $10.64 \%$ in 2016; and [4] a variable rise in hybrid messaging from $2.66 \%$ in $1980,1.45 \%$ in $1992,3.16 \%$ in 2004 , and peak at $5.18 \%$ by 2016$)$. Like Democratic party 
counterparts, the Republican party platforms generally expand on messages of American identity, community, and belonging over the 1980-2016 period for years in the content analysis.

In all, the Republican party platform seems to sharpen a consistent message to historical majoritarian appeals as far as American identity and (sub)group appeals by 2016. While its universal themes correspond to a civic identity notion of American nation, community and belonging, the hybrid and identitarian themes are somewhat consistent but expand over the years on particular cultural and religious orientations of American identity. Features of the latter categories consist of "Judeo-Christian heritage" and "traditional marriage and family...between one man and one woman." At the same time, these Republican party platform trends increasingly contrast with those of the Democratic party. The latter shows expansion in identitarian appeals to minority subgroups including in its universal appeals that differ from civic notions of American identity from Republican party platforms through reciting various narrower identity categories. The former maintains a civic identity message of American values in universal appeals, such as recurrent language of "optimism," equal rights before law, and "hopes and aspirations" of "the people" or "nation." Furthermore, the 1980, 1992, 2004, and 2016 Republican party platforms all reject discrimination as a feature of American appeals. The 2016 Democratic party platform is increasingly distinct in this messaging from the Republican party platform. It emphasizes various forms of minority inclusion, and features phrasing against "systemic racism," as the latter omits "diversity" in any such context by 2016 for the first time over the 1980-2016 period for years in the content analysis. The Republican party platform nevertheless shows consistency over the years in underlying narratives with growing salience to universal, hybrid, and identitarian appeals. For example, the language and phrases against "illegal" immigration in favor of a 
system in the national interest is common from 1980, 1992, 2004, and 2016 Republican party platforms.

As identitarian appeals are highest in 2016, Republican party platform messaging expands in similar ways that correspond to the Democratic party platform changes over the same period. This trend is similar to corresponding rises from both parties in the hybrid category. The universal categories for each party are more variable with fluctuations over the years, but likewise follow the trend in rising prominence and expansive language and phrases. In short, the content analysis suggests Republican and Democratic party platforms are each giving more weight to partisan-identity appeals. Each party appears to hone its message over the 1980-2016 period for years in the content analysis to different poles of values, 'nation,' or belonging in an increasingly salient ideal of American community. Whereas the Democratic party platforms most of all in 2016 emphasize "diversity" and issues of "systemic racism," the Republican party platforms particularly stress "traditional” American values and ideas of belonging.

\section{Deepening Partisan-Identity Polarization in Democratic and Republican Party Platforms}

There are two key findings from the content analysis of Democratic and Republican party platforms in support of the theoretical approach in this thesis to the issue of 'pernicious' or severe partisan polarization. First, there are changing ratios of messaging from both major parties towards a combination of universal or narrower conceptions of identity interests over the span of 1980, 1992, 2004, and 2016 platforms, accounting for every three election years in the 19802016 period, or every twelve calendar years. Crucially, the neutral category of platform messaging shows clear decline from both parties' formal presidential election year platforms. Neutral messaging for both parties' platforms was highest in 1980. The Democratic party platforms show decline in proportion of paragraph units of analysis from $78.70 \%$ in 1980 , 
$58.16 \%$ in $1992,56.62 \%$ in 2004 , and $36.57 \%$ by 2016 . They diminish with more intensity over the years than Republican party platforms. By comparison, the latter declines under the same measure from $73.47 \%$ in $1980,70.71 \%$ in $1992,63.84 \%$ in 2004 , and $59.38 \%$ by 2016 .

Furthermore, from both Democratic and Republican party platforms, the identitarian and hybrid categories of American identity appeals are highest by 2016 for the 1980-2016 period for years in the content analysis (i.e., [1] from $10.62 \%$ in 1980 to $32.46 \%$ by 2016 for identitarian text, and from $2.09 \%$ in 1980 to $14.37 \%$ by 2016 for hybrid text for the Democratic party platforms; and [2] from $7.90 \%$ in 1980 to $10.64 \%$ by 2016 for identitarian text, and from $2.66 \%$ in 1980 to $5.18 \%$ by 2016 for hybrid text for the Republican party platforms).

Secondly, the content analysis finds increasingly contrasting partisan-identity messages in a deepening polarization between Democratic and Republican party platforms. In other words, the two major parties' narratives on American identity concerns are increasingly prominent while diverging on universal, identitarian, and hybrid themes. For instance, Republican party platforms consistently emphasize universal appeals to a civic form of American identity, in tandem with a narrower conception of the American community. The Republican party platforms, most notably by 2016, appeal to a historical majoritarian idea of what it means to be American by featuring Judeo-Christian heritage and a traditional or conservative American culture around family, as well as ideals of sexual identity in marriage and gender issues in American social life. In the de facto increasingly diverse and multicultural American population or 'community' over the 19802016 period for years in the content analysis, the Republican party platform thereby increasingly underscores a narrower slice of the American polity. By contrast, again most notably by 2016, the Democratic party platforms increasingly appeal to a pluralistic message that recites various subgroups in minority inclusion, as well as opposition to American "systemic racism" it claims 
the country must redress. The Democratic party platforms are relatively consistent in narratives of "diversity" and American identity, except for 1992 where hybrid and identitarian messaging were at low points for the $1980-2016$ period for years in the content analysis $(4.59 \%$ compared to $14.37 \%$ by 2016 for the former, and $3.06 \%$ compared to $32.46 \%$ by 2016 for the latter). For Democratic party platforms, it is the expansiveness of these notions of identity and subgroup interests that are most evident from the content analysis, with an extensive array of language and phrases in American identity appeals especially in the identitarian category by 2016. Both major parties may consequently be trending to narrower and conflicting subgroup appeals to American identity, community, and belonging in their respective platforms over the 1980-2016 period based on years in the content analysis.

Briefly, the Democratic party across all years in the content analysis maintains a generally inclusive message in party platforms albeit increasingly enumerating differences of political interests and identity among subgroups in the de facto American community. By contrast, the Republican party directs a more exclusive idea on American community around “traditional” American 'nation' or identity considerations. While such partisan-identity themes from Republican party platforms are earlier apparent in 1992 for years in the content analysis, they appear less salient in 1980 and 2004 party platforms, then show prominently by 2016 . The Republican party platforms seem to increasingly reproduce a historical majoritarian appeal on religious-cultural or ethnic identity lines, whereas Democratic party platforms increasingly contest the meaning of 'American' in more identitarian albeit inclusive in a multicultural sense of community and belonging.

Accordingly, the findings are suggestive of a deepening trend in polarizing dynamics on partisan-identity lines in American politics from the two major American parties. They further 
support arguments that a 'formative rift' dynamic involving state identity and belonging as well as grievances around race and culture may serve an important role in severe party polarization in the United States case. The issue of partisanship is vast. Potential consequences may vary from 'pernicious,' or deep divisions spilling into ordinary and social life, to useful by occasionally generative and participatory pathways for democracies. By engaging the issue of partisanship through content analysis of major party platforms, this thesis informs in small part what could be relevant to US trends in severe partisanship and challenges for the liberal democratic regime. 


\section{CHAPTER IV: CONCLUSION}

This thesis has addressed the issue of partisan-identity polarization in the United States through examination of Democratic and Republican party platforms from 1980-2016 in an extensive content analysis. Its main goal was an empirical test of claims that partisanship on identity lines has been increasing in American politics in recent decades. The results offer support for such claims. As a key issue facing democracies today, polarization has coincided with challenges for democratic governance. Accordingly, partisan-identity dynamics in the US may be worthwhile to further explore and clarify implications for democratic erosion.

It was first important for this thesis to address why partisan-identity polarization matters. In brief recap, the issue of partisanship is foremost a matter of party identification and thereby loyalty to a political bloc, making it a key motivating factor in political participation, voter behavior, and activism. Its dynamics continue to influence both elite and mass political ideals and behavior in American politics. Elites play a key role in driving partisan polarization largely by mobilizing popular support in partisan appeals to secure power. In severe cases of partisanship or 'pernicious' polarization, these dynamics may cross-cut into social life and feature a mutually exclusive division of politicized identity and interests between groups within the polity. Political lines between once legitimate democratic opponents may harden to enemies, unworthy and contemptable as adversaries, nor even acceptable as family and friends, which could threaten social cohesion and ultimately democratic function. For example, consider an earlier finding that Levitsky and Ziblatt's (2018) highlight in their book How Democracies Die:

In 1960, political scientists asked Americans how they would feel if their child married someone who identified with another political party. Four percent of Democrats and five percent of Republicans reported they would be "displeased." In 2010, by contrast, 33 percent of Democrats and 49 percent of Republicans reported feeling "somewhat or very unhappy" at the prospect of interparty marriage. Being a Democrat or a Republican has become not just a partisan affiliation but an identity. 
Within these tensions, it may still be possible for these severe cases in partisanship to generate democratic development. For example, new checks and balances may develop from tensions of polarization in mutual distrust; political grievances over oppression may fuel a movement or create space for democratic reforms. Conversely, opposing elites and loyal supporters in severe polarization may pursue bending rules to their favor in a de-democratizing or deconsolidating effect for the regime. Partisan-identity divisions may reach a point of rigid intolerance and seemingly irreconcilable difference. These dynamics could degrade political stability under polarizing conditions and generate a ratchet response of 'autocratizing tendencies' between alternating blocs. Importantly, cases of severe partisanship featuring a 'formative' or 'existential' rift on ideas of national belonging may fuel democratic erosion through sustained and pernicious polarization that seems intractable to resolve.

Against this context, the thesis unpacked its content analysis over the US case in a thorough assessment of partisan messaging by tracing party platform devotion to universal, identitarian, or hybrid universal-identitarian appeals in numerical proportions of paragraphs in the texts and key words and phrases over the 1980-2016 period. In short, Democratic party platforms are increasingly emphasizing pluralism around various forms of minority inclusion and multiculturalism while against "systemic racism" in appeals to American nation or community. In a divergent partisan message, Republican party platforms have given increasing weight in messaging to historical majoritarian appeals but maintain a universal ideal of equal rights before law. Over time, they reinforce a historical majoritarian understanding of American identity, moral and group interests. Consequently, the two parties' platforms for years in the 1980-2016 period of the content analysis suggest a deepening partisan-identity polarization in American politics. Both parties' platforms show neutral messaging that is agnostic to partisan-identity 
appeals at peak starting in 1980, with clear patterns of decline across all years in the analysis and then lowest by 2016. Changing proportions are more intense from Democratic party platforms in comparison to Republican party platforms (i.e., decline from $78.70 \%$ in 1980 to $36.57 \%$ by 2016 , and from $73.47 \%$ in 1980 to $59.38 \%$ in 2016 , respectively). An explanation for this pattern may be that the meaning of texts differs under varying social and political contexts, which could make for variations in the content analysis. For instance, it is possible that "neutral" messaging from Republican party platforms may truly reflect historical majoritarian appeals of the party's distinct partisan-identity politics, albeit in an implicit and therefore ostensibly neutral frame. Then again, both parties' platforms peak for identitarian and hybrid categories of partisan-identity appeals by 2016. It may be that the Democratic party platform peaked for both categories in 2016 at higher proportions than the Republican party platform (i.e., $32.46 \%$ versus $10.64 \%$ identitarian, and $14.37 \%$ versus $5.18 \%$ hybrid, respectively) as a reflection of the party with America's first woman presidential candidate in history elevating partisan-identity contrasts against a dramatically different and uniquely brash Republican opponent. The aggregate data variability does not preclude the possibility that political differences in different contexts could drive such percentage variations in the texts. Still, the fact that Donald Trump won the 2016 Republican party presidential primary handily with $46.5 \%$ of the vote suggests his candidacy may be representative of Republican voters' preferred form of partisanship. The $2^{\text {nd }}$-place Republican presidential primary candidate, Ted Cruz, received only $27 \%$ of the vote. By comparison, the 2016 Democratic presidential candidate Hillary Clinton won a more closely contested primary with $52.8 \%$ of the vote against Bernie Sanders, who lost with $41.4 \%$ of primary voter support. The content analysis of Democratic and Republican party platforms nevertheless suggests there is a growing rift on partisan-identity lines of polarization between the parties. It demonstrates 
increasing emphasis in recent decades from both major party platforms on matters of 'nation' and belonging in the American community. Consequently, as the US case features a 'formative' or 'existential' rift around race and culture, these findings could be troublesome for the liberal democratic regime under 'pernicious' or severe partisan polarization.

The future of American politics is obviously an unknown, as one cannot predict the future. Theoretical implications from the findings of this thesis, which suggest possible 'pernicious' polarization in the US case, offer some ideas for paths ahead for democratic governance. It could be that hardening political lines make it more clear for masses to choose representatives as distinct among political choices. This result could arguably be democracyenhancing. For example, highly partisan voters may be more likely to participate in politics, more prudent in their political choices, more inclined to behave coherently as partisans in pursuit of a unified policy agenda with less ticket splitting, and more likely to have representatives who reflect their views. Thus, it could be a boon for democratic constituents to choose candidates between Democrats or Republicans. It is important to note, however, that stronger partisan identities could also lead the opposite direction in terms of democratic function, i.e., if voters are becoming less informed, more dogmatic, and much more inflexible and intolerant in their views as partisan-identity devotees despite all evidence before them. On the other hand, there may also be greater political activism and voter turnout in the US under dynamics of severe partisanidentity polarization. Both behaviors are at historic highs in recent decades; the 2020 presidential election was the highest turnout since the 1960s. On a similar note, sustained conditions of severe partisan-identity polarization may also motivate political elites to improve the political system and encourage voter turnout. The polarization could also influence mass mobilization to hold political power to account should one party overstep democratic rule. One such example 
may be the Women's March on Washington on the day after Trump's inauguration. Mass protests in the US Capitol and around the world emphasized reproduction, immigration, and civil rights issues against fears over the new administration's actions once in office.

Still, it may be realistic to expect severe partisanship involving state identity and belonging to be more enduring in 'pernicious' intergroup disputes and therefore difficult to resolve. Political rivals in the Democratic and Republican parties, as well as trickling into social life, could turn from banal democratic opponents to strident enemies. This dichotomy of partisan tribes may come to experience alternate realities in politics and ordinary life. Politics may increasingly become a moralistic concern of "good" and "evil," or "us and "them" between divergent value systems of partisan stalwarts. Mutual tolerance of political opponents may decline to detrimental effect on democratic function. The political dynamics could be difficult to reconcile. Already, the US has experienced legislative gridlock, elite incivility, rising income inequality, political disengagement by voters who identify with neither party and/or distrust both, and alienation between highly engaged ideological, partisan-identity camps all correlating with polarization in recent years. There could be major political change if polarization drawn on American identity factors encourages stronger biases and anger in American politics. Such dynamics could diminish commitment to democratic principles in electoral decision-making processes. Americans could choose partisan loyalty, ideology, and preferences in candidate orientations over what may be ideal in a democratic regime. The US case in severe partisanship could be more problematic under its 'formative rift' in polarization of mutually exclusive narratives over what comprises the American polity and national ideals. The exclusivity of one ideal system of values versus another, and who belongs, may make for substantial difficulties going forward for the regime. There may be greater likelihood for episodes of violence and 
gradual democratic erosion. If either Democrats or Republicans have the upper hand in a power imbalance, the polarization may find resolve albeit possible lasting exclusion of opposition or marginalized groups.

Outcomes of severe partisan-identity polarization could be deleterious for the democratic regime because of how its dynamics may bolster popular support for authoritarian behaviors or policy actions of elites. Political actors may be most influential as agents to determine dedemocratizing outcomes if their polarizing political appeals are rampant in pursuit of objectives to secure power or enact policies. A Republican party alternative example of recent mass mobilizations under Trump's leadership occurring near the end of his tenure after losing reelection alludes to the potential of this scenario. The Stop the Steal rally turned US Capitol riots, "insurrection," “coup attempt," or otherwise known as "storming of the capitol" on January 6, 2021, featured a loosely organized albeit zealous mass of partisans who violently sought to stop congressional certification of the 2020 presidential election after then-President Donald Trump repeatedly claimed election fraud at incendiary rallies. ${ }^{7}$ It were as though Trump-backing partisans hitherto earnestly took his word, believing that opponents had rigged the election against him to the point of necessary and direct mass intervention against elected leaders in US government. Then-President Trump underscored dire circumstances to his audience earlier that day: "We're gathered together in the heart of our nation's capital for one very, very basic and simple reason: To save our democracy." Notably, the former president and possible 2024 presidential election contender continues to discredit democratic institutions. For instance, he recently asserted without evidence that a recall election for California governor and Democrat Gavin Newsome was "probably rigged" ahead of the vote. He explains in an interview that

\footnotetext{
${ }^{7}$ See, e.g., reporting of FBI evidence on scant coordination around the US Capitol attack (Hosenball and Lynch 2021).
} 
the ballots are mail-out, mail-in ballots...I guess you can have a case where you can make your own ballot. When that happens, nobody's going to win except these Democrats...the one thing they're good at is rigging elections, so I predict it's a rigged election, let's see how it turns out (Joyella 2021).

Ratcheting effects of such 'pernicious' polarization may stem from one bloc of party elites reciprocating with similar strategies or otherwise ways that fail to neutralize polarizing rhetoric and behavior of the other. Polarizing appeals against counter-appeals in rhetoric may amplify partisan biases. A likely outcome could be democratic erosion more than widespread violence or regime breakdown, driven by elite cues and actions, including influence on mass views and behavior. Subtle but no less consequential results could be continuing gridlock and policy wavering between parties in power, and further decline in trust for governing institutions or between groups. Lastly, a reasonable expectation from these dynamics may be backlash to new or prior marginalized groups reaching political power. Depending on how opponents reciprocate, results may indeed be gainful or concerning for US democracy.

For future research, it would be interesting to explore party polarization as it relates to American life. This thesis has shed light onto partisan-identity dynamics of polarization from elite appeals between the two major parties through analysis of their platforms. Researchers might find ways to investigate similar dynamics albeit among ordinary Americans rather than looking to major party actors or platforms. Some related issues worth investigating may be possible consequences of declining political legitimacy and social cohesion. For example, there are worsening Cohesion Indicator Trends for the US from 2006 to 2021 according to the Fragile State Index (2021a). ${ }^{8}$ Furthermore, national political flashpoints in recent years offer support to

\footnotetext{
${ }^{8}$ The Cohesion Indicator Trends altogether consider three indicators. These are (1) Security Apparatus, (2) Factionalized Elites, and (3) Group Grievance. The Fragile State Index builds the indicators using a threefold mix of content analysis, quantitative data sets, and qualitative research methods. First, the Security Apparatus indicator accounts for any security threats to the state. Factors may include the state's monopoly on the use of force, the relationship between security and citizenry, police brutality in use of force, and arms control. Second, the
} 
the idea of rising partisan-identity tensions of polarization extending into daily life and social relations. A partisan split was palpable during summer 2020 uprisings and widespread protests against police brutality after the killing of George Floyd, including violent street clashes between Black Lives Matter opponents and Blue Lives Matter supporters of police, plus the pro-Trump rally-turned-riot on January 6, 2021, with masses 'storming' the US Capitol in a failed attempt to stop congressional certification of the 2020 presidential election after President Donald Trump frequently claimed election fraud. A close look at identity fracturing in American social life from non-party elite, including media, and the masses could contribute to greater understanding of the depth and severity in any partisan-identity rift and its implications. It would also be interesting to further explore possible underlying issues that might contribute to polarization around identity and belonging like the work of Inglehart and Norris (2016), i.e., the 'demand' side for why partisan-identity appeals may have a receptive mass audience at certain times and not others. A deep-dive into single country cases of apparent partisan-identity polarization from the US to Latin America or Eastern Europe using qualitative research or mixed methods may compliment their comparative survey and statistical analysis.

Will partisan elites and voters increasingly view US elections as illegitimate under pernicious polarization? If congressional gridlock continues in the US, could policy careening

Factionalized Elites indicator looks at fragmentation of state institutions on identity lines (e.g., ethnicity, class, racial, or religious) or between ruling elites. The indicator also accounts for the rhetoric of ruling elites, whether nationalistic, xenophobic, or of longing for return to a "greater" period or communal solidarity. It may reflect representation flaws such as wider components of citizenry rejecting the state's governing leadership as legitimate, i.e., popular perceptions of illegitimacy towards the ruling class. Factors may include representation, identity, resource distribution, and equality and equity in law. Not least, the Group Grievance indicator considers fragmentation and rifts between different groups in the society, including social or political. It accounts for present or even historical grievances influencing society and intergroup relations. There may be grievance factors over lack of autonomy, self-determination, or political independence, as well as possible persecution or repression of certain groups by the state or from dominant groups in society. Factors may include post-conflict response, resource equality, divisions including tolerance levels and intergroup relations, and communal violence such as vigilante justice or episodes of mass violence (Fragile State Index 2021b) 
from one party in power to another contribute to further troubles for trust in government? During the 2020 presidential elections, President Trump repeated that the only way he would lose re-election is if the 'radical Democrats' rigged it. By contrast, Democrats worried that mailin ballot delays in transit and vote counts might propel Trump to victory. It was unclear that either side could conceive of the other's fair win. Potential for destabilizing or weakening effects of partisan-identity polarization on the quality of democracy is palpable. The actions of party elites and those in power may determine whether tensions tighten in a ratchet response of growing severity in partisanship.

Diffusing tension around partisan-identity polarization may mean that leaders must find ways to reaffirm tolerance of political opponents and opposing viewpoints, including among neighbors, friends, and family, etc. Disagreement in democratic society is healthy, after all; it means mutual acceptance in agreeing to disagree and forging a path forward with understanding of shared interests. Party elites should avoid demonizing the 'other,' whether as irredeemable, "deplorable," as a "threat" or an "enemy of the people." The Republican party could be more accepting towards invariably changing norms, and the Democratic party could be more understanding that generational values are slower to adapt to change, otherwise both parties may face backlash in countermovements and possible consequences in furthering the polarization. Likewise, the Democratic party's recent stress on "systemic racism" may be counterproductive. It alludes to a certain oikophobia of American civic identity. Opposing elites and less receptive masses may perceive such appeals as anti-American. Both parties nevertheless hold major stakes. Somehow, those in power will need to find ways to reconcile differences between sides in seemingly intractable politics of identity and belonging that runs deep in terms of the American 
'nation' or community. The incentives to reciprocate against political opponents ("enemies") may alas be too appealing, at democracy's peril. 


\section{REFERENCES}

Abramowitz, Alan and Jennifer McCoy. 2018. "United States: Racial Resentment, Negative Partisanship, and Polarization in Trump's America." The ANNALS of the American Academy of Political and Social Science. 681(January): 137-156.

Abramowitz, Alan I. and Kyle L. Saunders. 2008. "Is Polarization a Myth?” The Journal of Politics. 70(April): 542-555.

Barber, Michael and Jeremy C. Pope. 2019. “Does Party Trump Ideology? Disentangling Party and Ideology in America.” American Political Science Association. 113(1): 38-54.

Bartels, Larry. 2000. "Partisanship and Voting Behavior, 1952-1996." American Journal of Political Science. January. 44(January): 35-50.

Baumgartner, Frank R., Suzanna L. De Boef, and Amber E. Boydstun. 2008. "The Decline of the Death Penalty and the Discovery of Innocence.” Cambridge MA: Cambridge University Press. Chapter 4

Bayagich, Megan. 2017. “The Resurgence of Women's Protest in the United States.” Center for Political Studies Institute for Social Research. April 10. https://cpsblog.isr.umich.edu/?p=1984 (Accessed December 5, 2020).

BBC News. 2021. “Capitol riots: Trump says his speech was totally appropriate.” https://www.bbc.com/news/world-us-canada-55638017 (Accessed on January 12, 2021).

Benoit, William, L. 2013. "Content Analysis in Political Communication.” The Sourcebookfor Political Communication Research. eds. Erik P. Bucy and R. Lance Holbert. New York and London: Routledge.

Bermeo, Nancy. 2016. “On Democratic Backsliding.” Journal of Democracy. 27(January): 5-19. 
Bogaards, Matthijs. 2009. "How to classify hybrid regimes? Defective democracy and electoral authoritarianism." Democratization. 16(April): 399-423.

Bonikowski, Bart. 2017. "Ethno-nationalist populism and the mobilization of collective resentment." The British Journal of Sociology. 68 Suppl 1(S1): S181-S213.

Brown, David S., Michael Touchton and Andrew Whitford. 2011. "Political Polarization as a Constraint on Corruption: A Cross-national Comparison." World Development. 39(September):" 1516-1529.

Brown, Jacob R. and Ryan D. Enos. 2021. "The measurement of partisan sorting for 180 million voters." Nature human behaviour, 10.1038/s41562-021-01066-z. Advance online publication. https://doi.org/10.1038/s41562-021-01066-z

Carey, John and Katherine Clayton, Gretchen Helmke, Brendan Nyhan, Mitchell Sanders, and Susan Stokes. 2020. "Who will defend democracy? Evaluating tradeoffs in candidate support among partisan donors and voters." Journal of Elections, Public Opinion and Parties. (July).

Carothers, Thomas. 2002. "The end of the transition regime." Journal of Democracy. 13(January): 5-21.

Cassani, Andrea. 2014. "Hybrid what? Partial consensus and persistent divergences in the analysis of hybrid regimes." International Political Science Review. 35(September): 542558.

Center for Systemic Peace. 2020. "Democracy cannot be defended by force; it is enforced through accountability." https://www.systemicpeace.org/ (Accessed on January 28, 2021). 
Cheeseman, Nic and Brian Klaas. 2018. How to Rig an Election. New Haven: Yale University Press.

Collier, David and Steven Levitsky. 1997. "Democracy with Adjectives: Conceptual Innovation in Comparative Research." World Politics. 49(April): 430-451.

Diamond, Larry. 2002. "Elections Without Democracy: Thinking about hybrid regimes.” Journal of Democracy. 13(April).

Druckman, James N., Erik Peterson and Rune Slothuus. 2013. "How Elite Partisan Polarization Affects Public Opinion Formation." The American Political Science Review. 107(February): 57-79.

Ercan, Selen A. and Jean-Paul Gagnon. 2014. "The Crisis of Democracy: Which Crisis? Which Democracy?" Democratic Theory. 1(Winter): 1-10.

Fiorina, Morris P. and Samuel J. Adams. 2008. "Political Polarization in the American Public." Annual Review of Political Science. 11(June): 563-588.

Foa, Roberto Stefan and Yascha Mounk. 2017. "The End of the Consolidation Paradigm.” Journal of Democracy.

Fragile State Index. 2021a. "Country Dashboard: United States.” The Fund for Peace. https://fragilestatesindex.org/country-data/ (Accessed on October 5, 2021).

Fragile State Index. 2021b. "Indicators." The Fund for Peace. https://fragilestatesindex.org/indicators/ (Accessed on October 5, 2021).

Freedom House. 2019a. "Freedom in the World 2019." https://freedomhouse.org/sites/default/files/Feb2019_FH_FITW_2019_Report_ForWebcompressed.pdf (Accessed on January 11, 2021). 
Freedom House. 2019b. "Freedom in the World 2019: Democracy in Retreat." https://freedomhouse.org/report/freedom-world/2019/democracy-retreat (Accessed on January 11, 2021).

Freedom House. 2020a. "Freedom in the World 2020: United States." https://freedomhouse.org/country/united-states/freedom-world/2020 (Accessed December $6,2020)$.

Freedom House. 2020b. "Freedom in the World 2020: A Leaderless Struggle for Democracy." https://freedomhouse.org/report/freedom-world/2020/leaderless-struggle-democracy (Accessed on January 11, 2021).

Freedom House. 2021. "Freedom in the World 2020 Methodology." https://freedomhouse.org/reports/freedom-world/freedom-world-research-methodology (Accessed on January 11, 2021).

Frye, Timothy. 2002. "The Perils of Polarization: Economic Performance in the Postcommunist World.” Cambridge University Press. 54(April): 308-337.

Gebrekidan, Selam. 2020. "For Autocrats, and Others, Coronavirus Is a Chance to Grab Even More Power." The New York Times. March 30. https://www.nytimes.com/2020/03/30/world/europe/coronavirus-governmentspower.html (Accessed on December 6, 2020).

Gidron, Noam, James Adams and Will Horne. 2019. "Towards a Comparative Research Agenda on Affective Polarization in Mass Publics." APSA Comparative Politics Newsletter. 29(1): 30-36.

Gilens, Martin and Benjamin I. Page. 2014. "Testing Theories of American Politics: Elites, Interest Groups, and Average Citizens." Perspectives on Politics. 12(3): 564-581. 
Goren, Paul. 2005. "Party Identification and Core Political Values." American Journal of Political Science. 49(October): 881-896.

Graham, Matthew and Milan W. Svolik. 2020. "Democracy in America? Partisanship, Polarization, and the Robustness of Support for Democracy in the United States." American Political Science Review. 2020(May): 392-409.

Hartocollis, Anemona and Yamiche Alcindor. 2017. “Women's March Highlights as Huge Crowds Protest Trump: 'We're Not Going Away'.” The New York Times. January 21. https://nyti.ms/2kbJ0pb (Accessed December 5, 2020).

Hetherington, Marc J. 2001. “Resurgent Mass Partisanship: The Role of Elite Polarization.” The American Political Science Review. 95(September): 619-631.

Hobolt, Sara B., Thomas J. Leeper and James Tilley. 2020. "Divided by the Vote: Affective Polarization in the Wake of the Brexit Referendum." British Journal of Political Science. 1-18 (July).

Hobson, Christopher. 2018. “Democracy: Trap, Tragedy, or Crisis?” Political Studies Review. 16(1): 38-45.

Hosenball, Mark and Sarah N. Lynch. 2021. "Exclusive: FBI finds scant evidence U.S. Capitol attack was coordinated - sources." Reuters. https://www.reuters.com/world/us/exclusivefbi-finds-scant-evidence-us-capitol-attack-was-coordinated-sources-2021-08-20/ (Accessed on October 4, 2021).

Howe, Paul. 2017. "Eroding Norms and Democratic Deconsolidation." Journal of Democracy. 28(October): 15-29.

Huntington, 1991. “Democracy's Third Wave.” Journal of Democracy. 2(2): 12-34. 
Inglehart, Ronald and Pippa Norris. 2016. “Trump, Brexit, and the Rise of Populism: Economic Have-Nots and Cultural Backlash.” HKS Faculty Research Working Paper Series. (August).

Joyella, Mark. 2021. “On Newsmax, Donald Trump Says California Recall Is 'Probably Rigged'." Forbes. September 8. https://www.forbes.com/sites/markjoyella/2021/09/08/on-newsmax-donald-trump-sayscalifornia-recall-is-probably-rigged/?sh=325a58c74b45 (Accessed on October 5, 2021).

Juergensmeyer, Mark. 2018. "Religious Nationalism in a Global World.” Religions. 10(97):

Kaufman, Robert R. and Stephan Haggard. 2019. "Democratic Decline in the United States: What Can We Learn from Middle-Income Backsliding?” Perspectives on Politics. 17(June): 417-432.

Kongkirati, Prajak. 2018. "From Illiberal Democracy to Military Authoritarianism: Intra-Elite Struggle and Mass-Based Conflict in Deeply Polarized Thailand." The ANNALS of the American Academy of Political and Social Science. 681(1): 24-40.

Landis, J. Richard, \& Gary G. Koch. 1977. "The Measurement of Observer Agreement for Categorical Data.” Biometrics. 33(1), 159-174.

Layman, Geoffrey C., Thomas M. Carsey and Juliana Menasce Horowitz. 2006. "Party Polarization in American Politics: Characteristics, Causes, and Consequences." Annual Review of Political Science. 9(1): 83-110.

LeBas, Adrienne and Ngonidzashe Munemo. 2019. "Elite Conflict, Compromise, and Enduring Authoritarianism: Polarization in Zimbabwe, 1980-2008." The ANNALS of the American Academy of Political and Social Science. 681(1): 209-226. 
LeBas, Adrienne. 2018. "Can Polarization Be Positive? Conflict and Institutional Development in Africa." American Behavioral Scientist. 62(1): 59-74.

Levitsky, Steven and Daniel Ziblatt. 2018. How Democracies Die. New York, Crown.

Levitsky, Steven and Lucan A. Way. 2010. Competitive Authoritarianism: Hybrid Regimes after the Cold War. New York: Cambridge University Press.

Linz, Juan and Alfred Stepan. 1996. Problems of Democratic Transition and Consolidation: Southern Europe America, and Post-Communist Europe. Baltimore. John Hopkins University Press.

Lombard, Matthew, Jennifer Snyder-Duch, and Cheryl Campanella Bracken. 2010. "Practical Resources for Assessing and Reporting Intercoder Reliability in Content Analysis Research Projects.” Accessed on January 10, 2020, http://matthewlombard.com/reliability/index_print.html\#How\%20should\%20researchers $\% 20$ calculate $\% 20$ intercoder $\% 20$ reliability $\% 20$ What $\% 20$ software $\% 20$ is $\% 20$ available

Luhrmann, Anna and Staffan I. Lindberg. 2019. "A third wave of autocratization is here: What is new about it?" Democratization. 26(September): 1095-1113.

Lupu, Noam. 2014. "Party Polarization and Mass Partisanship: A Comparative Perspective." Political Behavior. 37: 331-356.

Mason, Lilliana. 2014. “I Disrespectfully Agree: The Differential Effects of Partisan Sorting on Social and Issue Polarization.” American Journal of Political Science. 59(1).

McCoy, Jennifer and Murat Somer. 2019. "Toward a Theory of Pernicious Polarization and How It Harms Democracies: Comparative Evidence and Possible Remedies." The ANNALS of the American Academy of Political and Social Science. 681(1): 234-271. 
McCoy, Jennifer and Tahmina Rahman, Murat Somer. 2018. "Polarization and the Global Crisis of Democracy: Common Patterns, Dynamics, and Pernicious Consequences for Democratic Polities.” American Behavioral Scientist. 62(1): 16-42.

McCoy, Jennifer and Tahmina Rahman. 2016. "Polarized Democracies in Comparative Perspective: Toward a Conceptual Framework.” Paper presented at the International Political Science Association. Posnan, Poland. July. https://www.researchgate.net/publication/336830321_Polarized_Democracies_in_Compa rative_Perspective_Toward_a_Conceptual_Framework

Mietzner, Marcus. 2018. "Fighting Illiberalism with Illiberalism: Islamist Populism and Democratic Deconsolidation in Indonesia." Pacific Affairs. 91(2): 261-282.

Moran, Benedict and Jorgen Samso. 2019. "Rwanda builds new national identity 25 years after genocide.” PBS News Hour. April 7. https://www.pbs.org/newshour/show/rwanda-buildsnew-national-identity-25-years-after-genocide (Accessed February 15, 2021).

Moshman, David. 2007. "Us and Them: Identity and Genocide." An International Journal of Theory and Research. 7(2): 115-135.

Mufti, Mariam. 2018. "What Do We Know about Hybrid Regimes after Two Decades of Scholarship?" Politics and Governments. 6(2): 112-119.

Republican National Committee. 2020. Resolution Regarding the Republican Party Platform. https://prod-cdnstatic.gop.com/media/documents/RESOLUTION_REGARDING_THE_REPUBLICAN_ PARTY_PLATFORM.pdf?_ga=2.109560193.504857691.15982196032087748323.1598219603 (Accessed May 5, 2021). 
Schmitter, Philippe C. and Terry L. Karl. 1991. "What Democracy Is... and Is Not." Journal of Democracy. 2(3): 75-88.

Selway, Joel. 2020. "Thailand's national moment: Protests in continuing battle over nationalism." The Brookings Institution. November 2. https://www.brookings.edu/blog/order-from-chaos/2020/11/02/thailands-nationalmoment-protests-in-a-continuing-battle-over-nationalism/\#cancel (Accessed February 15, 2021).

Somer, Murat. 2001. "Cascades of Ethnic Polarization: Lessons from Yugoslavia." The ANNALS of the American Academy of Political and Social Science. 573(January): 127-151.

Southall, Roger. 2018. "Polarization in South Africa: Toward Democratic Deepening or Democratic Decay?" The ANNALS of the American Academy of Political and Social Science. 681(1): 194-208.

The American Presidential Project. 2019. National Political Party Platforms https://www.presidency.ucsb.edu/documents/presidential-documents-archiveguidebook/national-political-party-platforms

The Economist Intelligence Unit. 2018. "Democracy Index 2018: Me too? Political participation, protest and democracy." https://www.eiu.com/public/topical_report.aspx?campaignid=Democracy2018 (Accessed September 1, 2019).

The Economist. 2014. "What's gone wrong with democracy." February 27. https://www.economist.com/essay/2014/02/27/whats-gone-wrong-with-democracy (Accessed September 8, 2019). 
Touchton, Michael, Casey Klofstad and Joseph Uscinski. 2020. "Does partisanship promote antidemocratic impulses? Evidence from a survey experiment.” Journal of Elections, Public Opinion and Parties. (November).

Tworzecki, Hubert. 2018. "Poland: A Case of Top-Down Polarization." The ANNALS of the American Academy of Political and Social Science. 681(January): 97-119.

V-Dem Institute. 2019. “Democracy Facing Global Challenges.” May 21. https://www.vdem.net/media/filer_public/99/de/99dedd73-f8bc-484c-8b91-44ba601b6e6b/vdem_democracy_report_2019.pdf(Accessed September 8, 2019).

V-Dem Institute. 2020. “Autocratization Surges - Resistance Grows: Democracy Report 2020.” https://www.v-dem.net/media/filerpublic/de/39/de39af54-0bc5-4421-89aefb20dcc53dba/democracy_report.pdf(Accessed December 17, 2020).

Vegetti, Federico. "The Political Nature of Ideological Polarization: The Case of Hungary.” The ANNALS of the American Academy of Political and Social Science. 681(1): 78-96.

Waldner, David and Ellen Lust. 2018. "Unwelcome change: coming to terms with democratic backsliding." Annual Review of Political Science. 21(May): 93-113.

Werner, Annika, Onawa Lacewell and Andrea Volkens. 2015. "Platform Coding Instructions (5th revised edition). Comparative Platform Project. February. https://platformproject.wzb.eu/down/papers/handbook_2014_version_5.pdf

Whitehead, Andrew L., Samuel L. Perry and Joseph O. Baker. 2018. "Make America Christian Again: Christian Nationalism and Voting for Donald Trump in the 2016 Presidential Election." Sociology of Religion. 79(2): 147-171 


\section{APPENDIX A: CODING RUBRIC}

\section{Coding Rubric: Identitarian and/or Universal Messaging in US Major Party Platforms}

Coders address each paragraph (unit of analysis) with a central question:

Does the paragraph imply or explicitly express some notion of American polity, whether universal, identitarian or sub-group (i.e., narrow, exclusive, or individual over the collective), or both? If yes, coders (minimum $\mathrm{x} 2$ ) record the categorization, and the researcher notates context plus any associated key words.

\begin{tabular}{|c|c|c|c|}
\hline Code & Category & $\begin{array}{l}\text { Coding Rules (addressed } \\
\text { against central question) }\end{array}$ & Data Examples \\
\hline \multirow[t]{5}{*}{11111} & \multirow[t]{5}{*}{ Universal } & \multirow{5}{*}{$\begin{array}{l}\text { Includes an expression of } \\
\text { common purpose or } \\
\text { collective identity, } \\
\text { universality; civic identity } \\
\text { and/or common interests } \\
\text { emphasized. }\end{array}$} & $\begin{array}{l}\text { Our platform is uplifting and visionary. It reflects the } \\
\text { views of countless Americans all across this country } \\
\text { who believe in prosperity with a purpose - who } \\
\text { believe in Renewing America's Purpose. Together. }\end{array}$ \\
\hline & & & $\begin{array}{l}\text { The twenty-fifth man to receive our party's nomination } \\
\text { is equal to the challenges facing our country. After a } \\
\text { period of bitter division in national politics, our } \\
\text { nominee is a leader who brings people together. In a } \\
\text { time of fierce partisanship, he calls all citizens to } \\
\text { common goals. To longstanding problems, he brings a } \\
\text { fresh outlook and innovative ideas and a record of } \\
\text { results. }\end{array}$ \\
\hline & & & $\begin{array}{l}\text { We seek to be faithful to the best traditions of our } \\
\text { party. We are the party that ended slavery, granted } \\
\text { homesteads, built land grant colleges, and moved } \\
\text { control of government out of Washington, back into the } \\
\text { hands of the people. We believe in service to the } \\
\text { common good - and that good is not common until it } \\
\text { is shared. }\end{array}$ \\
\hline & & & $\begin{array}{l}\text { The highest hopes of the American people - a world } \\
\text { at peace, scientific progress, a just and caring society } \\
\text { - cannot be achieved by prosperity alone, but neither } \\
\text { can they be fulfilled without it. Yet prosperity is not an } \\
\text { end in itself. Rather, it is the means by which great } \\
\text { things can be achieved for the common good. Our } \\
\text { commitment to the nation's economic growth is an } \\
\text { affirmation of the real riches of our country: the works } \\
\text { of compassion that link home to home, community to } \\
\text { community, and hand to helping hand. This is the } \\
\text { foundation of America, and that foundation is sound. } \\
\text { Even though our economy, and that of the world to } \\
\text { which we are now so closely tied, has been utterly } \\
\text { transformed over the last two decades, Americans } \\
\text { remain true to the faith of our founding fathers. }\end{array}$ \\
\hline & & & $\begin{array}{l}\text { They're why we fought to reclaim the value of treating } \\
\text { all Americans with dignity and respect. And they're } \\
\text { why President Barack Obama has ended one war and is } \\
\text { responsibly drawing down another. They're why we're } \\
\text { restoring our alliances and image around the world and } \\
\text { pursuing a foreign policy that's making us safer. }\end{array}$ \\
\hline
\end{tabular}




\begin{tabular}{|c|c|c|c|}
\hline & & \multirow{2}{*}{$\begin{array}{l}\text { defined by the scope and } \\
\text { background of this project, } \\
\text { and hence coders should } \\
\text { categorize them as "none of } \\
\text { the above" (00000), unless } \\
\text { there includes some } \\
\text { emphasis or notion of } \\
\text { common polity (1111), } \\
\text { sub-group identity(ies) } \\
(22222) \text {, or both (33333). }\end{array}$} & $\begin{array}{l}\text { Persons with disabilities are nearly twice as likely to be } \\
\text { self-employed as the general population. To encourage } \\
\text { their entrepreneurship, it makes sense to include them } \\
\text { in the Small Business Administration's } 8(a) \\
\text { certification program, which opens up federal } \\
\text { contracting for emerging businesses. Any restructuring } \\
\text { of the tax code should consider ways in which } \\
\text { companies can benefit from the talent and energy of } \\
\text { their disabled employees. }\end{array}$ \\
\hline & & & $\begin{array}{l}\text { We recognize the importance of small business to } \\
\text { women, people of color, tribes, and rural America and } \\
\text { will work to help nurture entrepreneurship. }\end{array}$ \\
\hline \multirow[t]{4}{*}{33333} & \multirow[t]{4}{*}{ Both } & \multirow{4}{*}{$\begin{array}{l}\text { Reflects common American } \\
\text { identity or universality while } \\
\text { simultaneously } \\
\text { incorporating appeal(s) or } \\
\text { messaging to/including } \\
\text { narrow/sub-group identities } \\
\text { or addressing the individual } \\
\text { above and beyond the } \\
\text { collective/civic. }\end{array}$} & $\begin{array}{l}\text { We offer not only a new agenda, but also a new } \\
\text { approach - a vision of a welcoming society in which } \\
\text { all have a place. To all Americans, particularly } \\
\text { immigrants and minorities, we send a clear message: } \\
\text { this is the party of freedom and progress, and it is your } \\
\text { home. }\end{array}$ \\
\hline & & & $\begin{array}{l}\text { Democrats are strongly committed to enacting } \\
\text { comprehensive immigration reform that supports our } \\
\text { economic goals and reflects our values as both a nation } \\
\text { of laws and a nation of immigrants. The story of the } \\
\text { United States would not be possible without the } \\
\text { generations of immigrants who have strengthened our } \\
\text { country and contributed to our economy. Our } \\
\text { prosperity depends on an immigration system that } \\
\text { reflects our values and meets America's needs. But } \\
\text { Americans know that today, our immigration system is } \\
\text { badly broken - separating families, undermining honest } \\
\text { employers and workers, burdening law enforcement, } \\
\text { and leaving millions of people working and living in } \\
\text { the shadows. }\end{array}$ \\
\hline & & & $\begin{array}{l}\text { President Obama and the Democrats fought for the } \\
\text { DREAM Act, legislation ensuring that young people } \\
\text { who want to contribute fully to our society and serve } \\
\text { our country are able to become legal residents and } \\
\text { ultimately citizens. Although this bill has a long history } \\
\text { of bipartisan support, Republicans decided to play } \\
\text { politics with it rather than do the right thing. So the } \\
\text { Obama administration provided temporary relief for } \\
\text { youth who came to the United States as children, } \\
\text { through no fault of their own, grew up as Americans } \\
\text { and are poised to make a real contribution to our } \\
\text { country. }\end{array}$ \\
\hline & & & $\begin{array}{l}\text { No one should face discrimination based on disability } \\
\text { status. President Obama and the Democratic Party will } \\
\text { continue to lead efforts to facilitate the access of } \\
\text { Americans with disabilities to the middle class, } \\
\text { employment opportunities, and the ability to lead full, } \\
\text { productive, and satisfying lives. The administration and } \\
\text { the Democratic Party are committed to assisting the } \\
\text { approximately } 50 \text { million people in this country living } \\
\text { with disabilities, assuring their full integration into } \\
\text { society. }\end{array}$ \\
\hline
\end{tabular}




\begin{tabular}{|c|c|c|c|}
\hline & & & $\begin{array}{l}\text { We believe in an America where everybody gets a fair } \\
\text { shot and everybody plays by the same set of rules. At } \\
\text { the core of the Democratic Party is the principle that no } \\
\text { one should face discrimination on the basis of race, } \\
\text { ethnicity, national origin, language, religion, gender, } \\
\text { sexual orientation, gender identity, or disability status. } \\
\text { Democrats support our civil rights statutes and we have } \\
\text { stepped up enforcement of laws that prohibit } \\
\text { discrimination in the workplace and other settings. We } \\
\text { are committed to protecting all communities from } \\
\text { violence. We are committed to ending racial, ethnic, } \\
\text { and religious profiling and requiring federal, state, and } \\
\text { local enforcement agencies to take steps to eliminate } \\
\text { the practice, and we continue to support enforcement of } \\
\text { Title VI. }\end{array}$ \\
\hline \multirow[t]{5}{*}{00000} & \multirow[t]{5}{*}{ None } & \multirow{5}{*}{$\begin{array}{l}\text { None of the above, other; } \\
\text { neutral/silent in regard to } \\
\text { emphases of what comprises } \\
\text { the American polity or it } \\
\text { does not specifically address } \\
\text { common or sub- } \\
\text { group/individual interests. } \\
\text { Calculated by \{total } \\
\text { paragraphs }\} \text { minus three } \\
\text { discrete category totals } \\
\text { above; coders do not record } \\
\text { none/neutral units of } \\
\text { analysis. }\end{array}$} & $\begin{array}{l}\text { We commit ourselves to rebuilding the American } \\
\text { military and returning to a foreign policy of strength } \\
\text { and purpose and a renewed commitment to our allies. } \\
\text { We will deploy defenses against ballistic missiles and } \\
\text { develop the weapons and strategies needed to win } \\
\text { battles in this new technological era. }\end{array}$ \\
\hline & & & $\begin{array}{l}\text { We believe that from freedom comes opportunity; from } \\
\text { opportunity comes growth; and from growth comes } \\
\text { progress and prosperity. }\end{array}$ \\
\hline & & & $\begin{array}{l}\text { Affordable housing is in the national interest. That is } \\
\text { why the mortgage interest deduction for primary } \\
\text { residences was put into the federal tax code, and why } \\
\text { tax reform of any kind should continue to encourage } \\
\text { homeownership. At the same time, a balanced national } \\
\text { housing policy must recognize that decent housing } \\
\text { includes apartments, and addresses the needs of all } \\
\text { citizens, including renters. }\end{array}$ \\
\hline & & & $\begin{array}{l}\text { We support the right of the people to conduct their } \\
\text { businesses in accordance with their religious beliefs } \\
\text { and condemn public officials who have proposed } \\
\text { boycotts against businesses that support traditional } \\
\text { marriage. We pledge to protect those business owners } \\
\text { who have been subjected to hate campaigns, threats of } \\
\text { violence, and other attempts to deny their civil rights. }\end{array}$ \\
\hline & & & $\begin{array}{l}\text { In the international arena, a weak Administration has } \\
\text { invited aggression. The results of the Administration's } \\
\text { unilateral approach to disarmament are already clear: } \\
\text { An emboldened China in the South China Sea, a } \\
\text { resurgent Russia occupying parts of Ukraine and } \\
\text { threatening neighbors from the Baltic to the Caucasus, } \\
\text { and an aggressive Islamist terror network in the Middle } \\
\text { East. We support maintaining and, if warranted, } \\
\text { increasing sanctions, together with our allies, against } \\
\text { Russia unless and until Ukraine's sovereignty and } \\
\text { territorial integrity are fully restored. We also support } \\
\text { providing appropriate assistance to the armed forces of } \\
\text { Ukraine and greater coordination with NATO defense } \\
\text { planning. All our adversaries heard the message in the } \\
\text { Administration's cutbacks: America is weaker and } \\
\text { retreating. Concomitantly, we honor, support, and }\end{array}$ \\
\hline
\end{tabular}




\begin{tabular}{|l|l|l|}
\hline & & $\begin{array}{l}\text { thank all law enforcement, first responders, and } \\
\text { emergency personnel for their service. }\end{array}$ \\
\hline
\end{tabular}




\section{APPENDIX B: INTERCODER RELIABILITY}

\begin{tabular}{|c|c|c|c|c|}
\hline \multicolumn{5}{|c|}{ Intercoder Reliability Measures* } \\
\hline \multicolumn{3}{|c|}{ Democratic Party } & & Republican Party \\
\hline \multicolumn{5}{|c|}{ Cohen's Kappa** } \\
\hline 1980 & 0.286 & Fair agreement & 0.337 & Fair agreement \\
\hline 1992 & 0.553 & Moderate agreement & 0.495 & Moderate agreement \\
\hline 2004 & 0.416 & Moderate agreement & 0.127 & Slight agreement \\
\hline 2016 & 0.596 & Moderate agreement & 0.346 & Fair agreement \\
\hline \multicolumn{5}{|c|}{ Percentage Agreement*** } \\
\hline 1980 & & $74.13 \%$ & & $71.35 \%$ \\
\hline 1992 & & $75.51 \%$ & & $76.04 \%$ \\
\hline 2004 & & $66.67 \%$ & & $54.26 \%$ \\
\hline 2016 & & $70.90 \%$ & & $61.62 \%$ \\
\hline
\end{tabular}

*Two coders, Democratic party and Republican party platforms (1980, 1992, 2004, 2016).

$* *<0$ : Poor agreement; 0.000-0.20: Slight agreement; 0.21-0.40: Fair agreement; 0.41-0.60: Moderate agreement; 0.61-0.80: Substantial agreement; 0.81-1.00: Almost perfect agreement (Landis and Koch 1977). ***Number of agreements divided by total frequencies, then multiplied by 100 for a percentage calculation. 


\section{APPENDIX C: DEMOCRATIC PARTY, CODER 1 AND 2 COMPARISON}
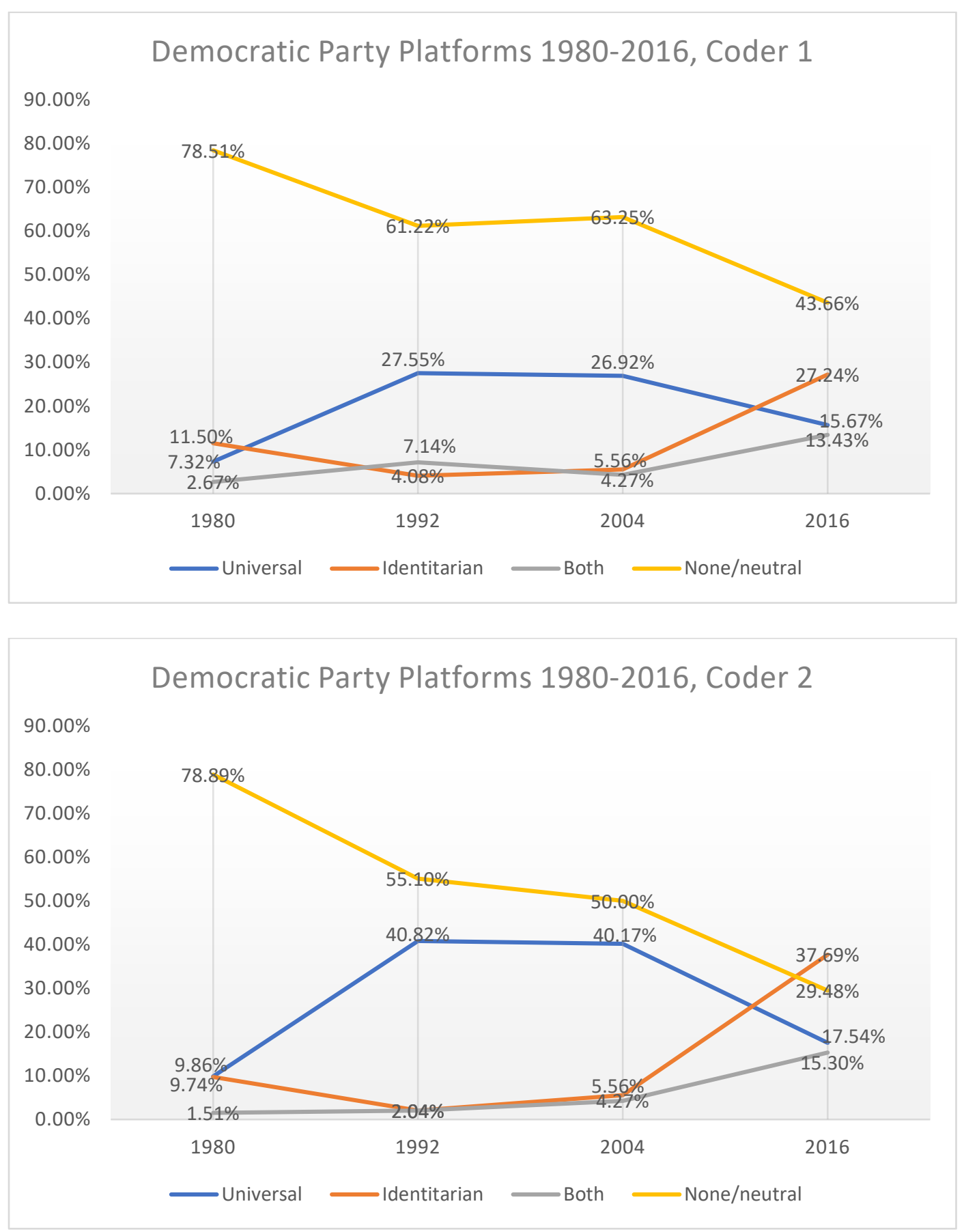


\section{APPENDIX D: REPUBLICAN PARTY, CODER 1 AND 2 COMPARISON}
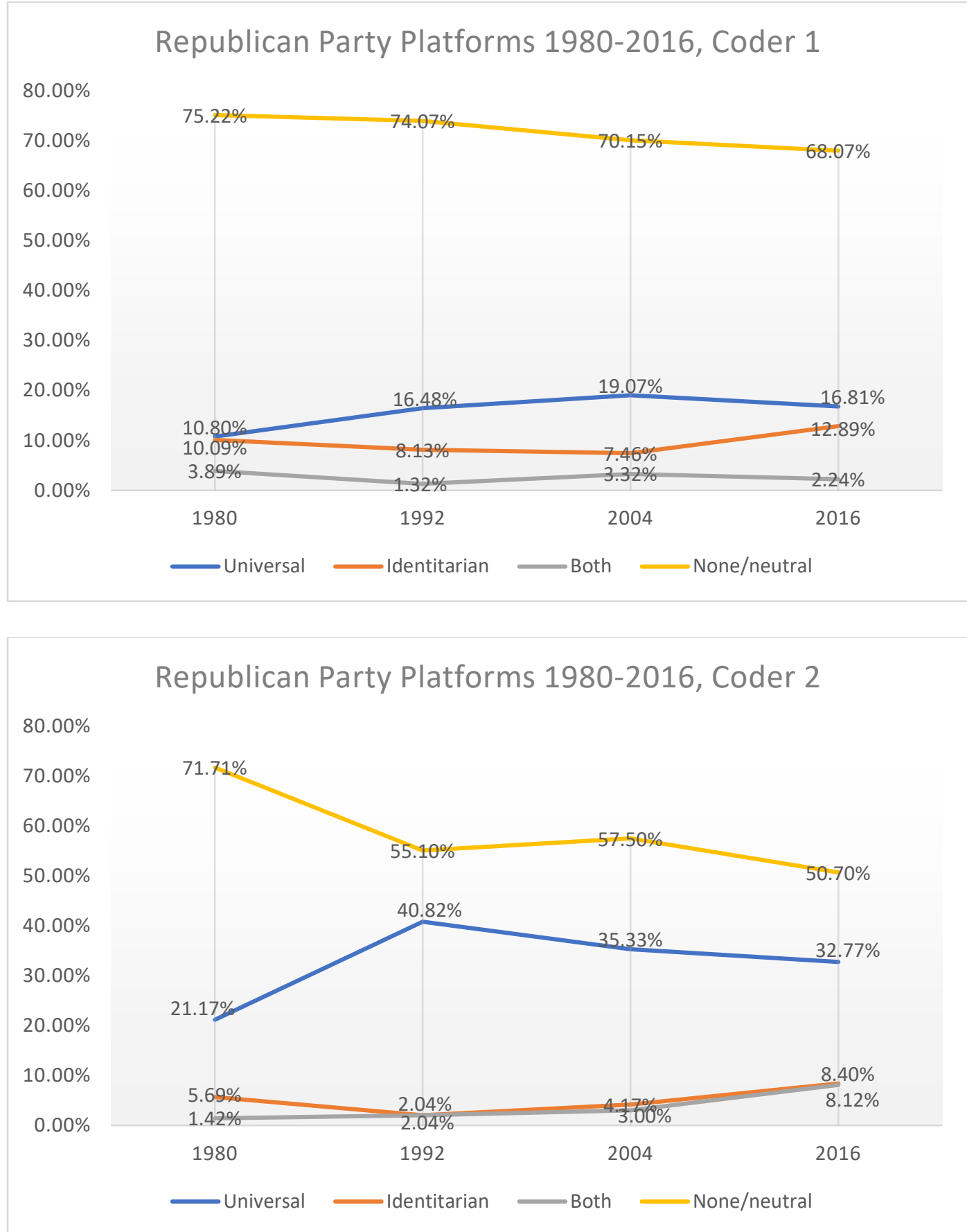